\title{
Diagnosing the variability in temperature and velocity in the Middle Atlantic Bight
}

\author{
by \\ Jacob Samuel Tse Forsyth \\ B.A., Bowdoin College (2015)
}

Submitted to the Department of Earth, Atmospheric, and Planetery Sciences

in partial fulfillment of the requirements for the degree of

Doctor of Philosophy

at the

MASSACHUSETTS INSTITUTE OF TECHNOLOGY

and the

\section{WOODS HOLE OCEANOGRAPHIC INSTITUTION}

February 2021

(C)2021 Jacob Samuel Tse Forsyth. All rights reserved.

The author hereby grants to MIT and WHOI permission to reproduce and to distribute publicly paper and electronic copies of this thesis document in whole or in part in any medium now known or hereafter created.

Author

Joint Program in Oceanography/Applied Ocean Science \& Engineering Massachusetts Institute of Technology \& Woods Hole Oceanographic Institution

October 29, 2020

Certified by

Magdalena Andres

Associate Scientist

Woods Hole Oceanographic Institution

Thesis Supervisor

Certified by

Glen Gawarkiewicz

Senior Scientist

Woods Hole Oceanographic Institution

Thesis Supervisor

Accepted by

Glenn Flierl

Chair, Joint Committee for Physical Oceanography

Massachusetts Institute of Technology \& Woods Hole Oceanographic Institution 


\title{
Diagnosing the variability in temperature and velocity in the Middle Atlantic Bight \\ by
}

Jacob Samuel Tse Forsyth

\author{
Submitted to the Department of Earth, Atmospheric, and Planetery Sciences \\ on October 29, 2020, in partial fulfillment of the \\ requirements for the degree of \\ Doctor of Philosophy
}

\begin{abstract}
Observations of hydrographic and dynamical properties on the Middle Atlantic Bight shelf document strong variability at time scales spanning events that last a few days to century long trends. This thesis studies individual processes which impact shelf temperature and velocity structure, and quantifies the mean velocity conditions at the shelf break. Chapter 2 uses model output to study the dynamics that lead to the breakdown of summertime thermal stratification, and how the processes which reduce stratification vary from year to year. In summer, the atmosphere heats the surface of the ocean, leading to strong thermal stratification with warm water overlying cool water. During fall, strong storm events with downwelling-favorable winds are found to be the primary process by which stratification is reduced. The timing of these events and the associated destratification varies from year to year. In Chapter 3, the velocity structure of the New Jersey shelf break is examine, with a focus on the Shelfbreak Jet. Using 25 years of velocity measurements, mean velocity sections of the Shelfbreak Jet are created in both Eulerian and stream coordinate frameworks. The jet exhibits strong seasonal variability, with maximum velocities observed in spring and minimum velocities in summer. Evidence is found that Warm Core Rings, originating from the Gulf Stream and passing through the Slope Sea adjacent to the New Jersey shelf, tend to shift the Shelfbreak Jet onshore of its mean position or entirely shutdown the Shelfbreak Jet's flow. At interannual timescales, variability in the Shelfbreak Jet velocity is correlated with the temperature on the New Jersey Shelf, with temperature lagging by about 2 months. Chapter 4 focuses on the impact of Warm Core Rings on the velocity and temperature structure on the New Jersey shelf. Warm Core Rings that have higher azimuthal velocities and whose cores approach closer to the shelf are found to exert greater influence on the shelf's along-shelf velocities, with the fastest and closest rings reversing the direction of flow at the shelf break. Warm Core Rings are also observed to exert long-lasting impacts on the shelf temperature, with faster rings cooling the shelf and slower rings warming the shelf. Seasonal changes in thermal stratification strongly affect how rings alter the shelf temperature. Rings in summer tend to cool the shelf, and rings throughout the rest of the year generally warm the shelf.
\end{abstract}

Thesis Supervisor: Magdalena Andres

Title: Associate Scientist

Woods Hole Oceanographic Institution

Thesis Supervisor: Glen Gawarkiewicz

Title: Senior Scientist

Woods Hole Oceanographic Institution 


\section{Acknowledgments}

The completion of this thesis would not have been possible without massive help from a whole village of people.

First and foremost, I cannot imagine how I would have finished this program without my partner Jennifer Kenyon. She supported and assisted me through the stresses of qualifying exams, late nights finishing up manuscripts, and managing to actually finish writing this thesis on time. Without her, and our dog Ruby, this whole process would have been a lot more difficult.

I never would have realized my love for science research without my parents finding every opportunity for me to experiment in my budding interest in science in middle school and high school. They have always enabled me to find what made me happiest and most fulfilled in my education and now professional career.

I need to thank my advisors Magdalena Andres and Glen Gawarkiewicz for introducing me to oceanographic research when I was a summer student fellow in such a way that I decided to commit these last 5 years to research. From teaching me the basics of coding, to placing me in charge of a scientific cruise, I have grown and learned so much from these two. They both have pushed me to take every opportunity that I could, and have made sure that I was always doing research that I enjoyed working on every day.

My friends made surviving the dark winters in Woods Hole warm, and the summers full of fun. Days of hanging out, fishing, board games, video games, pot lucks, and sports have made these years so enjoyable. Special thanks to the CARPO softball team (and all the other softball teams that let me play), as well as the WHOI lunch time soccer crew.

Thank you to office mates that have had to endure my presence on a daily basis. The support of my office mates through classes and qualifying exams was necessary. A special acknowledgement to Joleen Heiderich who answered countless stupid questions and allowed me to bounce many ideas off her for more than 6 years of sharing an office together.

Two of the three chapters are reliant on the $C M V$ Oleander data. I am greatly appreciative of Charlie Flagg, Thomas Rossby, Kathy Donohue, Sandy Fontana, Ruth Curry, and everyone else that helps run and maintain the scientific equipment, as well as Bermuda Container Lines for allowing scientific instruments to be built into their ship.

There are many scientists who have provided great support and advice to this work, especially my committee members.

Everyone within the Academic Programs Office were always so helpful, great to work with, and ready to just have a little chat.

Thank you to the National Science Foundation and Academic Programs Office for funding my research. This research was funded under WHOI Academic Programs Endowed Funds, NSF \#OCE1634094, and NSF \#OCE-1924041. 


\section{Contents}

1 Introduction $\quad 21$

1.1 Hydrographic and Dynamical Properties of the MAB . . . . . . . . . . . . 21

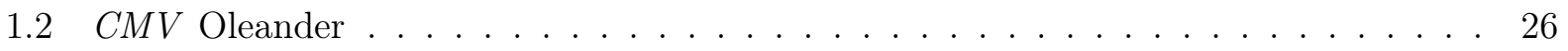

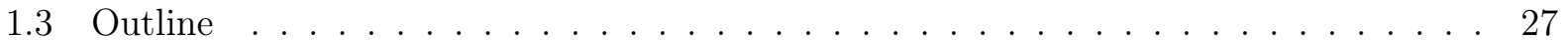

2 The interannual variability of the breakdown of fall stratification on the New

$\begin{array}{ll}\text { Jersey shelf } & 29\end{array}$

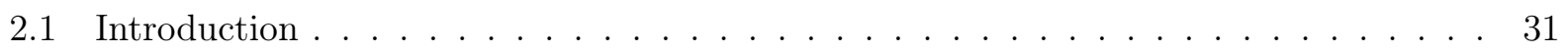

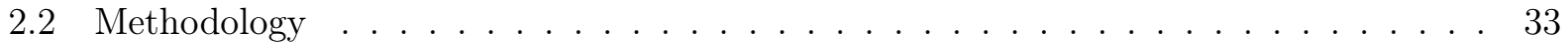

2.2.1 The Regional Circulation Model . . . . . . . . . . . . . . . . 34

2.2.2 The One-Dimensional Model . . . . . . . . . . . . . . . . . . . . 35

2.2 .3 Shallow Water $06 \ldots \ldots \ldots \ldots \ldots \ldots$

2.2.4 Defining Stratification . . . . . . . . . . . . . . . . 38

2.3 Interannual Variability of the Breakdown of Stratification . . . . . . . . . . . . 41

2.4 Physical Mechanisms Contributing to the Breakdown in Stratification . . . . . . . 46

2.4 .1 Ekman Buoyancy Flux . . . . . . . . . . . . . . . . . . . . 47

2.4 Enhanced Shear f . . . . . . . . . . . . . . . . . . . . 52

2.5 Tropical Storm Ernesto _ . . . . . . . . . . . . . . . . . . 53

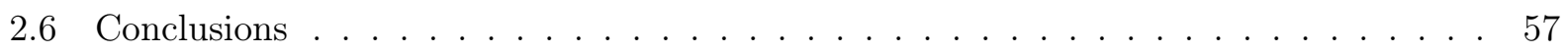

3 Shelfbreak Jet structure and variability off New Jersey using ship of opportunity data from the $C M V$ Oleander $\quad 59$

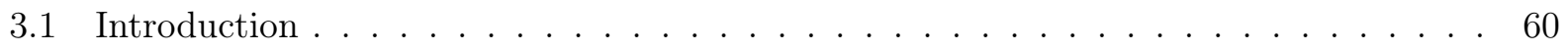


3.2 Data and Methods . . . . . . . . . . . . . . . . . . . 62

3.2.1 CMV Oleander measurements . . . . . . . . . . . . . . . . . 62

3.2 .2 Satellite . . . . . . . . . . . . . . . . . . 65

3.3 Mean and Climatological Structure . . . . . . . . . . . . 66

3.3.1 Eulerian Mean Shelfbreak Jet Velocity Structure and Transport . . . . . . . . 66

3.3.2 Stream-coordinate Mean Shelfbreak Jet Velocity Structure and Transport . 71

3.4 Conditional Averageing for a Broader View . . . . . . . . . . . . . . 75

3.4.1 Variability in the Position of the Jet . . . . . . . . . . . 75

3.4.2 Determining the factors causing jet presence or absence . . . . . . . . . . 79

3.4.3 Interannual variability and connections with temperature . . . . . . . . . 82

3.4.4 Long term Shelfbreak Jet Variability . . . . . . . . . . . . . . . 87

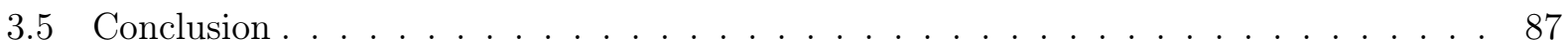

4 The impact of Warm Core Rings on Middle Atlantic Bight shelf temperature $\begin{array}{ll}\text { and Shelfbreak Jet velocity } & 91\end{array}$

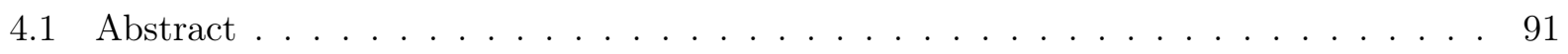

4.2 Introduction . . . . . . . . . . . . . . . . . . . . . . 92

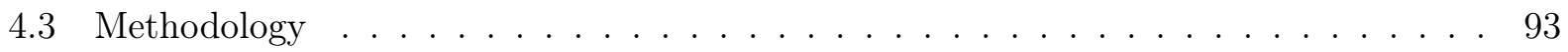

$4.3 .1 \quad C M V$ Oleander . . . . . . . . . . . . . . . . . 93

4.3 .2 Satellite Data . . . . . . . . . . . . . . . . . . . . . 95

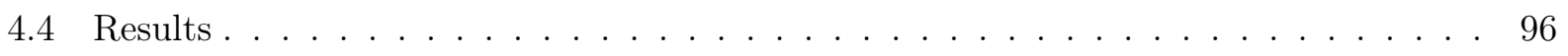

4.4.1 Warm Core Ring impact on shelf break velocities . . . . . . . . . . . . 96

4.4.2 Warm Core Rings impact on shelf temperature . . . . . . . . . . . . 103

4.5 Conclusion . . . . . . . . . . . . . . . . . . 108

5 Conclusions and Future Work 111

5.1 Conclusions . . . . . . . . . . . . . . . . . . . . . . . 111

5.2 Middle Atlantic Bight . . . . . . . . . . . . . . . . . . . . . 112

5.3 Future $C M V$ Oleander Work . . . . . . . . . . . . . . . . . . 114

$\begin{array}{ll}\text { A Figures } & 115\end{array}$ 
B Tables

References

119 


\section{List of Figures}

1-1 Map of the Northwest Atlantic with key regions and features labelled. . . . . . . . . 22

1-2 Monthly climatologies from 1977-2018 of temperatures on the MAB shelf from the $C M V$ Oleander XBTs. The black contour indicates the $10^{\circ} \mathrm{C}$. Updated figure from Forsyth

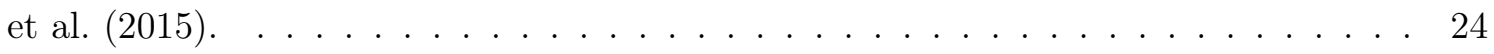

1-3 Time series of spatially and 12 month moving averaged temperatures on the MAB shelf from Oleander XBTs. Linear trends are calculated: 40 year trend (grey dashed line), 1977-2001 trend (yellow dashed line), and 2001-2017 (purple dashed line). . . . 25

2-1 Transects of potential density (colored shading) for different climatological months from the MABGOM model output. The transect shown here is along "Model Transect" from Figure 2-3. Contours of potential temperature are plotted every $2{ }^{\circ} \mathrm{C}$ in black, the bold line marks the $14{ }^{\circ} \mathrm{C}$ contour. The red circle is at the $55-\mathrm{m}$ isobath, within the cold pool. . . . . . . . . . . . . . . . . . . 32

2-2 Map of the MABGOM model domain. The continental shelf is highlighted in blue and bounded by the smoothed 80-m isobath (black bold line). The 1000, 2000, and 4000$\mathrm{m}$ isobaths in the model are countoured in grey. The red line marks the boundary of the model. The purple box shows the domain of Figure $2-3 . \ldots$. . . . . . . . . 36

2-3 A zoomed in section of Figure 2-2 (marked as the purple box). Here we also identify the model transect along which output is extracted (red line) and the 55-m isobath on this transect (red circle). The SW06 mapped transect is plotted as a purple line with the two ASIS buoys, Romeo and Yankee, plotted as purple circles. . . . . . . . . 37 
2-4 The mean change of $\Delta \sigma$ as a function of the number of MABGOM model time intervals after a storm is over with standard errors plotted as error bars. The means are only calculated for storms which did not have another storm within the restratification period considered ( 8 time intervals of 12.42 hours after a storm has ended). Left panel only considers downwelling-favorable storms, and the right column only considers upwelling-favorable storms. Black dashed line shows the mean change in stratification by the storms considered. Both y-axes span the same range. Negative values represent destratification. . . . . . . . . . . . . . . . . . . . . 40

2-5 Interannual variability of the initial fall stratification from the MABGOM model (thick black line associated with the left y axis) and the interannual variability of the destratification point (right y axis) for the MABGOM model (red), the PWP HEAT (blue), and PWP ALL (purple). PWP WIND never reaches the destratification point by the end of each year and thus is not shown. . . . . . . . . . . . . . 41

2-6 Interannual variability of the initial fall stratification from the MAGBOM model (thick black line associated with the left y axis) and the interannual variability of how storms in the MABGOM model impact stratification (red) and how heat fluxes (PWP HEAT) impact stratification (teal). For PWP HEAT the net change in $\Delta \sigma$ from initial fall stratification until the destratification point as defined from the MABGOM model is plotted. . . . . . . . . . . . . . . . . . .

2-7 Interannual variability of the impact of storms in the MABGOM model on overall stratification (red), and the accumulated along-shelf wind stress during the storms in the MABGOM model (blue). Left panel is the net effect of downwelling-favorable storms each year, and the right column is the net effect of upwelling-favorable storms

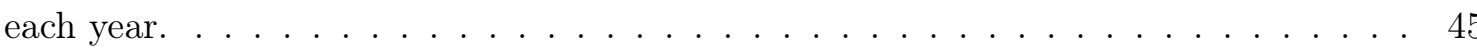

2-8 Interannual variability of the initial fall stratification from the MABGOM model (thick black line associated with the left y axis) and the interannual variability of the impact of storms in the MABGOM model on overall stratification (red), stratification due to potential temperature (yellow), and stratification due to salinity (green). Left panel is the net effect of downwelling-favorable storms each year, and the right column is the net effect of upwelling-favorable storms each year. . . . . . . . . . . . . 45 
2-9 Mean cross-shelf gradients and mean velocities for storms when $\tau_{x}<0$ (left column) and $\tau_{x}>0$ (right column). (a-b) Mean cross-shelf velocity at the 55-m isobath (blue) during storms. The black line is the mean cross-shelf velocity during the fall. Positive velocities denote onshore transport and negative velocities denote offshore transport. (c-d) Cross-shelf gradients in, potential density (red), salinity's contribution to potential density (green), and potential temperature's contribution to potential density (yellow). (e-f) Mean cross-shelf velocity during storms (a-b) multiplied by the crossshelf gradients (c-d) with colors corresponding to the gradients above (c-d). Negative values are increasing density and positive values are decreasing density. . . . . . . . . 48

2-10 Accumulated along-shelf wind stress (the sum of the average along-shelf wind stress in each time interval during each storm) versus the cross-shelf advective impact on the change in stratification due to changes in potential temperature (yellow squares) and salinity (green triangles) during each storm. . . . . . . . . . . . . . . . 49

2-11 The net change in stratification (delta sigma) versus the cross-shelf advective impact on stratification for each storm. The color is the accumulated along-shelf wind stress (sum of the along-shelf wind stress for the duration of the storm) for the storm. . . . 51

2-12 Mean along-shelf velocity (colored solid lines) and velocity profiles calculating from mean thermal-wind shear (colored dashed lines) during downwelling-favorable winds and upwelling-favorable winds. Black lines represent the background mean velocities

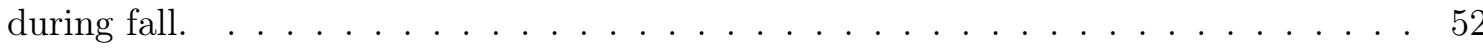

2-13 Fraction of time during strong wind events that the Richardson number was less than 0.25 at each depth. The blue line represents the downwelling-favorable winds and the red line represents the upwelling-favorable winds. . . . . . . . . . . . . 53

2-14 Comparing model wind forcing (blue) with the measured winds from the two ASIS buoys Yankee (red) and Romeo (orange) (positions of buoys in Figure 3). (a) Alongshelf winds on a 12 hour moving average and (b) Cross-shelf winds on a 12 hour moving average. Vertical lines show the boundaries that define time periods before the storm, during the storm and after the storm. . . . . . . . . . . 54 
2-15 Comparison of salinity conditions associated with storms between the MABGOM model and the observations. The left column shows the MABGOM model output and the right column shows the SW06 data. (a-b) Top row displays mean salinity fields for pre-storm conditions. (c-d) Middle row displays mean salinity fields for post-storm conditions. (e-f) Bottom row shows the change from the pre-storm to the post-storm (positive values indicate an increase in salinity) . . . . . . . . . . 55

2-16 As in Figure 2-15, but with potential temperature $(\theta) \ldots \ldots \ldots 6$

2-17 As in Figure $2-15$ but with potential density $(\sigma) \ldots \ldots \ldots \ldots$

3-1 Map of the MAB including the locations of the Shelfbreak Jet (blue) and Gulf Stream (red). The Oleander path (grey dashed line) goes from Port Elizabeth, New Jersey, to Bermuda. Grey contours of bathymetry are shown indicating the 40, 1000, 2000, and $4000-\mathrm{m}$ isobath, with the $100-\mathrm{m}$ isobath shown in black. . . . . . . . . . . 61

3-2 Eulerian mean along-shelf velocity (left column) and cross-shelf velocity (right column) from 1362 sections. The e-folding isotach (black line) is plotted for mean along-

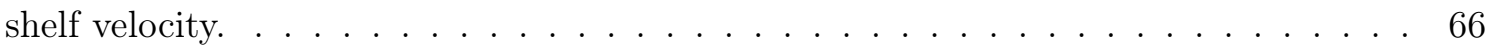

3-3 Eulerian mean along-shelf velocity (top) and stream coordinates mean along-shelf velocity (bottom) with extrapolated data above the dashed line. The e-folding isotach (black line) is plotted for each case. . . . . . . . . . . . . . . . . 67

3-4 Eulerian mean (blue) and stream coordinates mean (red) normalized relative vorticity from the shallowest bin of velocity data. Mean standard errors of the normalized relative vorticity are shown in the shaded colors. . . . . . . . . . . . . . . 68

3-5 Eulerian mean along-shelf velocities in each month. $\mathrm{T}_{e}$ is the transport in Sverdrups within each months e-folding isotach (solid black line) calculated based on the maximum velocity in each month. $\mathrm{T}_{e}$ cannot be calculated during February and November. $T_{u}$ is the transport in Sverdrups within the climatogical e-folding isotach (dashed black line in February and November) shown in Figure $3-2 . \ldots . . . . .70$ 
3-6 Normalized probablities of the location of the Shelfbreak Jet in isobath (left), and distance from Ambrose Lighthouse (right). The mean grounding position of the Shelfbreak Front ( $80 \mathrm{~m}$ isobath) is found at $149 \mathrm{~km}$ and plotted in the dashed grey line (Linder \& Gawarkiewicz, 1998). . . . . . . . . . . . . . . . . 72

3-7 Stream coordinates mean along-stream velocity (left column) and cross-stream velocity (right column) of the Shelfbreak Jet. The e-folding isotach (black line) is plotted for the mean along-stream velocity. The Shelfbreak Jet is identified in 546 sections. . 73

3-8 Histogram of the maximum and minimum normalized relative vorticity, across the Shelfbreak Jet in every transect when the jet is identified. . . . . . . . . . . . . 74

3-9 Stream coordinate along-stream velocity means (in $\mathrm{m} \mathrm{s}^{-1}$ ) when the Shelfbreak Jet is identified onshore of its mean position (top, calculated from 105 transects) and offshore of its mean position (bottom, calculated from 71 transects) . . . . . . . . . 76

3-10 Stream coordinate along-stream velocity shear $\left(\partial u / \partial z \mathrm{~s}^{-1}\right)$ in the colored contours when the Shelfbreak Jet is identified onshore of its mean position (top) and offshore of its mean position (bottom). Solid black contours are the stream coordinate alongstream velocity means for the onshore and offshore shifted Shelfbreak Jet from Figure

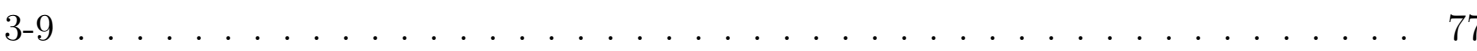

3-11 Composite maps of SSH anomalies (cm, top row) and SST anomalies $\left({ }^{\circ} \mathrm{C}\right.$, bottom row) when the Shelfbreak Jet is identified onshore of its mean position (left column) and offshore of its mean position (right column). Colored contours are not shown if the mean standard errors overlap with zero. The grey dashed line is the Oleander path, the grey solid line is the $80-\mathrm{m}$ isobath, and the solid black line is the mean position of the $25 \mathrm{~cm} \mathrm{SSH}$ contour which is a proxy for position of the Gulf Stream.

3-12 Eulerian mean along-shelf velocity (left column) and cross-shelf velocity (right column) during time periods when the Shelfbreak Jet is identified (top row), and time periods when the Shelfbreak Jet is not present (bottom row) . . . . . . . . . . 80 
3-13 Composite maps of SSH anomalies (cm, top row) and SST anomalies $\left({ }^{\circ} \mathrm{C}\right.$, bottom row) around the times that the Shelfbreak Jet cannot be identified in the ADCP data. Composites are shown one month before (left column), concurrently with (middle column), and one month after (right column) the Shelfbreak Jet is not identified in ADCP sections with over $70 \%$ data return. Contours not shown if the mean standard errors overlap with zero. The grey dashed line is the Oleander path, the grey solid line is the $80-\mathrm{m}$ isobath, and the solid black line is the mean position of the $25 \mathrm{~cm}$ SSH contour which is a proxy for the position of the Gulf Stream. Note the color bar ranges are both halved from Figure $3-11 \ldots \ldots \ldots \ldots$. . . . . . . . . . 81

3-14 Time series of the velocity over the shelf break (purple) and Shelfbreak Jet velocity (green), as defined in section 3.4.33. Both time series are 12-month moving averaged. The dashed lines show the long term trends. Only the linear trend of the Shelfbreak Jet velocity is significantly different from zero. . . . . . . . . . . . . . . . . . .

3-15 Time series of the velocity over the shelfbreak (purple) and temperautre on the shelf (red). Both time series are deseasoned with a 12-month moving average. The two time series are significantly anti-correlated $(\mathrm{p}<0.05)$ with a $1-3$ month lag, with velocity

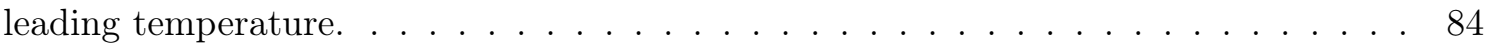

3-16 Hovmuller diagram of the upper $50 \mathrm{~m}$ along-shelf velocity (left contour plot) and upper $50 \mathrm{~m}$ temperautre (right contour plot). The middle panel shows a time series of the mean shelfbreak velocities from 140-182 m (purple dashed lines in left panel) and upper $50 \mathrm{~m}$ in purple and the mean shelf temperatures onshore of the $80 \mathrm{~m}$ isobath in red (vertical grey dashed line in left and right contour plots). . . . . . . . 86

4-1 Eddy tracks of the 14 WCRs (of our 16 total) that can be identified using the Chelton eddy tracks. Colors indicate the age of the ring when it crosses the $C M V$ Oleander Line (Chelton et al., 2011). One ring track does not cross the Oleander Line in the Chelton Tracks and is plotted in red. The axes are shown in the bottom right. Contours of the 100, 500, and 4000-m isobath are plotted in grey, with the 2400 and 2900-m isobath plotted in black. The shelf region, less than $100 \mathrm{~m}$ depth, is shaded in blue. The grey dashed line shows the Oleander Line. . . . . . . . . . . . . . . . 94 
4-2 Eulerian mean along-shelf velocity (left column) and cross-shelf velocity (right column) from 151 sections during WCRs. . . . . . . . . . . . . . . . 97

4-3 Eulerian mean along-shelf velocity (left column) and cross-shelf velocity (right column) from 151 sections during WCRs. The color bar is half the range as Figure 4-2. Black contours are the $0.06,0.08$, and $0.10 \mathrm{~m} \mathrm{~s}^{-1}$ isotachs calculated from the Eulerian mean along-shelf velocity $($ Figure $3-2) \ldots \ldots \ldots$. . . . . . . . . 97

4-4 The velocity at the shelf break plotted in colors, as a function of the ring speed $\left(S_{w c r}\right.$, $\mathrm{x}$-axis) and distance from the shelf break $\left(d_{s b}, \mathrm{y}\right.$-axis). A linear regression model show both independent variables have significant relationships to the velocity at the shelf break $(\mathrm{p}<0.01) \ldots \ldots \ldots \ldots \ldots \ldots \ldots$

4-5 Sea surface height colored contours for a ring passing the Oleander Line from August 7th, 1999 to September 15h 1999. The left panel shows the leading edge of the ring, and right panel shows the trailing edge of the ring. Red lines show the circulation of

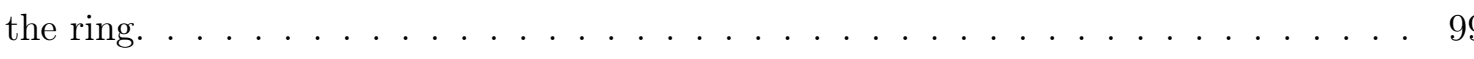

4-6 Composite averages of along-shelf velocity (left column) and cross-shelf velocity (right column) during the first ring section of each ring (top row), and during the last ring section of each ring (bottom row). In the cross-shelf velocity during the last ring section $(\mathrm{d})$, we label the direction of the flow indicating divergence. . . . . . . . . 101

4-7 Change in spatially averaged shelf temperature anomalies before and after a ring $\left(\Delta T_{s}\right)$ plotted against the average speed of each ring $\left(\bar{S}_{w c r}\right)$. The two variables are significantly correlated at the $95 \%$ confidence interval $(\mathrm{r}=-0.58 \& \mathrm{p}<0.05) \ldots \ldots$

4-8 The speed of the rings $\left(\bar{S}_{w c r}\right)$ and the month the ring crossed the Oleander Line. Purple dots are when $\Delta T_{s}$ is calculated, yellow squares do not have XBT data before and after the ring passes. . . . . . . . . . . . . . 105

4-9 $\Delta T_{s}$ plotted against the temperature stratification $\left(T_{c p}\right)$ in the XBT section before the ring passes (left) and the XBT section when the ring is intersecting the Oleander track (right). There are only $10 \mathrm{XBT}$ sections during the ring when $T_{c p}$ can also be calculated. $\Delta T_{s}$ is correlated with both the $T_{c p}$ before the ring passes $(\mathrm{r}=-0.6 \&$ $\mathrm{p}<0.05)$ and $T_{c p}$ when the ring is on the Oleander Line $(\mathrm{r}=-0.66 \& \mathrm{p}<0.05) \ldots \ldots$ 4-10 $\Delta T_{s}$ plotted against the upwelling velocities $\left(w_{u p}\right)$ estimated from equation 4.1 . . . 107 
A-1 Stream coordinate mean streamwise velocities in each month. . . . . . . . . . . . 115 


\section{List of Tables}

3.1 Calculations of the Shelfbreak Jet transport . . . . . . . . . . . . . . . 69

B.1 Properties of the Warm Core Rings . . . . . . . . . . . . . . . . . . 118 


\section{Chapter 1}

\section{Introduction}

The Middle Atlantic Bight (MAB) spans the shelf waters in the Northwest Atlantic from south of Cape Cod to Cape Hatteras (Figure 1-1). The MAB shelf's bathymetry is gently sloping from the coast down to the shelf break, at approximately the $100 \mathrm{~m}$ isobath, which is roughly $100 \mathrm{~km}$ offshore. At the shelf break, the depth increases rapidly, causing a topographic barrier for exchange of water masses. These coastal shelf waters are highly important to the surrounding areas through the fishery and tourism industries. Extreme temperature variability in recent years such as 2012, have led to large changes in the stock distribution of certain species of fish due to the relationship between recruitment and temperature (K. Friedland, 2012; Gawarkiewicz et al., 2013; Miller et al., 2016). Heightened temperatures on the shelf also lead to the MAB being a greater source of energy for tropical storms (Sallenger et al., 2012; Forsyth et al., 2015; Wang \& Wu, 2004). Developing an understanding of what drives the variability on the shelf enhances the ability of coastal communities and the fishing industry to adapt to the changing climate.

\subsection{Hydrographic and Dynamical Properties of the MAB}

The climatological hydrographic and dynamical properties on the MAB shelf have been documented on annual, and seasonal timescales (e.g. Houghton et al., 1982; Linder \& Gawarkiewicz, 1998; Lentz, 2008b)). Here I provide a brief overview of the literature involving the climatological hydrographic properties of the MAB, as well as their respective variability.

The mean along-shelf circulation is part of a larger coastal shelf system in which water flows 


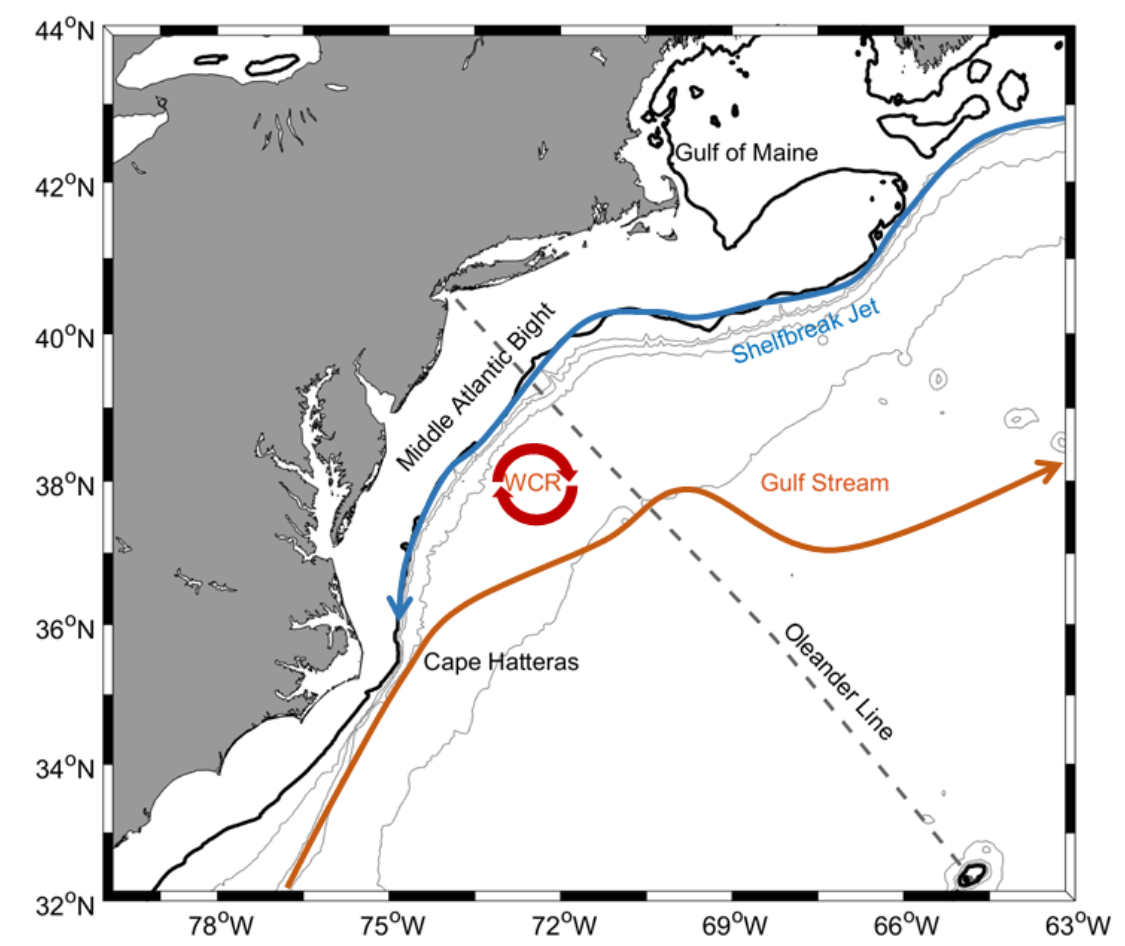

Figure 1-1: Map of the Northwest Atlantic with key regions and features labelled.

equatorward along the continental shelf, from Greenland down to Cape Hatteras (e.g. Chapman \& Beardsley, 1989; Loder et al., 1998; Fratantoni \& Pickart, 2007). This coastal along-shelf current has been measured to be primarily geostrophic with mean velocities between $0.05-0.1 \mathrm{~m} \mathrm{~s}^{-1}$, with faster velocities over deeper water and near the surface (Linder \& Gawarkiewicz, 1998; Shearman \& Lentz, 2003; Lentz, 2008a). Mean cross-shelf circulation on the MAB is also relatively coherent throughout. The mean cross-shelf surface flow is offshore, the mid-depth flow is onshore, and velocity at the bottom reverses to offshore where the depth is greater than $50 \mathrm{~m}$ (Lentz, 2008a; Zhang et al., 2011). The cross-shelf velocities tend to be weaker than the along-shelf velocities and are a result of surface and bottom Ekman layers. Seasonally, these currents have small amplitude variations due to changes in the wind stress, and the cross-shelf density gradient (Lentz, 2008b). The timing of the seasonal variability is dependent on the location within the MAB due to the rotated orientation of the shelf, and variable depths.

The mean along-shelf flow is fastest at the shelf break due to the presence of the Shelfbreak Front. The Shelfbreak Front separates fresher cooler shelf water from the saltier warmer slope waters. Within the front, the isopycnals intersect with the bathymetry around the $100 \mathrm{~m}$ isobath, surfacing 
further offshore (Linder \& Gawarkiewicz, 1998). Studies of the Shelfbreak Front have shown that its position meanders with wavelengths of 10-50 km, amplitudes of 10-25 km, and meander periods on the order of days (Lozier et al., 2002; Gawarkiewicz et al., 2004). These temporal and spatial oscillations have been attributed to baroclinic and/or barotropic instabilities. The Shelfbreak Front also has a mean seasonal migration of around $20 \mathrm{~km}$, moving most onshore in the winter (Linder \& Gawarkiewicz, 1998). Variations of the Shelfbreak Front on longer time scales are unknown.

Associated with the Shelfbreak Front, is the geostrophic Shelfbreak Jet. Velocities of the Shelfbreak Jet are typically along-isobaths with a depth averaged velocity of around $0.15 \mathrm{~m} \mathrm{~s}^{-1}$ and a maximum surface velocity up to $0.35 \mathrm{~m} \mathrm{~s}^{-1}$ (Flagg et al., 2006; Fratantoni \& Pickart, 2007). The Shelfbreak Jet reaches a maximum depth averaged velocity in winter, when the front is most onshore, of around $0.2 \mathrm{~m} \mathrm{~s}^{-1}$, while in summer the mean depth averaged velocity is around $0.1 \mathrm{~m} \mathrm{~s}^{-1}$ (Flagg et al., 2006). Studies of the interannual variability of the Shelfbreak Jet found a standard deviation in the depth-averaged veloctities of $0.05 \mathrm{~m} \mathrm{~s}^{-1}$ which was attributed to be thermohaline driven (Rossby et al., 2005; Flagg et al., 2006). A more in depth look into the variability of the Shelfbreak Jet is the subject of Chapter 3.

Temperatures on the MAB shelf have large variability on seasonal, interannual, and decadal timescales (Shearman \& Lentz, 2010; Forsyth et al., 2015). The seasonal cycle of temperatures evolves through both the dynamics and thermodynamics (Beardsley et al., 1985; Lentz et al., 2003). In winter, the MAB shelf waters are well mixed with weak thermal gradients except at the shelf break, where the cross-shelf temperature gradients are enhanced (Figure 1-2, Forsyth et al. (2015); Linder and Gawarkiewicz (1998)). During spring, air-sea heat fluxes warm the surface waters, leaving an isolated pool of subsurface waters known as the cold pool (defined as under $10^{\circ} \mathrm{C}$ Houghton et al. (1982)). The cold pool temperatures are set by the coldest shelf waters in winter, and remain isolated throughout the summer months. The thermal stratification peaks in August. After August, the stratification begins to break down through both surface cooling and wind-driven dynamics (Lentz et al., 2003). These processes in fall mix the shelf waters, leading to the uniform temperatures on the shelf (Beardsley et al., 1985; Lentz et al., 2003). The year to year variability in the processes responsible for mixing the shelf waters in fall are discussed in Chapter 2.

Longer term records of temperature from lightships, lighthouses, National Ocean and Atmospheric Administration (NOAA) buoys, and Ships of Opportunity (SOOP) have allowed for analysis 

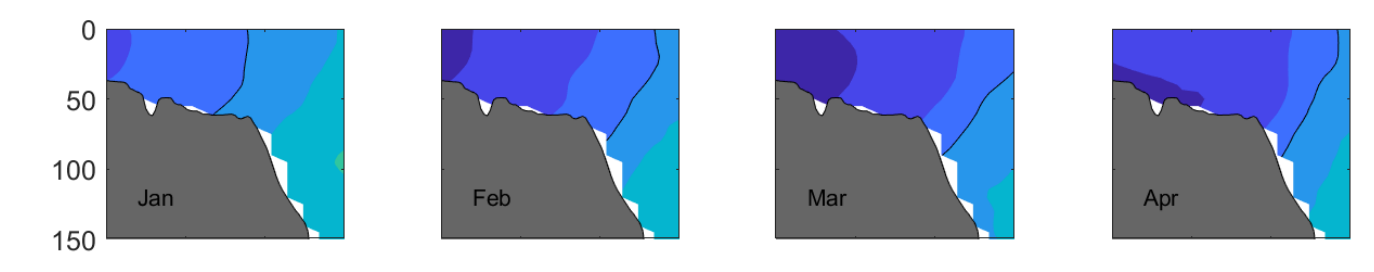

Temperature $\left({ }^{\circ} \mathrm{C}\right)$
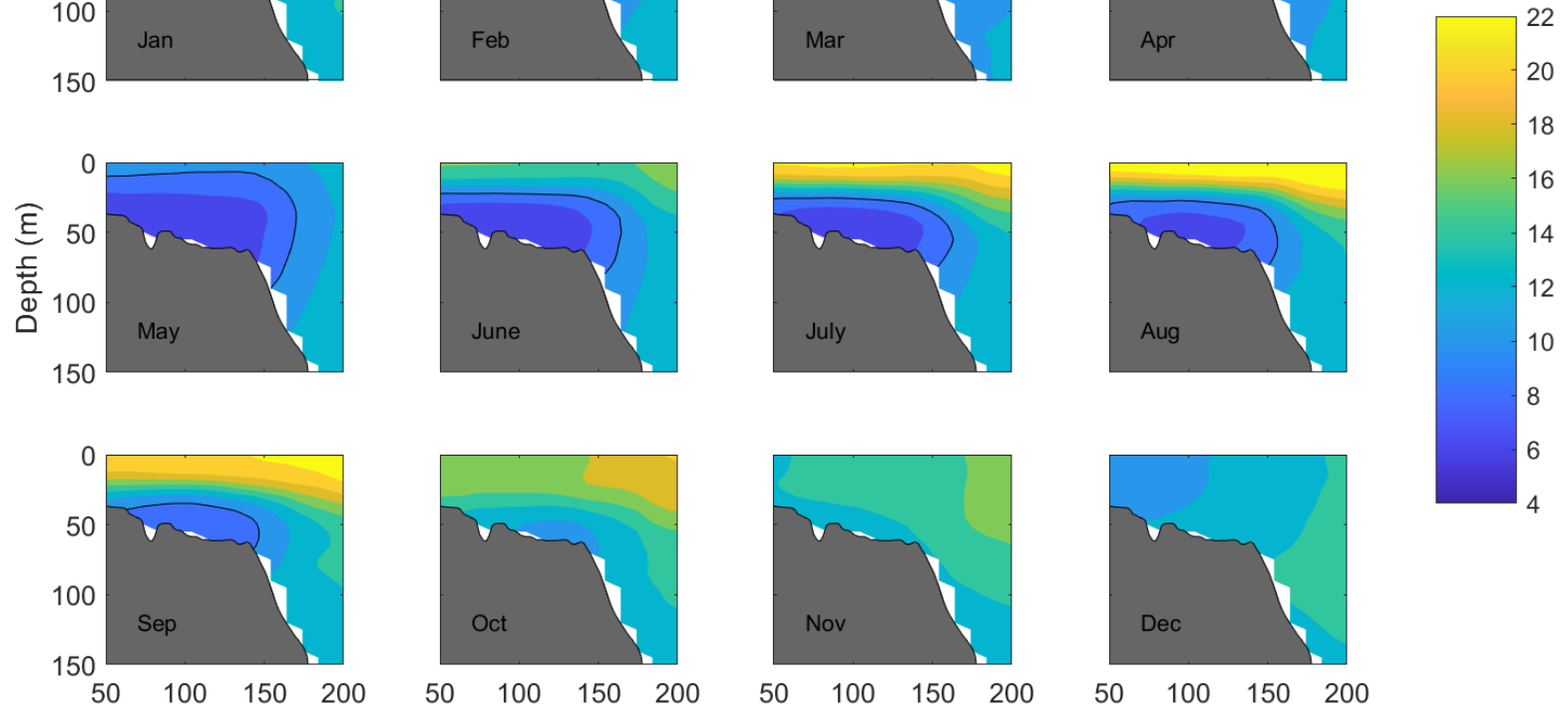

Distance from Ambrose Light (km)

Figure 1-2: Monthly climatologies from 1977-2018 of temperatures on the MAB shelf from the $C M V$ Oleander XBTs. The black contour indicates the $10^{\circ} \mathrm{C}$. Updated figure from Forsyth et al. (2015).

of variability on interannual and decadal timescales (Shearman \& Lentz, 2010; Forsyth et al., 2015). Over 100 years of sea surface temperature (SST) data on the MAB detailed a temperature increase of $0.7^{\circ} \mathrm{C} / 100$ yr (Shearman \& Lentz, 2010). This long term trend was due to along-shelf heat transport and not local air-sea heat exchange. 40 years of expendable bathythermograph (XBT) data from the $C M V$ Oleander (discussed in detail in Section 1.2) show a long term warming trend throughout the MAB shelf of $.03{ }^{\circ} \mathrm{C} / \mathrm{yr}$, over 4 times larger than the 100 year trend (Figure 1-3, Forsyth et al. (2015)). The data from the XBTs also showed a more recent accelerated warming trend that was concentrated near the shelf-break. More recent studies looking at satellite SST data have found warming trends that surpass the trends found in the XBT data (Mills et al., 2013; Z. Chen et al., 2020). On shorter time scales, modeling work has shown that year to year variability in winter-spring temperatures on the MAB shelf are primarily set by the temperatures at the end of fall, and the cumulative air-sea heat flux (K. Chen et al., 2016). Ocean advection on the interannual variability timescale was found to play a secondary role in most years, though this varied from year to year. A large heatwave in winter and early spring during 2017 was primarily driven by a Warm 
Core Ring flooding the shelf with warmer waters, while the warming in 2012 was primarily driven by changes in the atmospheric circulation (Gawarkiewicz et al., 2019; K. Chen, Gawarkiewicz, et al., 2014). Overall this highlights the importance of studying variability on many time scales as different physical processes are responsible for variability in different frequency bands.

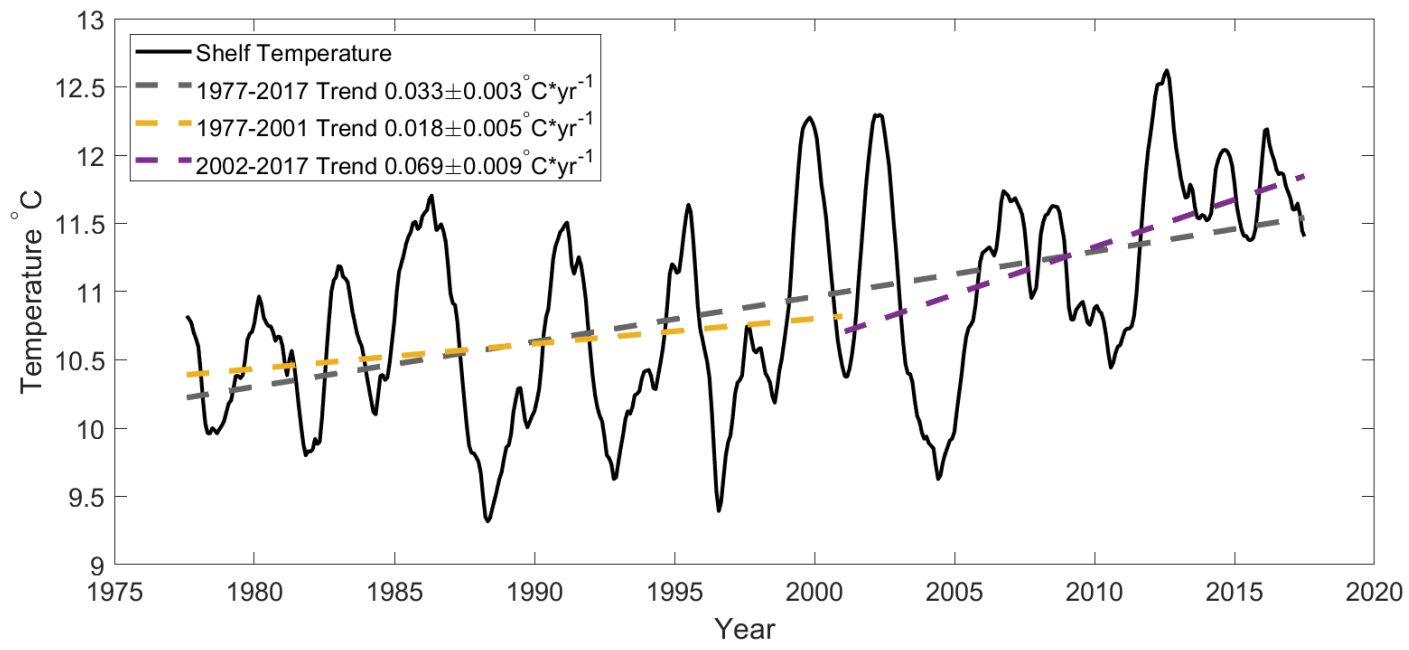

Figure 1-3: Time series of spatially and 12 month moving averaged temperatures on the MAB shelf from Oleander XBTs. Linear trends are calculated: 40 year trend (grey dashed line), 1977-2001 trend (yellow dashed line), and 2001-2017 (purple dashed line).

Salinity measurements from the MAB are less abundant in both time and space than temperature measurements, but variability from seasonal through decadal time scales have still been quantified. The mean salinity structure on the MAB shelf is characterized by a cross-shelf salinity gradient with increasing salinities offshore and isohalines sloping upwards in the offshore direction. Both seasonal and interannual variability in salinity is primarily dependent on river runoff, and secondarily on precipitation and evaporation (Manning, 1991; Bisagni, 2016). Interannual variations in the salinity fields tend to be larger than the seasonal cycles (Mountain, 2003). Seasonal salinity values peak in winter when river runoff and precipitation are low, and salinity reaches a minimum in summer, due to large river run off and high values of precipitation (Manning, 1991). Larger scale forcing can also impact the salinities on interannual timescales. A large positive salt anomaly occurred on the MAB from 2012-2016 due to a diversion of the Arctic freshwater that normally flows equatorward along the shelf (Holliday et al., 2020). Analysis from 1972-2012 showed that the annually and spatially averaged surface salinity in the MAB is not significantly changing (Bisagni, 2016). However, unlike 
temperatures, this low frequency variability is not consistent throughout the Northwest Atlantic coastal system, with locations upstream of the MAB freshening, and areas downstream of the MAB becoming saltier.

Events which occur over short time scales are also important in driving variability. Specific events like Warm Core Rings or large storms have the ability to drastically change the shelf's dynamic and thermodynamic properties over a few days (K. Chen, He, et al., 2014; Glenn et al., 2016). Warm Core Rings are anti-cyclonic eddies that are pinched off from the Gulf Stream and then advect into the Slope Sea. These anti-cyclonic rings can reverse the Shelfbreak Jet circulation, and bring warm salty Gulf Stream water onto the MAB shelf, as well as pull cooler shelf waters into the Slope Sea (e.g. Morgan \& Bishop, 1977; Joyce, 1984; Beardsley et al., 1985; Churchill et al., 1986; Zhang \& Gawarkiewicz, 2015). Recent research from the Ocean Observatories Initiative (OOI) Pioneer Array shows evidence that Gulf Stream waters are intruding onto the shelf more often than in the past decades (Gawarkiewicz et al., 2018). This is likely due to the increased number of Warm Core Rings per year since the year 2000 (Gangopadhyay et al., 2019). These short term events can have longer lasting effects, increasing both temperatures and salinities on the shelf for longer timescales than just the period of time where the ring is impinging on the shelf (Gawarkiewicz et al., 2019).

\section{$1.2 \quad C M V$ Oleander}

The $C M V$ Oleander refers to a line of ships that have been traveling between New Jersey and Bermuda on a weekly schedule which began collecting scientific data in 1977 (Rossby et al., 2019). Currently, the $C M V$ Oleander is equipped with auto-deploying XBTs measuring temperature with depth, a thermosalinograph measuring surface salinity and temperature, and two different Acoustic Doppler Current Profilers (ADCPs) which measure ocean currents as well as other acoustic properties. Along the cruise track, the $C M V$ Oleander traverses many regions of scientific importance. From New Jersey to Bermuda, the Oleander crosses the shelf, the shelf break, into the Slope Sea, the Gulf Stream, and the Sargasso Sea. The importance of the shelf and shelf break regions have been discussed, however, one of the main purposes of the Oleander is to study the Meridional Overturning Circulation (MOC) by measuring the volume and heat transport of the Gulf Stream. Ocean current measurements from the ADCPs began in 1992 and continue to provide on temporal variations in 
the Gulf Stream and MOC (Rossby et al., 2014).

From 1977 to the present, XBT data has been collected across the Oleander's path. The time span of this data set allowed for calculations of ocean warming across an incredibly long period. Additionally, the XBT dataset has data recorded throughout the water column, allowing for the discovery that the previously known surface temperature warming of the MAB shelf was occurring throughout the water column (Forsyth et al., 2015). In-situ measurements are incredibly important in understand the changing shelf system.

Additional long term observing platforms are now being used within the Northwest Atlantic like the Ocean Observing Initiative Pioneer Array, as well as glider programs along the east coast of the United States. Each monitoring program has their own strengths and processes they are able to observe. The data sets $C M V$ Oleander's strength lie in their longevity and continuity, allowing detailed studies into how the ocean has changed and is still changing from 30 to 40 years ago. Maintaining observations from the $C M V$ Oleander is important as the ocean is rapidly changing in this region.

\subsection{Outline}

In the 40 years of XBT analysis, the fall season had the largest interannual variability of temperature, and the largest warming trend of the four seasons (Forsyth et al., 2015). Lentz et al. (2003) was able to quantify that the majority of stratification was reduced in 4 high wind events in 1996, however, the observations in a single year did not give any indication if high wind events are always responsible for the breakdown of stratification in every year. In chapter 2, I diagnose the processes which break down stratification and the variability in their ability to reduce stratification across a ten year span from model output. Additional observations are used to verify that the processes which reduce stratification within the model are consistent with in-situ measurements.

Chapter 3 focuses on quantifying velocity structure over the shelf break using 25 years of data from the Oleander ADCPs. Velocities are examined in terms of the Eulerian mean structure, as well as tracking the Shelfbreak Jet and using a Stream Coordinate analysis. I calculate the variability of the velocity fields from monthly through decadal time scales. Analysis of different states of the Shelfbreak Jet are also done using conditional averages. Lastly, I find that the variability in velocity 
at the shelf break is connected with the variability in temperature.

Work in Chapter 3 showed that Warm Core Rings are drivers of variability at the shelf break. Chapter 4 examines first how varied Warm Core Rings can be from each other. Next, the ability for Warm Core Rings to impact shelf properties are studied. I look at how different rings impact the velocity structure on the shelf while they are in the Slope Sea on the $C M V$ Oleander line. Rings have been documented to greatly influence the temperature on the shelf, and I examine how rings can both warm the shelf, and cool the shelf. The ability for rings to change the shelf temperature is greatly dependent on the season in which they abut the shelf, with summer time rings cooling the shelf, and rings in spring and fall tending to warm the shelf. 


\title{
Chapter 2
}

\section{The interannual variability of the}

\section{breakdown of fall stratification on the}

\section{New Jersey shelf}

This chapter was originally published as: Forsyth, J., Gawarkiewicz, G., Andres, M., \& Chen, K. (2018). The interannual variability of the breakdown of fall stratification on the New Jersey shelf. Journal of Geophysical Research: Oceans, 123. https://doi.org/10.1029/2018JC014049.

\begin{abstract}
During the seasonal evolution of stratification on the New Jersey shelf in the fall, strong thermal stratification that was established in the preceding summer is broken down through wind-driven processes and surface cooling. Ten years of output from a Region Ocean Modeling Systems (ROMS) run and a one-dimensional mixed layer model are used here to examine the interannual variability in the strength of the stratification and in the processes which reduce stratification in fall. Our analysis shows the strength of the stratification at the end of the summer is not correlated with the timing of shelf destratification. This indicates that processes that occur within the fall are more important for the timing of stratification breakdown than are the initial fall conditions. Furthermore, winddriven processes reduce a greater fraction of the stratification in each year than does the surface cooling during the fall. Winds affect the density gradients on the shelf through both changes to the temperature and salinity fields. Processes associated with the downwelling-favorable winds are more effective than those during upwelling-favorable winds in breaking down the vertical density gradients. In the first process, cross-shelf advective fluxes during storms act to decrease stratification during downwelling-favorable winds and increase stratification during upwelling-favorable winds. Second, there is also enhanced velocity shear during downwelling-favorable winds which allows for more shear instabilities that break down stratification via mixing. Observational data and model output from Tropical Storm Ernesto compare favorably and suggest that downwelling-favorable winds act
\end{abstract}


through the mechanisms identified from the ROMS results. 


\subsection{Introduction}

Annually-averaged ocean temperatures observed off New Jersey on the Middle Atlantic Bight (MAB) shelf show both recent warming at enhanced rates relative to warming trends observed earlier in the record and recent increase in interannual variability (K. Chen, Gawarkiewicz, et al., 2014; K. D. Friedland \& Hare, 2007; Forsyth et al., 2015). The accelerated warming of the MAB shelf is also consistent with the enhanced warming trend in Sea Surface Temperature (SST) observed in the Gulf of Maine (e.g. Mills et al., 2013; Pershing et al., 2015). Previous work using data from the Oleander Line, an expendable bathythermograph (XBT) repeat line across the New Jersey shelf, suggests that since 1977, the most pronounced warming and the strongest interannual variability manifest in the fall (Forsyth et al., 2015). Fall temperature structure on the MAB shelf directly influences recruitment of commercially important fish species like yellowtail flounder (Sullivan et al., 2005), and the intensity and path of tropical storms that move up the U.S. east coast (Glenn et al., 2016; Lau et al., 2016).

The evolution of the seasonal stratification in fall directly influences the fall temperatures on the MAB continental shelf (Figure 2-1, Beardsley et al. (1985); Linder and Gawarkiewicz (1998). During the summer, when atmospheric heating warms the surface water and creates thermal stratification, a strong vertical thermocline separates the warm surface layer from the remnant winter water known as the cold pool (e.g Houghton et al., 1982; Lentz, 2017). This thermal stratification breaks down during the fall leading to relatively homogenous shelf waters in winter. The breakdown of fall stratification directly determines the thermal structure on the shelf (Figure 2-1) and thus is important in setting shelf conditions in the following seasons. This also has economic significance as the catches of both squid and lobster have extended later into the fall in some recent years (Hare et al., 2016; Rheuban et al., 2017).

This fall erosion of MAB shelf stratification is thought to result both from increased wind energy available for mixing and from the onset of surface cooling (Mooers et al., 1976; Beardsley et al., 1985). Lentz et al. (2003) (hereafter referred to as L03) report on observations from the fall of 1996 on the New England Shelf (northeast of our study area), where wind-driven processes dominated the breakdown of stratification, primarily through high-wind events in the downwelling-favorable direction (easterly in L03). Since the observational program in L03 only documented a single fall, how 

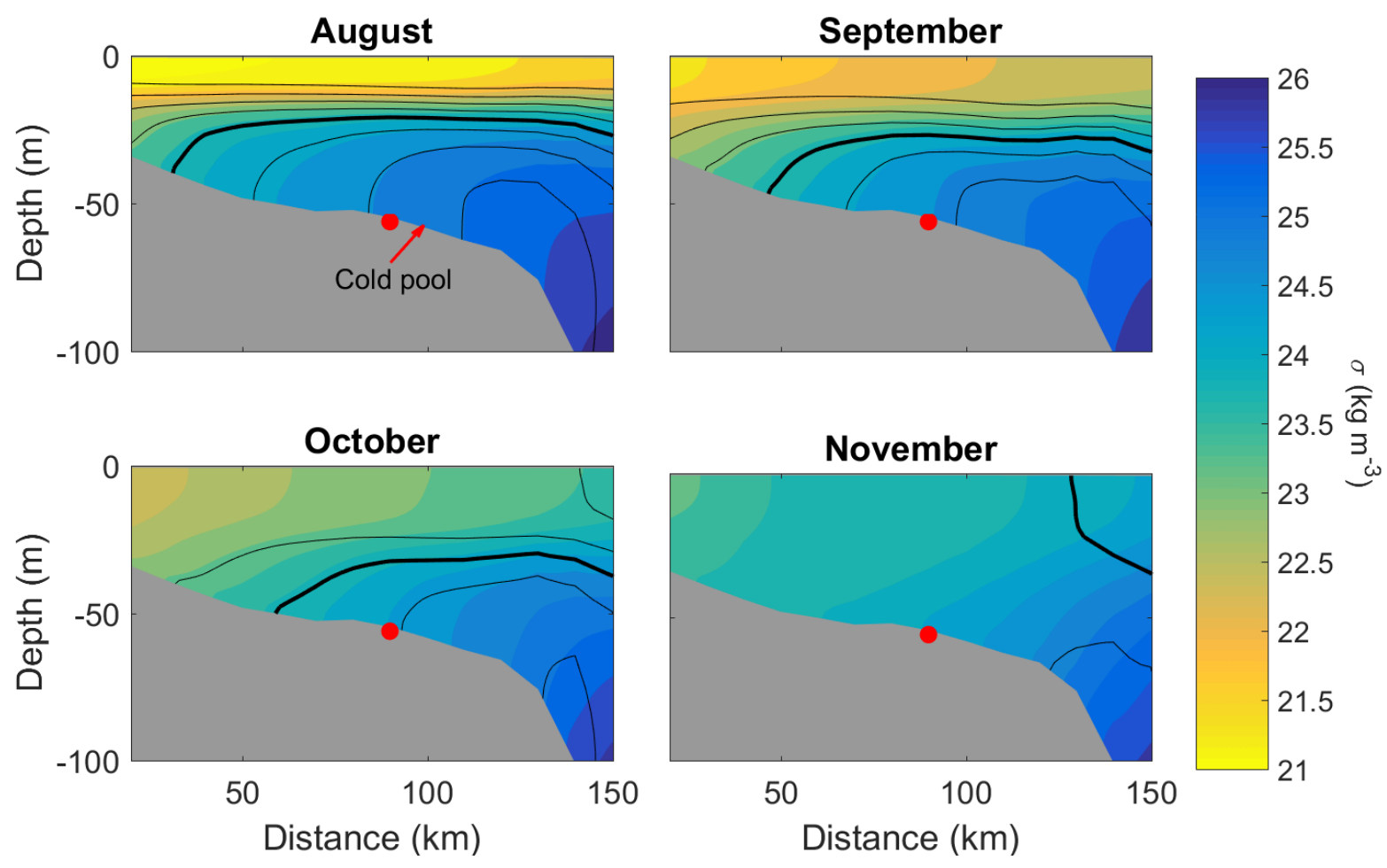

Figure 2-1: Transects of potential density (colored shading) for different climatological months from the MABGOM model output. The transect shown here is along "Model Transect" from Figure 2-3. Contours of potential temperature are plotted every $2{ }^{\circ} \mathrm{C}$ in black, the bold line marks the $14{ }^{\circ} \mathrm{C}$ contour. The red circle is at the 55-m isobath, within the cold pool. 
the breakdown in fall stratification varies interannually, including the timing and driving processes, remains an open question. In particular, the relative importance of wind mixing, surface cooling, and 3-dimensional oceanic processes are not well quantified from year to year. Considering the recent changes on the $\mathrm{MAB}$ shelf and the direct impact of stratification on the shelf conditions and ecosystem, it is both timely and important to understand better the breakdown of stratification in fall.

Here we examine the interannual variability in the relative impacts of both wind and surface cooling on the fall breakdown of stratification using a numerical model simulation from 20042013 across the New Jersey shelf. We study the New Jersey shelf as a region representative of the southern MAB defined as south of Hudson Canyon, focusing on the dynamics that breakdown stratification over the cold pool. Numerical model hindcasts provide a viable way of examining the problem over a ten year time span, in contrast to most observational programs in the area which have typically been limited to a single year (e.g Houghton et al., 1982; Lentz et al., 2003)). The model configuration and forcing are described in section 2.2 , together with a description of the data used to evaluate the validity of the model. In section 2.3 we describe the interannual variability on the New Jersey shelf as represented by the model in terms of (1) initial fall stratification, (2) the date of the initial destratification, and (3) the relative contributions of surface cooling and wind driven processes. In section 2.4, we show that downwelling-favorable winds are able to reduce stratification more effectively than upwelling-favorable winds through buoyancy fluxes of both heat and salt, and through enhanced velocity shear throughout the water column. Finally, we compare model output and observations from before and after Tropical Storm Ernesto in section 2.5 in order to qualitatively confirm that three-dimensional processes are important in the breakdown of stratification. Conclusions appear in section 2.6.

\subsection{Methodology}

We use two complementary modeling approaches to examine the breakdown of stratification in the fall. First, we examine the output from a regional general circulation model, driven by realistic oceanic and atmospheric forcings. Then we use a one-dimensional mixed layer model to elucidate the roles of wind forcing and buoyancy forcing during the stratification breakdown. Despite differ- 
ences between the model's mixing schemes, this approach helps clarify some of the contributions of three-dimensional processes by comparing the regional model output to the output from the one-dimensional model run with the various forcing terms.

\subsubsection{The Regional Circulation Model}

We use existing model output from a regional general circulation model (Middle Atlantic Bight and Gulf of Maine, MABGOM) described by K. Chen, He, et al. (2014); K. Chen and He (2015). Here we only describe important details of the model that are relevant to this study.

The model is the hydrostatic Regional Ocean Modeling System (ROMS) configured for the Northwest Atlantic continental shelf region. ROMS is a free-surface, primitive-equation model mapped onto vertically stretched, terrain-following coordinates using algorithms described by Shchepetkin and McWilliams (2005) and Haidvogel et al. (2008). Vertical turbulent mixing is calculated following the methodology of Mellor and Yamada (1982). Quadratic bottom drag is used with a drag coefficient of 0.003. The domain of the model extends from Cape Hatteras to Nova Scotia (Figure 2) covering the MAB and the Gulf of Maine. Horizontal resolution is $10 \mathrm{~km}$ in the along-shelf direction and $6 \mathrm{~km}$ in the cross-shelf direction. There are 36 vertical bins which are higher resolution near the surface and bottom in order to more accurately resolve the boundary layers.

The model's initial and boundary conditions are derived from the $1 / 12^{\circ}$ daily mean fields from the Hybrid Coordinate Ocean Model Naval Research Laboratory Coupled Ocean Data Assimilation (HYCOM/NCODA) output (Chassignet et al., 2007). The lack of coastal processes (e.g., river outflows and tidal mixing) in the HYCOM/NCODA leads to temperature and salinity biases that are strongest on the continental shelf. To correct for these biases, the HYCOM annual mean salinity and temperature fields are replaced with the HydroBase Hydrographic climatological field for each given year (Curry, 1996). Dynamic height and geostrophic transport are also adjusted to be consistent with the corrected temperature and salinity fields. This correction removes the annual mean biases, but maintains the daily variability of the HYCOM/NCODA output.

Surface forcing comes from the North America Regional Reanalysis (NARR) provided by National Oceanographic and Atmospheric Administration (NOAA) National Centers for Environmental Prediction (NCEP). This product has a 35-km spatial resolution and 3-hour temporal resolution. Surface buoyancy and momentum fluxes are calculated using the standard bulk formulae (Fairall et 
al., 2003). The surface net heat fluxes are additionally adjusted through a thermal relaxation term based on the daily blended cloud-free surface temperature field produced by NOAA Ocean Watch, with an adjustment time scale of 12 hours (e.g. K. Chen \& He, 2015).

The model hindcast begins on 1 November 2003 using the corrected HYCOM/NCODA fields and is run until 31 December 2013, providing 10 years of model output from 2004 through 2013. Model output is averaged over the $\mathrm{M}_{2}$ tidal cycle providing a temporal resolution of 12.42 hours.

We extract a cross-shelf transect from the model with $x>0$ in the north-east (i.e., along-shelf) direction and $y>0$ in the north-west (i.e., cross-shelf) direction (Figure 2-2). The transect is chosen to coincide with the Oleander Line along which data are collected by the CMV Oleander. The CMV Oleander is a NOAA Ship of Opportunity scientific sampling platform that has been in operation since 1977 taking measurements which include profiles of temperature and velocity, and surface salinity (Flagg et al., 2006). For the purpose of analysis, we focus here on the point where the 55-m isobath intersects this transect to study the breakdown of stratification over the cold pool (Linder \& Gawarkiewicz, 1998; Forsyth et al., 2015). Focusing on the 55-m isobath also minimizes any influence of the position of the model's meandering shelfbreak front. The shelfbreak front in this area of the MAB has a mean grounding position at the 80-m isobath (Fratantoni \& Pickart, 2007), with typical meanders of 10-20 km in the cross-isobath direction (Boicourt \& Hacker, 1976). A large amplitude meander was previously observed to have a cross-isobath amplitude of approximately 30 $\mathrm{km}$ which would reach the 60-m isobath on this transect (Gawarkiewicz et al., 2004). Using the 55-m isobath allows us to examine the processes which influence stratification in the fall without having to consider movements of the shelfbreak front.

\subsubsection{The One-Dimensional Model}

A one-dimensional mixed layer model (PWP model, Price et al. (1986)) is also used to isolate the impact of individual surface fluxes. The PWP model considers 1-D water column instability and mixing in response to surface heat, freshwater and momentum fluxes. The model is initialized with a temperature/salinity profile, and steps forward in time forced with 7 real-time atmospheric variables including turbulent (latent and sensible) and radiative (short and long-wave) fluxes, vector (eastward

and northward) wind stress and precipitation rate. At each time step, the fluxes are applied to the top layer of the water column except for short-wave radiation, which is distributed over multiple 


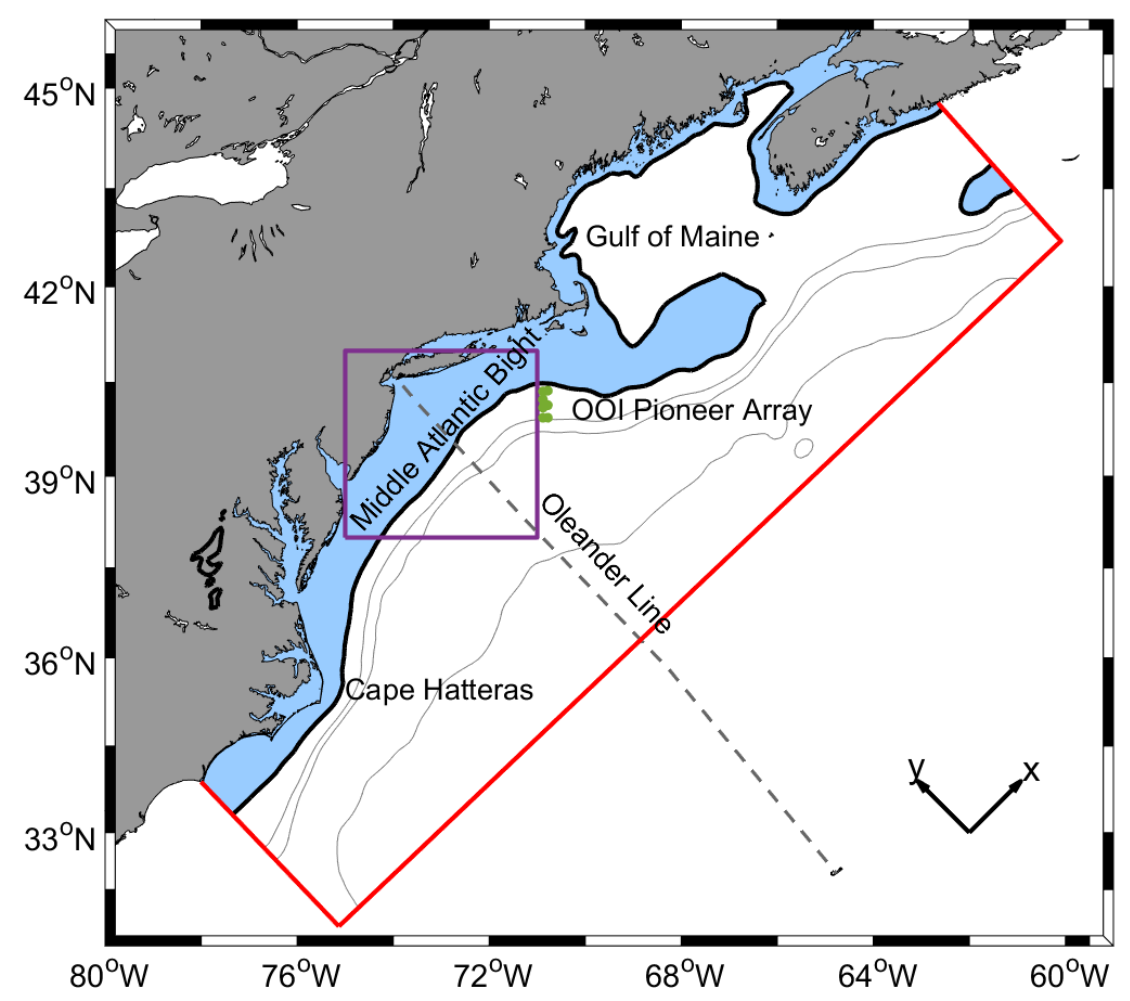

Figure 2-2: Map of the MABGOM model domain. The continental shelf is highlighted in blue and bounded by the smoothed $80-\mathrm{m}$ isobath (black bold line). The 1000, 2000, and 4000-m isobaths in the model are countoured in grey. The red line marks the boundary of the model. The purple box shows the domain of Figure 2-3.

layers using a distribution profile based on (Paulson \& Simpson, 1977). The water column then mixes from surface to depth to eliminate static instability. The model further considers entrainment below the initial mixed layer according to the Bulk Richardson Number criterion (critical value 0.65). In addition, the PWP model also considers instability below the mixed layer by ensuring Gradient Richardson Number $\left(\mathrm{R}_{g}\right)$ greater than a critical value $(0.25)$.

We run the PWP model from 1 August to 31 December of each year from 2004 to 2013. In each year, MABGOM output is used to initialize the PWP model. The year's initial water column in PWP is taken from the $1-14$ August mean of MABGOM temperature, salinity, and velocity profiles at the 55-m isobath (Figure 2-3). Surface heat fluxes and buoyancy fluxes are taken from 
the 3-hourly NARR product. Momentum fluxes are calculated from winds speed at $10 \mathrm{~m}$ from the NARR, using the bulk methodology of Large and Pond (1981).

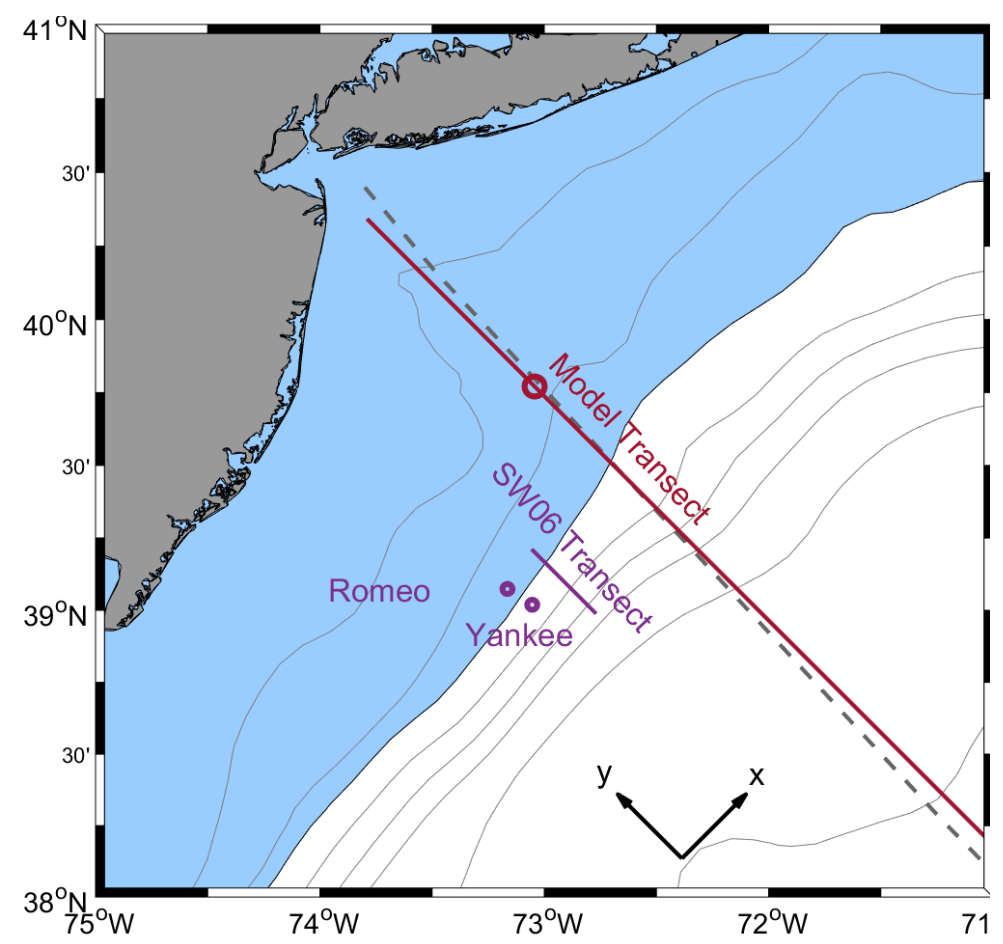

Figure 2-3: A zoomed in section of Figure 2-2 (marked as the purple box). Here we also identify the model transect along which output is extracted (red line) and the 55-m isobath on this transect (red circle). The SW06 mapped transect is plotted as a purple line with the two ASIS buoys, Romeo and Yankee, plotted as purple circles.

Three different forcing scenarios are used here for the PWP model. The first run, PWP ALL, uses heat, freshwater, and momentum fluxes as specified above. We also run the mixed-layer model with the heat fluxes in isolation which will be called PWP HEAT. Third, we run the mixed-layer model with only the momentum fluxes due to wind forcing which is abbreviated as PWP WIND.

\subsubsection{Shallow Water '06}

The MABGOM model has been tested and validated in previous work (K. Chen \& He, 2015). To further assess the model in simulating the effect storms have on stratification, we utilize observational data from the Shallow Water '06 (SW06) experiment, a large-scale experiment off the coast of New Jersey in summer 2006 (Tang et al., 2007). During the experiment, Tropical Storm Ernesto passed through the study area at the end of August overlapping with both shipboard and moor- 
ing measurements. The observations from the storm are used to examine the cross-shelf advective processes in the MABGOM model fields with the observations.

For this study, we use a combination of the mapped shipboard measurements of temperature and salinity from Scanfish surveys, and mooring observations of wind data from the two Air-Sea Interaction Spar (ASIS) buoys, Romeo and Yankee (Figure 2-3) deployed by H. Graber of the University of Miami. The shipboard measurements included a total of 12 surveys, each consisting of $4-8$ cross-shelf and alongshelf transects, occupied between 25 August and 9 September. Potential temperature and salinity fields were interpolated onto a mapped grid with horizontal resolution of 0.02-km and vertical resolution of 2-m (Tang et al., 2007). We extract a cross-shelf transect through this mapped grid for each survey. The final transect used, along with the mooring locations can be seen in Figure 2-3. Surveys from 25 August to 30 August were sampled before the tropical storm

and are used in the analysis in Section 5, while surveys after the tropical storm from 3 September to 9 September (Figure 2-14) are used to examine the stratification after the storm. The comparison between the pre-storm and post-storm transects allows for examination of the spatial pattern of the changes in stratification and, as will be seen, the verification of the importance of cross-shelf Ekman buoyancy flux. Wind speed and wind direction were measured by the ASIS buoys and provided as hourly averages. The winds are rotated onto along-shelf and cross-shelf components consistent with the orientation of the transect ( $\mathrm{x}$ and $\mathrm{y}$ in Figure 2-3). These winds were then box averaged over a 12-hour interval to emulate the model output.

For comparisons between the model and the observational data, we extracted model fields from the same days and same locations as SW06 for the shipboard measurements and the same times and a position between the two moorings for the meteorological data. Comparing model forcing with the meteorological data allows us to estimate the accuracy of the atmospheric forcing used. Qualitative similarities in the potential temperature and salinity fields provide evidence of the influence of cross-shelf advective processes. Differences between the model and data are likely due to additional processes like the warm core ring found in the observations.

\subsubsection{Defining Stratification}

In order to quantify stratification on the shelf and examine its temporal evolution in fall, we calculate a vertical density difference, $\Delta \sigma$, at each model time interval. $\Delta \sigma$ is the difference between the near- 
surface potential density and near-bottom potential density, where near-surface and near-bottom values are calculated from vertically averaging the upper-most and bottom-most $7.5 \mathrm{~m}$ of the water column respectively, consistent with the methodology of L03. The top $7.5 \mathrm{~m}$ of the water column is always within the mixed layer for all time points considered in this study. To examine separately the roles of temperature and salinity in setting and eroding stratification on the shelf, we define the contribution to $\Delta \sigma$ of potential temperature $\left(\Delta \sigma_{\theta}\right)$ and salinity $\left(\Delta \sigma_{S}\right)$ using a linear equation of state where

$$
\begin{aligned}
\Delta \sigma_{\theta} & =-\alpha \rho_{\text {ref }}\left(\left(\theta_{\text {bot }}-\theta_{\text {surf }}\right)\right) \\
\Delta \sigma_{S} & =\beta \rho_{\text {ref }}\left(\left(S_{\text {bot }}-S_{\text {surf }}\right)\right) .
\end{aligned}
$$

Here we denote potential temperature as $\theta$, salinity as $S$, and density as $\rho$. Reference values of $\theta$, $S$, and $\rho$ are mean values on the New Jersey shelf in the fall which are $\theta_{\text {ref }}=15.5^{\circ} \mathrm{C}^{-1}, S_{\text {ref }}=32$, and $\rho_{\text {ref }}=1025 \mathrm{~kg} \mathrm{~m}^{-3}$. For this study we use $\alpha$, the thermal expansion coefficient, as $2 \times 10^{-4}$ ${ }^{\circ} \mathrm{C}^{-1}$ and $\beta$, the haline contraction coefficient, as $7.5 \times 10^{-4}$, which are calculated from the reference values. Note that the MABGOM model does not use a linear equation of state, but we implement the definitions in equation 2.1 as a way of isolating the effects of temperature and salinity.

To calculate each year's initial fall stratification we temporally-average potential temperature and salinity profiles from 1 August through 14 August of a given year. We define the destratification point as the first time period (after mid-August) during which $\Delta \sigma \leq 0.5 \mathrm{~kg} \mathrm{~m}^{-3}$. This definition is used so that all time points considered in this study have existing stratification which can be reduced or increased. After this destratifiaction point, restratifcation events may occur, however, these events are always small relative to the initial fall stratification at the end of summer (Figure $2-4)$. Our results are not sensitive to the $\Delta \sigma$ value chosen to define the destratification point.

It will be confirmed here that storms impact the stratification on the continental shelf through both high wind stresses and strong heat fluxes. Throughout the 10 years examined in the models, 63 storms occur during the fall while the water column is stratified. We define storms following the methodology of L03, and consider all time periods where the average wind stress magnitude, $\tau$, is greater than $0.14 \mathrm{~N} \mathrm{~m}^{-2}$ as storms. Additionally, anomalous heat fluxes that occur in time intervals 

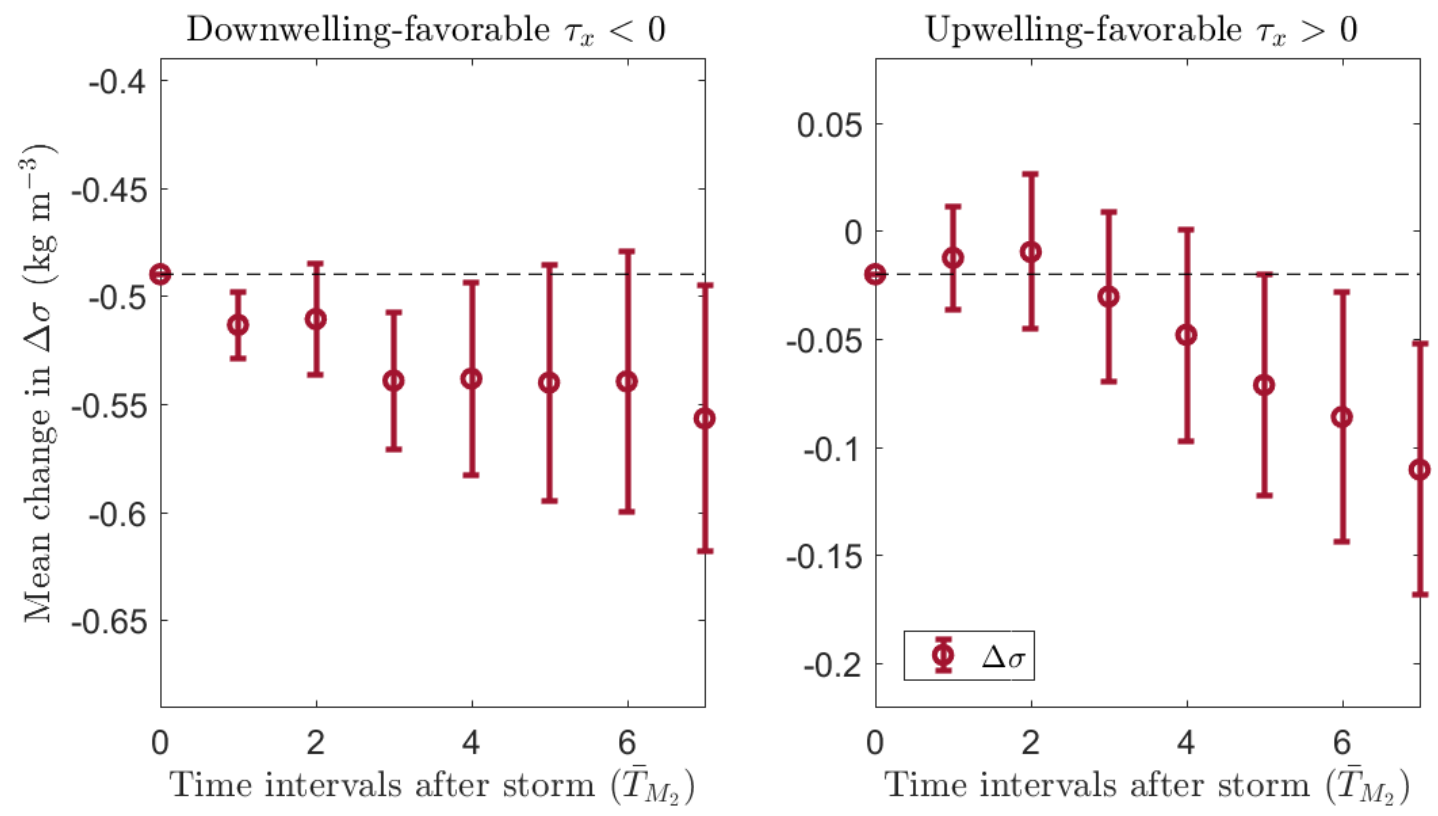

Figure 2-4: The mean change of $\Delta \sigma$ as a function of the number of MABGOM model time intervals after a storm is over with standard errors plotted as error bars. The means are only calculated for storms which did not have another storm within the restratification period considered ( 8 time intervals of 12.42 hours after a storm has ended). Left panel only considers downwelling-favorable storms, and the right column only considers upwelling-favorable storms. Black dashed line shows the mean change in stratification by the storms considered. Both y-axes span the same range. Negative values represent destratification.

adjacent to times of high wind stress are defined as part of the same storm event. Anomalous heat fluxes are defined based on the net surface heat flux output from the model. The net surface heat flux from the model is diurnally-averaged (over $\mathrm{M}_{2}$ tidal cycle, 12.42 hours), and then linearly detrended from 1 August to 31 December of each year. We consider a heat flux as anomalous if it is over two standard deviations from the diurnally-averaged linearly detrended output.

In order to calculate the net effects of an individual storm's heat flux and wind stress on stratification, we calculate the change in our stratification parameters $\left(\Delta \sigma, \Delta \sigma_{\theta}\right.$, and $\left.\Delta \sigma_{S}\right)$ from the time interval before the storm began and the time interval after the storm has ended (keeping in mind that the time intervals are 12.42 hours). Storms beginning later in the year after the destratification point are not considered. Furthermore, if stratification is reduced to less than $0.5 \mathrm{~kg} \mathrm{~m}^{-3}$ during an identified storm event, we only consider the effect of the storm up until the destratification point. 


\subsection{Interannual Variability of the Breakdown of Stratification}

On average, initial fall stratification on the New Jersey shelf is $3.9 \mathrm{~kg} \mathrm{~m}^{-3}$ over 2004-2013 (Figure 25). Stratification at the start of August ranges from a minimum of $3.3 \mathrm{~kg} \mathrm{~m}^{-3}$ in 2013 to a maximum of $4.6 \mathrm{~kg} \mathrm{~m}^{-3}$ in 2005 . Typically temperature plays an important role in setting the initial shelf stratification as the contribution of thermal stratification $\left(\Delta \sigma_{\theta}\right)$ constitutes $80 \%$ of the initial fall stratification $(\Delta \sigma)$, which is consistent with previous research on the MAB (Li et al., 2015).

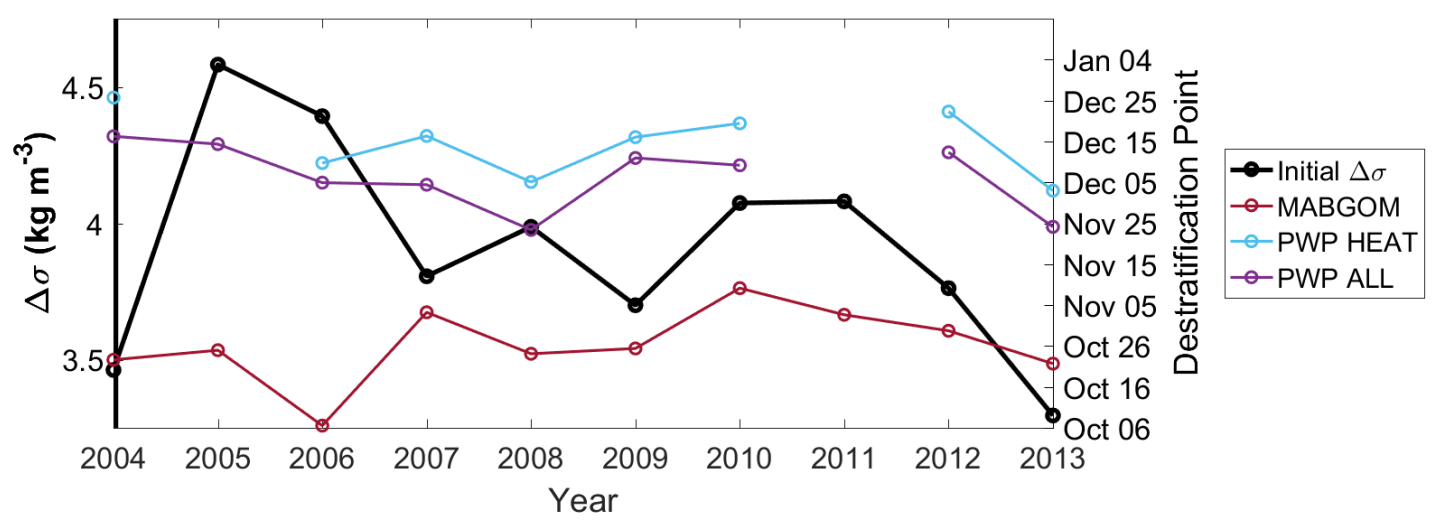

Figure 2-5: Interannual variability of the initial fall stratification from the MABGOM model (thick black line associated with the left y axis) and the interannual variability of the destratification point (right y axis) for the MABGOM model (red), the PWP HEAT (blue), and PWP ALL (purple). PWP WIND never reaches the destratification point by the end of each year and thus is not shown.

The destratification point simulated here varies strongly across the four different model runs (MABGOM, the regional general circulation model; PWP ALL, one-dimension mixed layer model with heat, freshwater, and momentum fluxes; PWP HEAT, one-dimension mixed layer model with only heat fluxes; and PWP WIND, one-dimension mixed layer model with only momentum fluxes) and from one year to the next within each model (Figure 2-5). The shelf water column typically first destratifies by late October in the MABGOM model, but the destratification point ranges from early October to early November in different years. Of the four model runs, the shelf water column in the three-dimensional MABGOM model always reaches the destratification point at least 2 months before that modeled with any of the one-dimensional PWP simulations and none of the PWP runs consistently reaches a destratified state by 31 December in every year. For the PWP simulations, ALL and HEAT destratify at a similar date. This suggests that it is the heat fluxes rather than momentum fluxes that drive the destratification in the one-dimensional cases. 
However, the more rapid destratification in the MABGOM simulation compared to the PWP simulations suggests that three-dimensional processes play an important role in eroding the stratification on the New Jersey shelf. Specifically, the role of the Ekman buoyancy fluxes in reducing stratification is significant and is described in further detail in section 2.4. Somewhat counter intuitively, over the 10-year period simulated by the MABGOM model, each year's initial fall stratification is not significantly correlated with that year's destratification point. This lack of correlation implies that it is the forcing that occurs within each fall (rather than the initial conditions at the beginning of fall) that determine when the shelf is destratified.

Previous work has suggested that surface cooling and increased wind stress are both important mechanisms that reduce stratification during fall (Houghton et al., 1982; Beardsley et al., 1985). Their relative importance and the roles of temperature versus salinity in the destratification processes are examined here by comparing output from the various model runs. We first determine for each year the destratification point in the MABGOM model. With this date, we then calculate the change in stratification as modeled with the PWP HEAT run, starting with the initial fall stratification and ending with the PWP HEAT model's stratification on this (MABGOM model derived) date. This isolates the impact that heat fluxes alone have in reducing stratification (Figure 2-6). Considering all years together, heat fluxes alone reduced the initial fall stratification by $20 \%$. The interannual variability in the influence of heat flux in eroding initial fall stratification varies from a $38 \%$ reduction in 2009 to actually increasing initial fall stratification by $5 \%$ in 2013 . Despite this strong interannual variability in the effect of heat flux on stratification, the heat flux generally tends to reduce only a small fraction of the initial stratification. Finally, this calculated impact of the heat fluxes on the reduction of stratification is not correlated with the date of the end of stratification.

With this limited influence of heat flux on the erosion of stratification established, we further investigate the impact that fall storms have on the stratification by summing within each year the stratification change from each individual storm and comparing this across models. Fall storms in the MABGOM model reduce stratification by a greater amount than do total heat fluxes alone from the PWP HEAT experiment (Figure 2-6). The net reduction in stratification from storms varies between eroding more than $100 \%$ of the initial fall stratification (2004) to eroding around $33 \%$ of the initial fall stratification (2012). Storms are able to reduce the initial fall stratification by more than $100 \%$ due to restratification events that can occur throughout the fall such as surface heating 


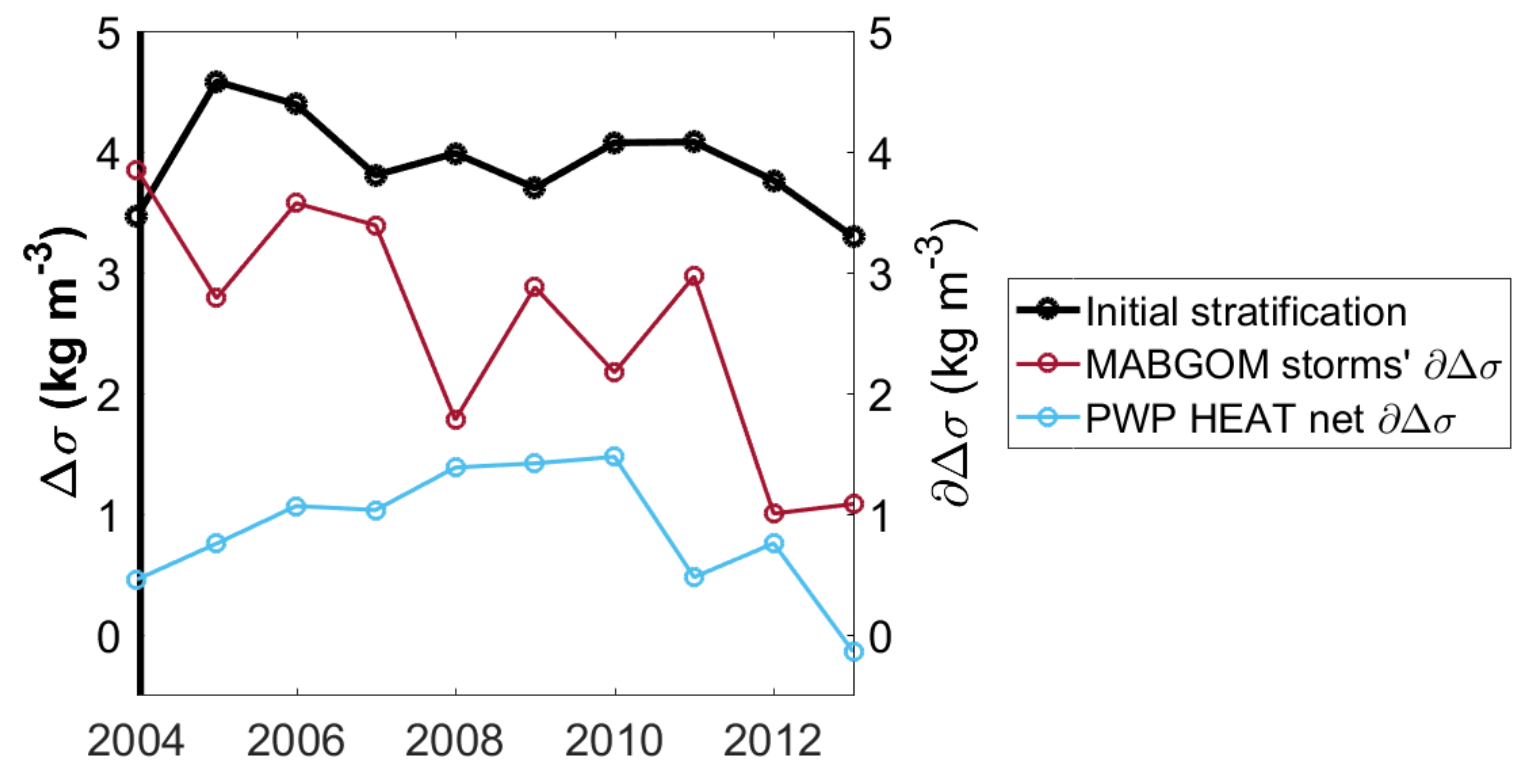

Figure 2-6: Interannual variability of the initial fall stratification from the MAGBOM model (thick black line associated with the left y axis) and the interannual variability of how storms in the MABGOM model impact stratification (red) and how heat fluxes (PWP HEAT) impact stratification (teal). For PWP HEAT the net change in $\Delta \sigma$ from initial fall stratification until the destratification point as defined from the MABGOM model is plotted.

or advective processes. These restratification events are not connected to storms, as stratification tends to be eroded in the time following a storm event (Figure 2-4). Overall, storm events appear to be more important in reducing stratification than the seasonal surface cooling, as found in L03.

Storms in each of the one-dimensional model runs also reduce significantly less stratification than do storms in the MABGOM model. Comparisons between simulations using Mellor-Yamada and PWP mixing schemes have shown that both mixing schemes yield similar results in simulating the mixed layer suggesting that the differences between our two simulations are in large part due to three-dimensional oceanic effects (Halliwell, 2004). As storms (rather than the seasonal cycle of heat flux) appear to be the most important factor in reducing stratification on the New Jersey shelf, and three-dimensional effects are important in reducing stratification, we next consider the processes by which storms can reduce stratification.

Storms can be differentiated by wind direction; i.e. those with winds that are predominately upwelling-favorable $\left(\tau_{x}>0\right.$, south-westerly) and those with winds that are predominately downwellingfavorable $\left(\tau_{x}<0\right.$, north-easterly). Differentiating storms this way shows that it is the downwelling- 
favorable winds that are consistently more effective at reducing stratification (Figure 2-8). Downwellingfavorable winds are also more common than upwelling-favorable winds, however, even when normalizing the change in stratification for accumulated along-shelf wind stress (the integral of the along-shelf wind stress times duration of each storm) downwelling-favorable winds are still more effective at reducing stratification than are upwelling-favorable winds (Csanady, 1982).

Stratification is reduced after both downwelling-favorable and upwelling-favorable storms (Figure 2-4). The change in stratification following storm events is significantly correlated to the along-shelf wind stress. In the first two tidal cycles after a storm, the along-shelf winds tend to be in the same direction as they were during the storm event which results in an increase of stratification after an upwelling-favorable storm, and a decrease in stratification after a downwelling-favorable storm. However, beyond two tidal cycles after a storm event is over, the along-shelf winds tend to reverse direction leading to predominately downwelling-favorable winds after upwelling-favorable storm events and upwelling-favorable winds after downwelling-favorable storms. As the winds reverse in direction, the stratification is reduced more after an upwelling-favorable storm due to downwellingfavorable winds.

Over the ten years hindcast by the MABGOM model, downwelling-favorable storms tend to reduce less stratification in the later years of the model run. The amount of stratification reduced by storms is strongly correlated with the accumulated along-shelf wind stress only for downwellingfavorable storms (Figure 2-7). Accumulated along-shelf wind stress is not correlated to the number of storms within a year nor the destratification point, suggesting that the ability for storms to reduce stratification is due to strong individual events which vary in frequency and intensity from year to year. In windier years, like that during the observational program described in L03, it would be expected that storms would reduce more stratification than other processes would.

During storms with downwelling-favorable winds, both the thermal and haline stratification are reduced, but the reduction in thermal stratification is typically greater than the reduction in haline stratification (Figure 2-8). The exceptions are 2004 and 2005 when the downwelling-favorable storms did erode stratification more through changes in the salinity profiles rather than through changes in the temperature profiles. This difference in 2004 and 2005 cannot be explained through the wind since other years with similar accumulated wind stress values reduced stratification primarily through thermal changes. Instead, $55 \%$ of the interannual variability in the reduction of stratification 


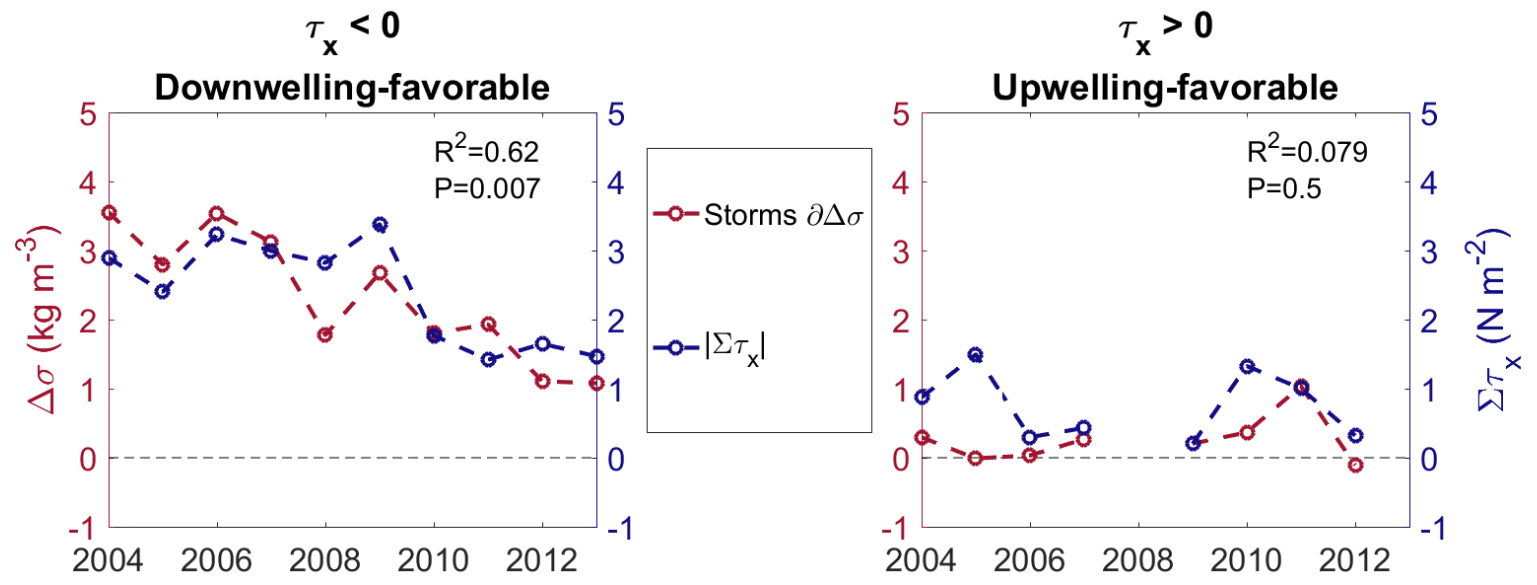

Figure 2-7: Interannual variability of the impact of storms in the MABGOM model on overall stratification (red), and the accumulated along-shelf wind stress during the storms in the MABGOM model (blue). Left panel is the net effect of downwelling-favorable storms each year, and the right column is the net effect of upwelling-favorable storms each year.

due to salinity in downwelling-favorable storms can be explained by the interannual variability in the mean fall cross-shelf salinity gradient (gradients here calculated over a $20 \mathrm{~km}$ distance). 2004 and 2005 have the strongest cross-shelf salinity gradient and also the greatest change in stratification due to haline changes, while 2012 has the weakest cross-shelf salinity gradient and the least reduction in stratification due to salinity changes.
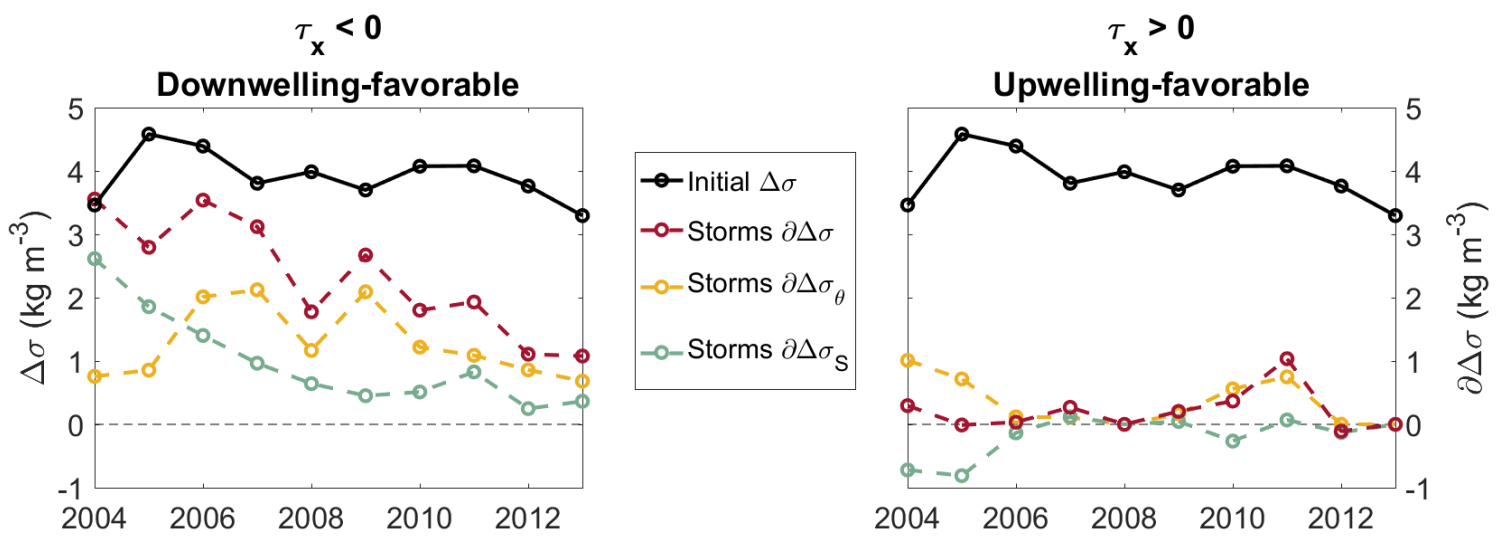

Figure 2-8: Interannual variability of the initial fall stratification from the MABGOM model (thick black line associated with the left y axis) and the interannual variability of the impact of storms in the MABGOM model on overall stratification (red), stratification due to potential temperature (yellow), and stratification due to salinity (green). Left panel is the net effect of downwellingfavorable storms each year, and the right column is the net effect of upwelling-favorable storms each year.

In contrast, during upwelling-favorable winds, stratification doesn't tend to change except in 
2011 which is driven by the strongest upwelling-favorable storm in the ten years studied. Interestingly, changes to the salinity structure during upwelling-favorable winds tend to either increase the stratification, or not change the stratification appreciably. The physical mechanisms that connect the winds, cross-shelf gradients, and the change in stratification will be examined in section 2.4.

To account for the greater frequency of downwelling-favorable winds, we normalize the change in stratification by accumulated wind stress for each storm. The median change in the haline stratification per unit wind stress per unit time (unit time is the model output time interval of 12.42 hours) for downwelling-favorable wind storms and upwelling-favorable wind storms is -0.35

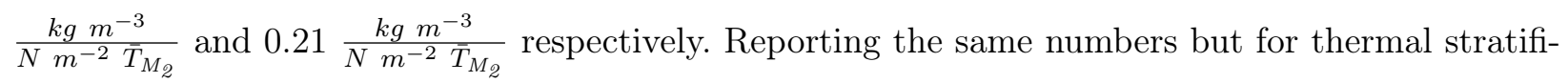
cation gives $-0.53 \frac{\mathrm{kg} \mathrm{m} \mathrm{m}^{-3}}{\mathrm{~N} \mathrm{~m}^{-2} \bar{T}_{M_{2}}}$ and $-0.28 \frac{\mathrm{kg} \mathrm{m}^{-3}}{\mathrm{Nm}^{-2} \bar{T}_{M_{2}}}$ and for total stratification gives $-0.96 \frac{\mathrm{kg} \mathrm{m}^{-3}}{\mathrm{~N} \mathrm{~m} \mathrm{~m}^{-2} \bar{T}_{M_{2}}}$ and $-0.15 \frac{\mathrm{kg} \mathrm{m}^{-3}}{\mathrm{~N} \mathrm{~m}^{-2} \bar{T}_{M_{2}}}$. Normalizing the changes in stratification by the accumulated wind stress shows that downwelling-favorable storms are able to reduce stratification more effectively than upwelling-favorable storms because of both changes to the thermal and haline stratification. A similar conclusion was found in L03 from observations south of New England where only strong downwelling-favorable winds significantly reduced stratification. L03 attributed this to an Ekman buoyancy flux, and a changing along-shelf thermal-wind shear. The use of the MABGOM model here allows for more direct calculations in order to examine what processes lead to the enhanced reduction of stratification by downwelling-favorable winds over multiple years as considered next.

\subsection{Physical Mechanisms Contributing to the Breakdown in Strat- ification}

L03 proposed two mechanisms that can cause downwelling-favorable winds to reduce stratification more effectively than upwelling-favorable winds. The first is an Ekman buoyancy flux, where negative along-shelf wind stress leads to an onshore Ekman transport in the surface layer and an offshore transport in the bottom boundary layer (Straneo et al., 2002). On the New Jersey shelf, there is a mean cross-shelf salinity gradient with fresher waters in the onshore direction (Manning, 1991). Hence onshore Ekman velocities in the surface layer transport saltier waters onshore and fresher waters offshore at depth which reduces the vertical density gradient. When the Ekman velocities are in the opposite direction, the vertical density gradient is increased (i.e. during upwelling-favorable 
winds).

The other postulated mechanism discussed by L03 is due to the increased along-shelf vertical shear of the velocities that occurs during downwelling-favorable winds due to an enhanced background thermal-wind shear associated with tilting of the isopycnals. On the MAB outer shelf, the mean thermal-wind shear causes the equatorward along-shelf velocities to decrease with depth. If the Ekman transports act as described above, along-shelf winds would steepen the isopycnals which would increase the cross-shelf density gradient and thus enhance the surface to bottom along-shelf velocity shear. Enhanced velocity shear may allow for more shear instabilities to mix the water column thereby decreasing the stratification.

\subsubsection{Ekman Buoyancy Flux}

To determine if the first mechanism, associated with the Ekman buoyancy flux, is a significant factor in reducing stratification during storms, we examine the mean cross-shelf velocities and mean cross-shelf gradients in $\Delta \sigma, \Delta \sigma_{\theta}$, and $\Delta \sigma_{S}$ during storms distinguishing between those with downwelling-favorable winds and those with upwelling-favorable winds (Figure 2-9). The surface Ekman layer is obvious in the model output, with mean surface cross-shelf velocities flowing to the right of the along-shelf winds (Figure 2-9 a-b). The average surface velocities for both wind

directions (blue curves) deviate by around $7.5 \mathrm{~cm} \mathrm{~s}^{-1}$ from the mean fall cross-shelf velocity (black curves). At depth, there is a reversal of the cross-shelf velocity for both wind directions with a large vertical shear between $15-25 \mathrm{~m}$.

The mean cross-shelf density gradients are similar during both downwelling- and upwellingfavorable storms as the initial conditions are not dependent on the wind direction (Figure 2-9 c-d). During the fall, the cross-shelf variations of temperature within the surface mixed layer are generally weak, while at depth, the cross-shelf variation in temperature is determined by the characteristics of the cold pool (Figure 2-1). At the $55 \mathrm{~m}$ isobath, the cross-shelf gradients in temperature indicate warmer water in the onshore direction, but this gradient is of opposite sign on the offshore side of the cold pool. In this region of the New Jersey shelf, the cross-shelf salinity gradient is negative onshore, i.e., salinity decreases shoreward, and is fairly uniform throughout the water column. Thus in fall on the New Jersey shelf, the cross-shelf density gradient is dependent on both temperature and salinity gradients. 

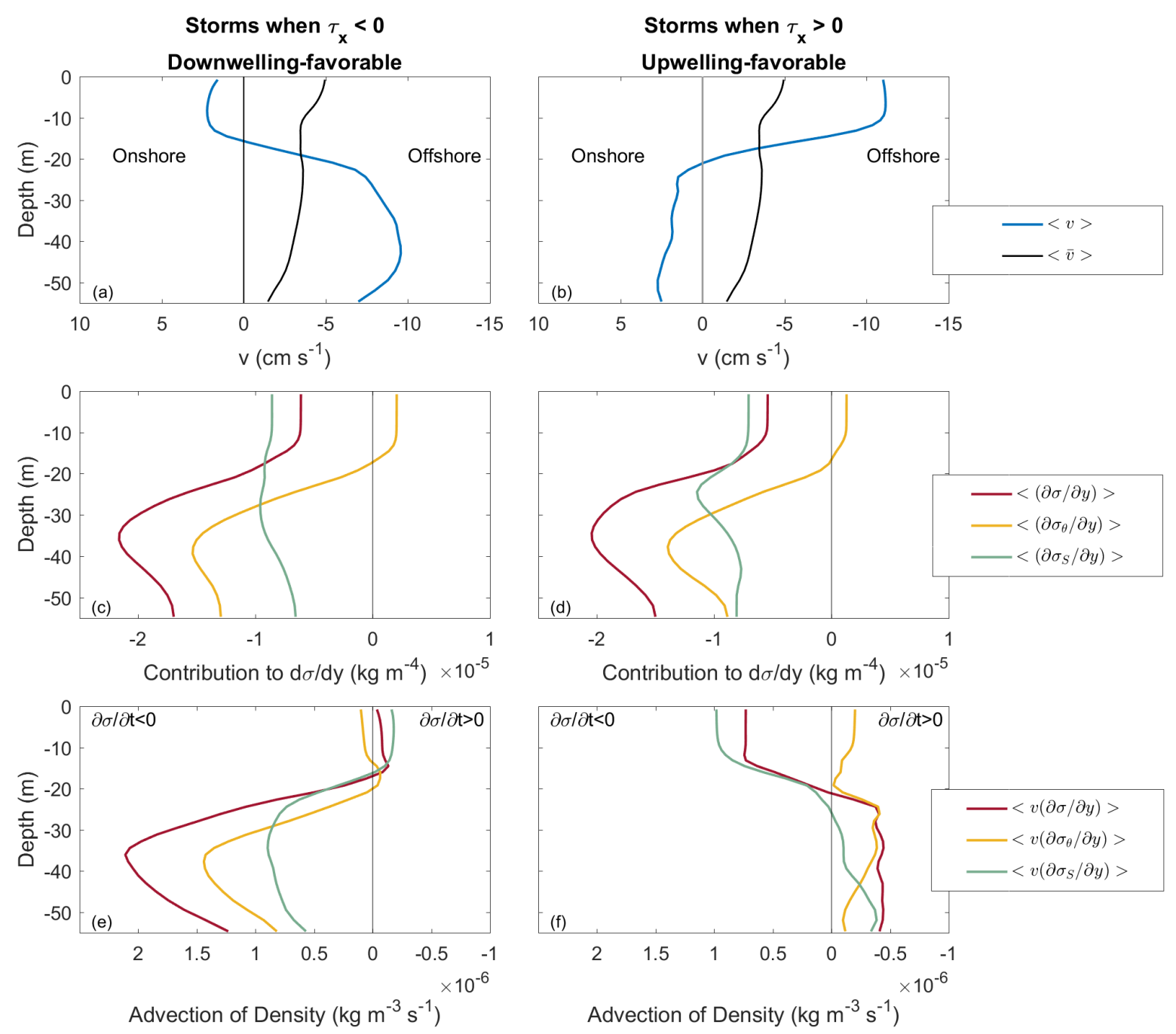

Figure 2-9: Mean cross-shelf gradients and mean velocities for storms when $\tau_{x}<0$ (left column) and $\tau_{x}>0$ (right column). (a-b) Mean cross-shelf velocity at the 55-m isobath (blue) during storms. The black line is the mean cross-shelf velocity during the fall. Positive velocities denote onshore transport and negative velocities denote offshore transport. (c-d) Cross-shelf gradients in, potential density (red), salinity's contribution to potential density (green), and potential temperature's contribution to potential density (yellow). (e-f) Mean cross-shelf velocity during storms (a-b) multiplied by the cross-shelf gradients (c-d) with colors corresponding to the gradients above (c-d). Negative values are increasing density and positive values are decreasing density. 
Multiplying the mean cross-shelf velocities with the mean cross-shelf densities for each storm gives the Ekman buoyancy fluxes. These fluxes are then composite averaged for storms characterized by each of the two along-shelf wind directions (Figure 2-9 e-f). The net effect of the Ekman buoyancy flux during storms is to reduce stratification for downwelling-favorable winds and to increase stratification for upwelling-favorable winds. Due to the differences between the cross-shelf temperature and salinity gradients, the transport of salt dominates the change in density at the surface, while both the transport of heat and salt impact the change of density near the bottom (Figure 2-9 c-d).

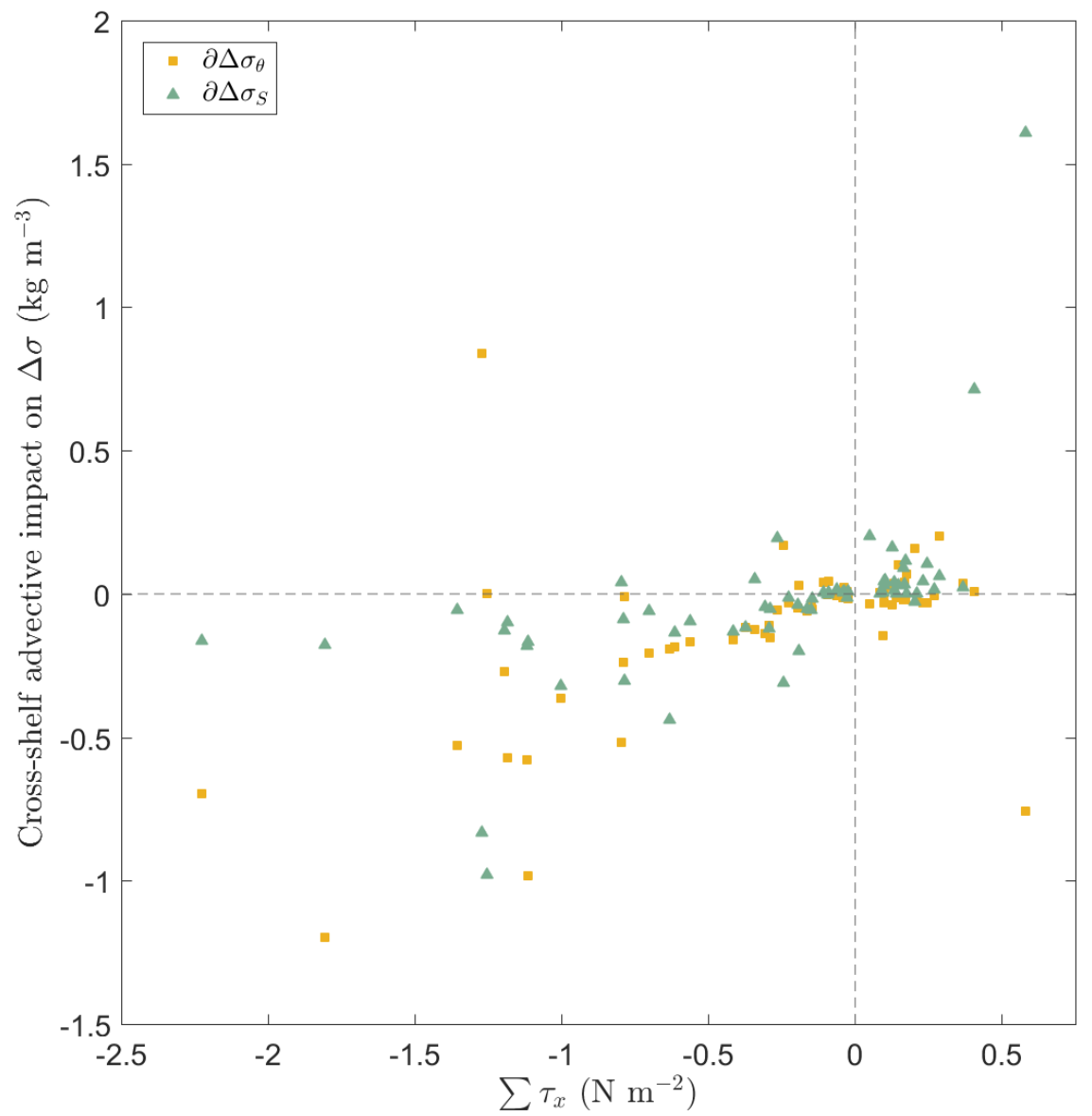

Figure 2-10: Accumulated along-shelf wind stress (the sum of the average along-shelf wind stress in each time interval during each storm) versus the cross-shelf advective impact on the change in stratification due to changes in potential temperature (yellow squares) and salinity (green triangles) during each storm.

During downwelling-favorable storms, cross-shore velocities are weak at the surface but strong 
at depth, thereby causing both temperature and salinity transports to be important to the density changes over the water column. The cross-shelf salt flux leads to saltier waters moved onshore at the surface and fresher waters moved offshore at depth causing a mean reduction in stratification by 0.13 $\mathrm{kg} \mathrm{m}^{-3}$ (Figure 2-10). Transport of warmer waters into the cold pool during downwelling-favorable winds also reduces the stratification with a mean reduction of $0.17 \mathrm{~kg} \mathrm{~m}^{-3}$ (Figure 2-10). The mean reduction in stratification by a downwelling-favorable storm is $0.60 \mathrm{~kg} \mathrm{~m}^{-3}$, which suggests that cross-shelf buoyancy fluxes are responsible for around half of the change in stratification during storms (Figure 2-11). These mean values are skewed by a few very strong storms. Calculations using median values instead for downwelling-favorable storms shows that the salt flux reduces stratification by $0.06 \mathrm{~kg} \mathrm{~m}^{-3}$, and the heat flux reduces stratification by $0.11 \mathrm{~kg} \mathrm{~m}^{-3}$ (Figure 2-10), with the median net reduction of stratification as $0.49 \mathrm{~kg} \mathrm{~m}^{-3}$. Results based on the median values suggest that these buoyancy fluxes are responsible for roughly $35 \%$ of the reduction in stratification during downwelling-favorable storms (Figure 2-11).

Cross-shelf velocities during upwelling-favorable storms are strong at the surface and weak at depth (Figure 2-9 b), which causes the salinity transports to be more important than heat fluxes to the change in stratification over the water column (Figure 2-9 f). During these upwelling-favorable storms, the mean cross-shelf salt flux increases stratification by $0.14 \mathrm{~kg} \mathrm{~m}^{-3}$ while the mean crossshelf heat flux decreases stratification by $0.02 \mathrm{~kg} \mathrm{~m}^{-3}$ (Figure 2-10). The mean buoyancy fluxes act to increase stratification in the water column, however the net impact of upwelling-favorable storms reduces stratification on average by $0.09 \mathrm{~kg} \mathrm{~m}^{-3}$. Median values for upwelling-favorable storms show the cross-shelf salt flux increases stratification by $0.04 \mathrm{~kg} \mathrm{~m}^{-3}$. The cross-shelf heat flux does not change stratification, and the net reduction in stratification is only $0.03 \mathrm{~kg} \mathrm{~m}^{-3}$. Using either mean or median values, the cross-shelf salt flux during upwelling-favorable winds is highly important in suppressing the overall reduction in stratification (Figure 2-11).

The buoyancy fluxes discussed above highlight that downwelling-favorable winds are more effective at reducing stratification than winds in the opposite direction. Mean buoyancy fluxes are responsible for a difference of $0.45 \mathrm{~kg} \mathrm{~m}^{-3}$ between the opposing wind directions in terms of impacting the stratification, while calculations using median values still result in a $0.23 \mathrm{~kg} \mathrm{~m}^{-3}$ difference (Figure 2-11). Overall, cross-shelf advective fluxes of both salinity and potential temperature (Figure 2-10) are an important mechanism for changing the stratification during storms. Advective 


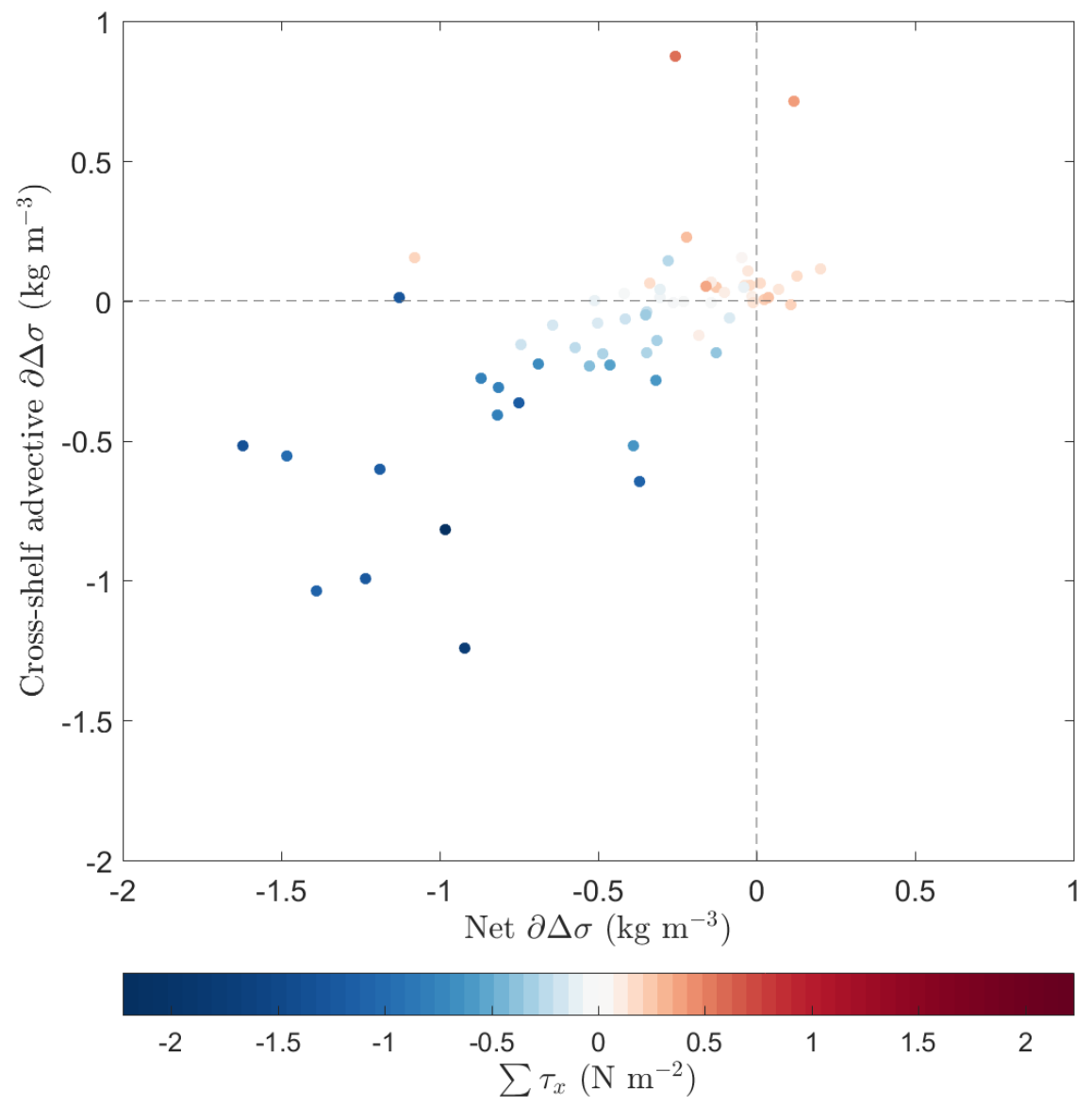

Figure 2-11: The net change in stratification (delta sigma) versus the cross-shelf advective impact on stratification for each storm. The color is the accumulated along-shelf wind stress (sum of the along-shelf wind stress for the duration of the storm) for the storm.

processes can be reversed, however, we have shown that within this shelf system, storm induced destratification remains after the storm and thus these processes are important to the overall shelf destratification (Figure 2-4).

The New Jersey shelf maintains strong cross-shelf salinity gradients throughout the year due to river output along the coast (Manning, 1991). Within the New Jersey shelf system, the strong cross-shelf salinity gradients allow for large changes of stratification due to an Ekman buoyancy flux during storms. This is in contrast to L03 on the New England Shelf where the cross-shelf salinity gradients are significantly weaker as there is less river outflow in that region and as such L03 only focused on changes to the thermal stratification during fall. The spatial distribution of salinity is thus 
important in determining how stratification is broken down in different coastal regions. Furthermore, the along-shelf direction on the New England shelf is east and west but the along-shelf direction off the coast of New Jersey is north-east to south-west. A downwelling-favorable storm over New Jersey may not be downwelling-favorable south of Cape Cod. Because of the along-shelf variations, the breakdown of stratification on the MAB shelf is likely not coherent and would require further study to examine the spatial variability.
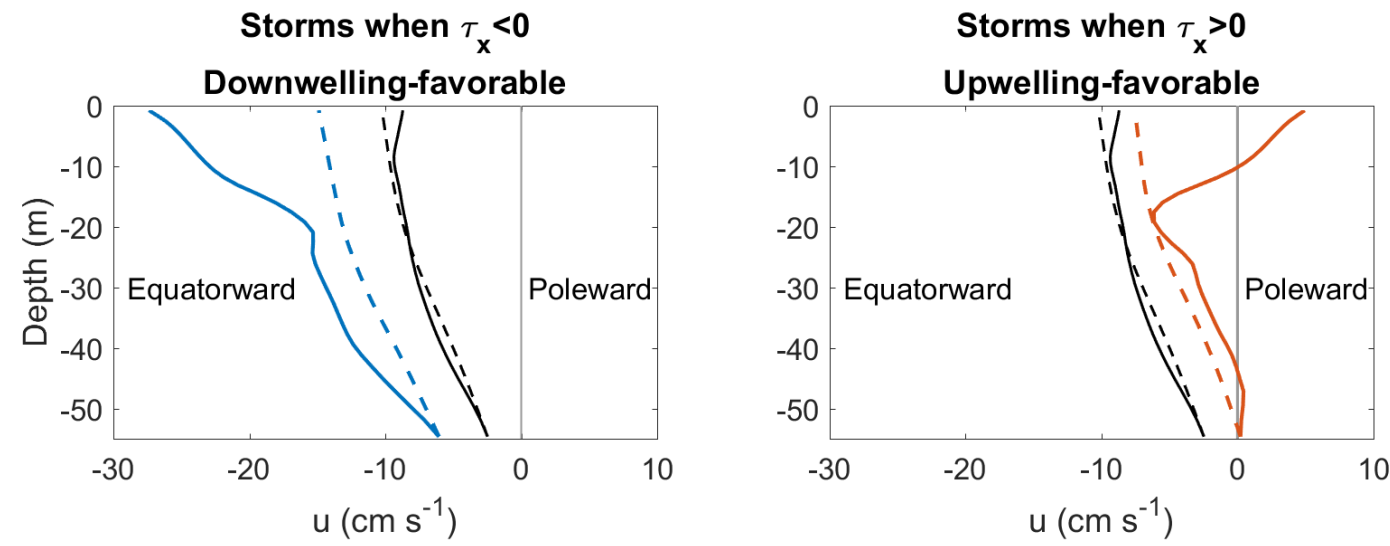

Figure 2-12: Mean along-shelf velocity (colored solid lines) and velocity profiles calculating from mean thermal-wind shear (colored dashed lines) during downwelling-favorable winds and upwellingfavorable winds. Black lines represent the background mean velocities during fall.

\subsubsection{Enhanced Shear}

Another mechanism contributing to the dependence of the erosion of stratification on wind direction is an increase in velocity shear during downwelling-favorable winds which was also found in L03. This enhanced shear was proposed to potentially be a result of an enhanced cross-shelf density gradient, leading to enhanced along-shelf thermal-wind shear. Calculating the average along-shelf geostrophic velocities during storms of both along-shelf wind directions, and referencing the velocities to the bottom, shows only a very weak enhanced surface to bottom shear for downwelling-favorable winds (Figure 2-12). The enhanced shear due to the changing thermal-wind shear is not enough to explain the overall increased shear.

While the mechanism that leads to the enhanced shear in the model output is not clear, we can

nevertheless calculate the Richardson number $\left(R_{g}=\frac{g \Delta \rho \Delta z}{\rho_{0}\left(\Delta u^{2}+\Delta v^{2}\right)}\right)$ during the storms to see if the enhanced shear meets the conditions for shear instabilities more often during downwelling-favorable 


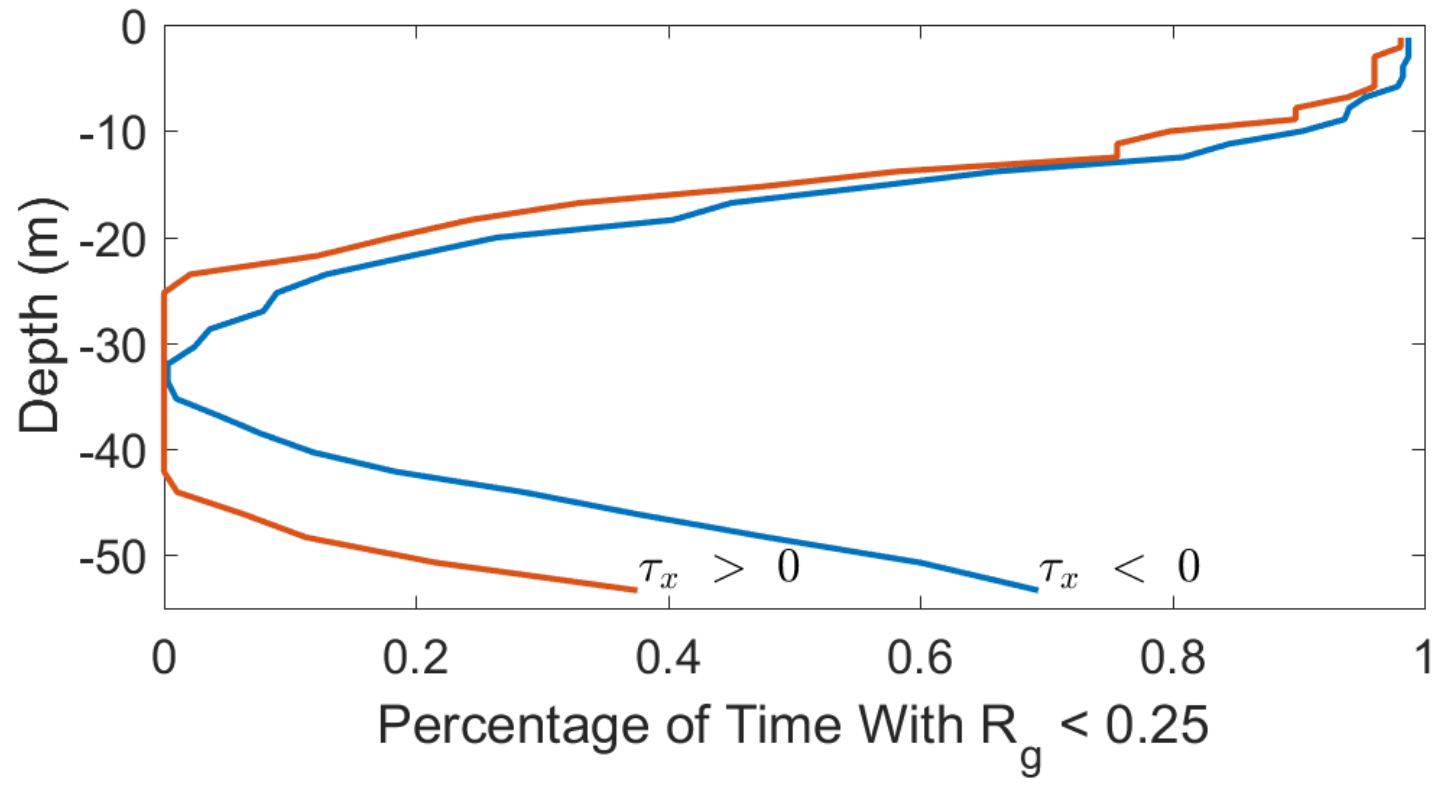

Figure 2-13: Fraction of time during strong wind events that the Richardson number was less than 0.25 at each depth. The blue line represents the downwelling-favorable winds and the red line represents the upwelling-favorable winds.

storms, thus allowing a greater reduction in stratification. We calculate the Richardson number at each time interval during storms, and then calculate the fraction of time during storms that the Richardson number is less than 0.25 , a necessary but not sufficient condition for shear instabilities (Price et al., 1986). In the top 30-m, both upwelling favorable and downwelling favorable storms meet the criterion necessary for shear instabilities an equal fraction of the time (Figure 2-13). However, below 30-m, downwelling-favorable storms meet the conditions for shear instabilities a greater fraction of the time than do upwelling-favorable winds. Instabilities and mixing at depth could be an important driver for the breakdown in stratification due to the presence of the cold pool. The added ability for downwelling-favorable winds to mix in the cold pool likely enables a greater reduction in stratification relative to upwelling-favorable winds.

\subsection{Tropical Storm Ernesto}

Comparing the model output with observations from Tropical Storm Ernesto in 2006 suggests that the processes that reduce stratification described above which are based on the model output are consistent with observations. Comparisons of the winds from the model and data confirm that the 
along-shelf winds are downwelling-favorable and that the forcing used in the model well represents the observed along-shelf winds (Figure 2-14). The cross-shelf winds reach similar magnitudes in the model and observations, however, they peak later within the storm in the model. Neither the direction nor the magnitude of the cross-shelf winds during storms were found to be significantly correlated to the change in stratification within the MABGOM model, thus the accuracy with the along-shelf winds, which is more relevant to the stratification change, allows for further comparisons.
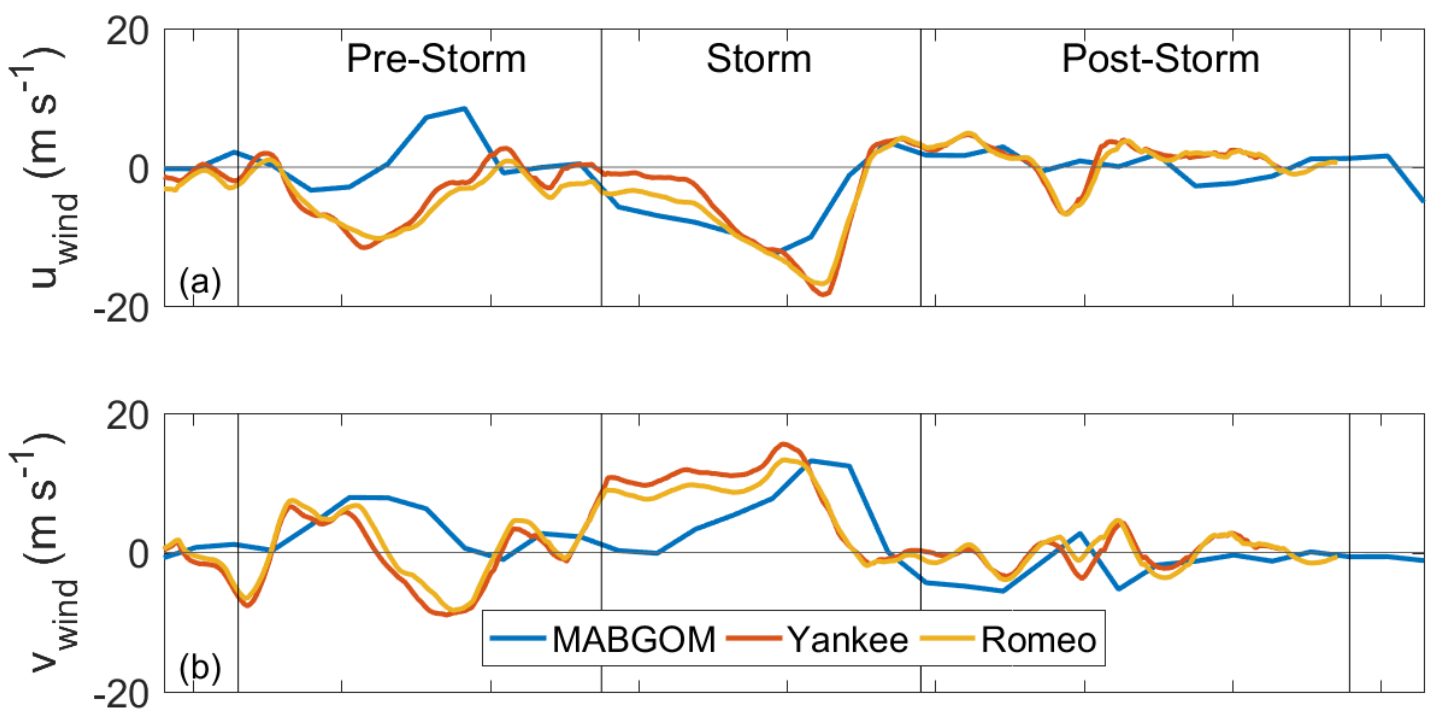

Aug 25 Aug 27 Aug 29 Aug 31 Sep 02 Sep 04 Sep 06 Sep 08 Sep 10

Figure 2-14: Comparing model wind forcing (blue) with the measured winds from the two ASIS buoys Yankee (red) and Romeo (orange) (positions of buoys in Figure 3). (a) Along-shelf winds on a 12 hour moving average and (b) Cross-shelf winds on a 12 hour moving average. Vertical lines show the boundaries that define time periods before the storm, during the storm and after the storm.

Within the model, the changes to the salinity, potential temperature, and potential density during Ernesto all act as expected from the above analysis for a downwelling-favorable storm. The salinity transects show the expected cross-shelf salinity gradients with fresher waters onshore (Figure 2-15 a,c). Salinity increases at the surface, and decreases near the bottom reducing stratification (Figure 2-15 e). Cross-shelf velocities during this storm (not shown here) acting on the cross-shelf salinity gradient lead to a buoyancy flux that reduces stratification.

Potential temperature fields within the model show weak cross-shelf thermal gradients at the surface and stronger gradients at depth with the cold pool onshore of this study location (Figure 2-16 a,c). The overall changes to potential temperature show a universal cooling, with enhanced 


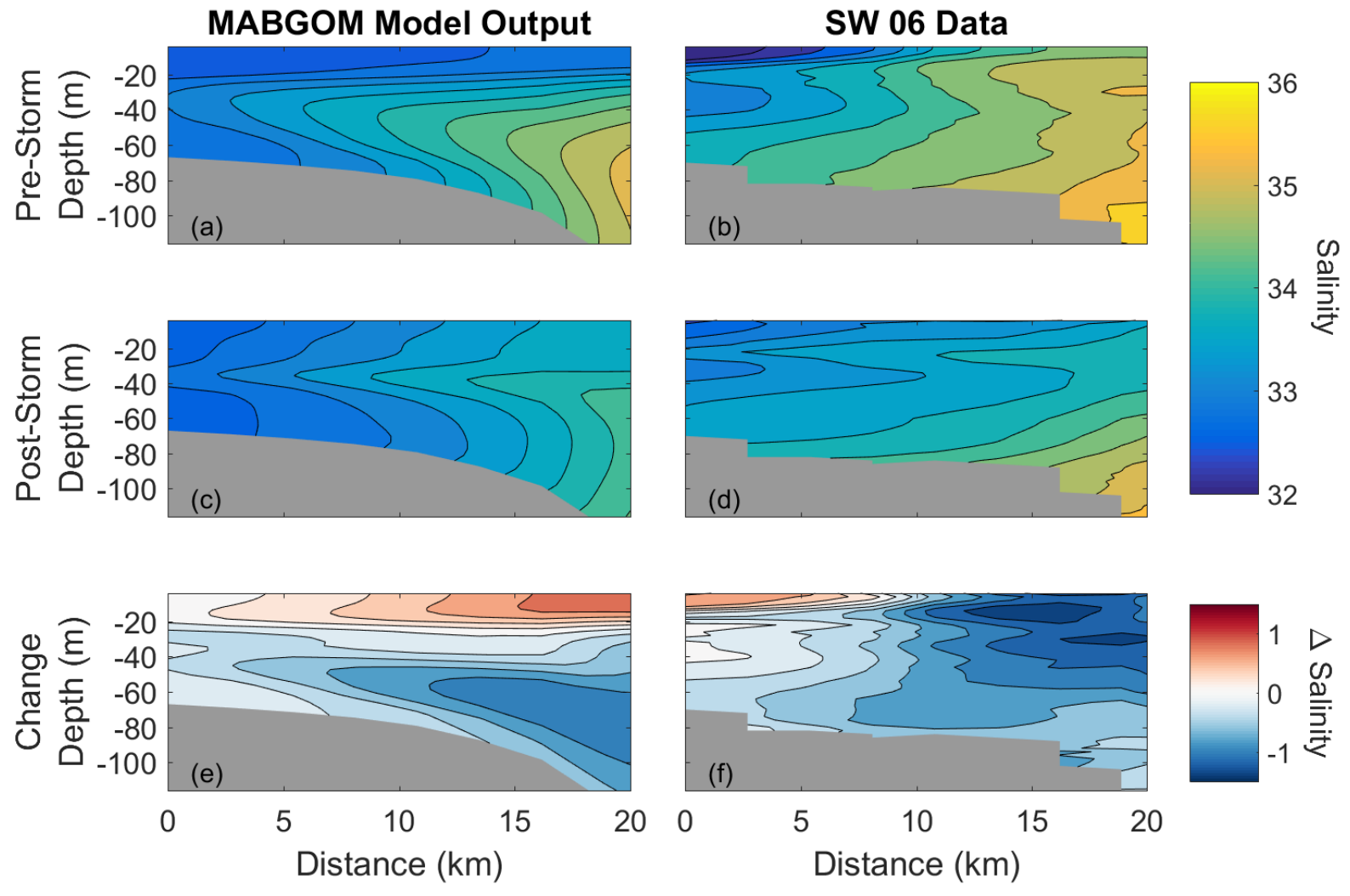

Figure 2-15: Comparison of salinity conditions associated with storms between the MABGOM model and the observations. The left column shows the MABGOM model output and the right column shows the SW06 data. (a-b) Top row displays mean salinity fields for pre-storm conditions. (c-d) Middle row displays mean salinity fields for post-storm conditions. (e-f) Bottom row shows the change from the pre-storm to the post-storm (positive values indicate an increase in salinity).

areas of cooling near the surface and at depth (Figure 2-16 e). Strong cooling near the surface is due to the negative surface heat flux, and also wind driven mixing into the thermocline. However, we also see that within the model, there is cooling at depth. This location is offshore of the cold pool, which means there are colder waters in the onshore direction close to the bottom. Thus, the offshore velocities at depth transport colder waters, which leads to the cooling here at depth.

The salinity transects from SW06 also show fresher waters onshore (Figure 2-15 b,d). The changes in salinity compare well between the observations and the model on the furthest onshore edge of the transect with increasing salinity at the surface and decreasing salinity at depth (Figure 2$15 \mathrm{f}$ ). This suggests that the cross-shelf salinity fluxes are important on the shelf. However, offshore of the $90-\mathrm{m}$ isobath there is freshening during the storm throughout the water column. Before the storm waters with 35.9 psu are observed offshore of the shelf indicating the presence of Gulf 


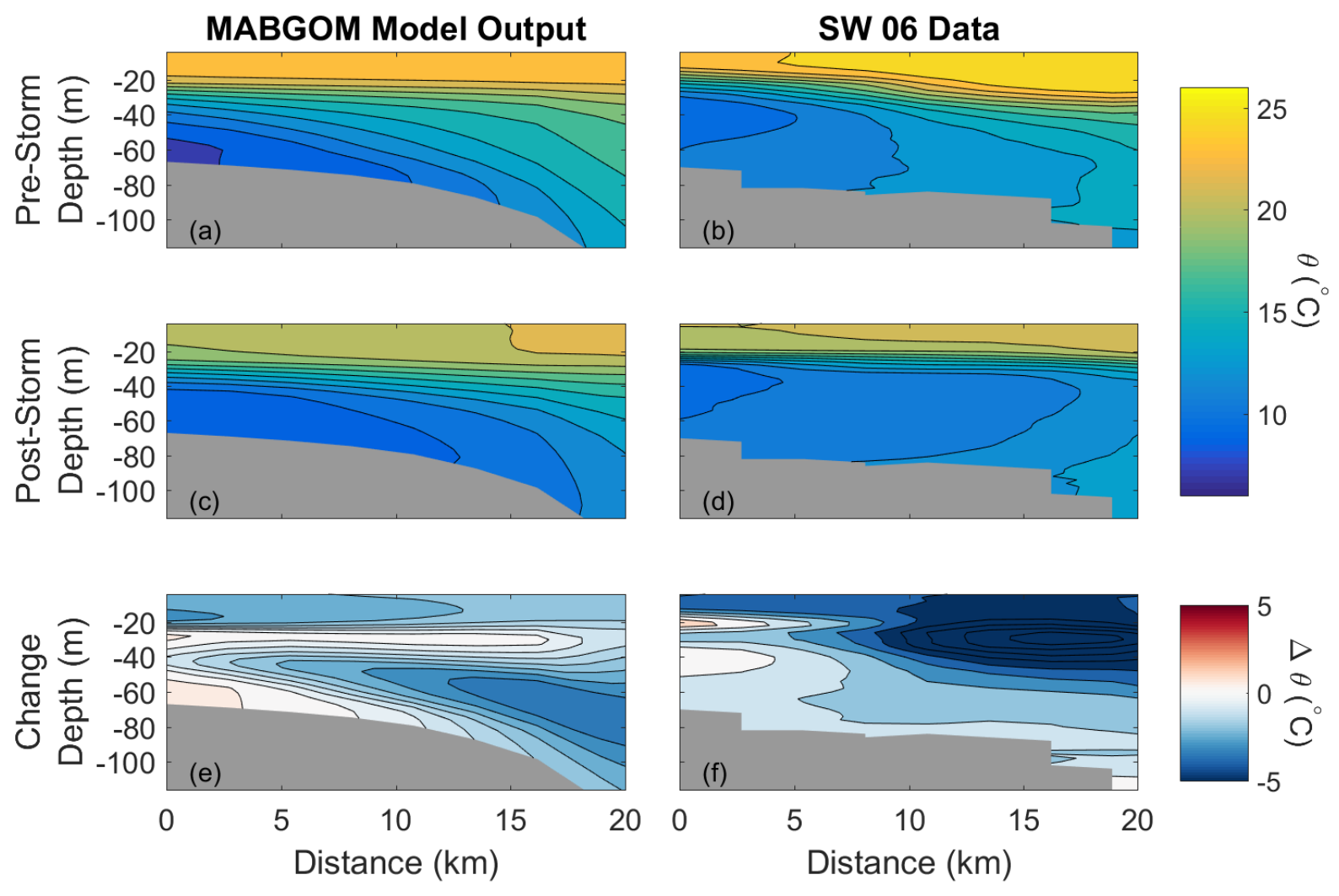

Figure 2-16: As in Figure 2-15, but with potential temperature $(\theta)$.

Stream/warm core ring water. After the storm, the salinities are significantly reduced offshore, likely due to the ring moving away from the shelfbreak via processes unrelated to the storm.

Potential temperature fields from the SW06 experiment are very similar to the model fields (Figure 2-16 b,d). The observations show cooling throughout the water column, with much stronger cooling near the surface when compared to the model (Figure 2-16 f). This difference in surface cooling can be partially attributed to the difference in surface temperatures between the model and observations as the observations are found to be much warmer initially at the surface. The cooling at depth could be attributed to the offshore transport of cold pool waters, once again suggesting that buoyancy fluxes are important during storms.

Overall, both the model and observations show qualitatively the expected changes to potential density for a downwelling-favorable storm, which is an increase of density at the surface, and a decrease at depth leading to a reduction in stratification (Figure 2-17). The increase in density at the surface is due to the negative surface heat fluxes, and also the increasing salinity on the 


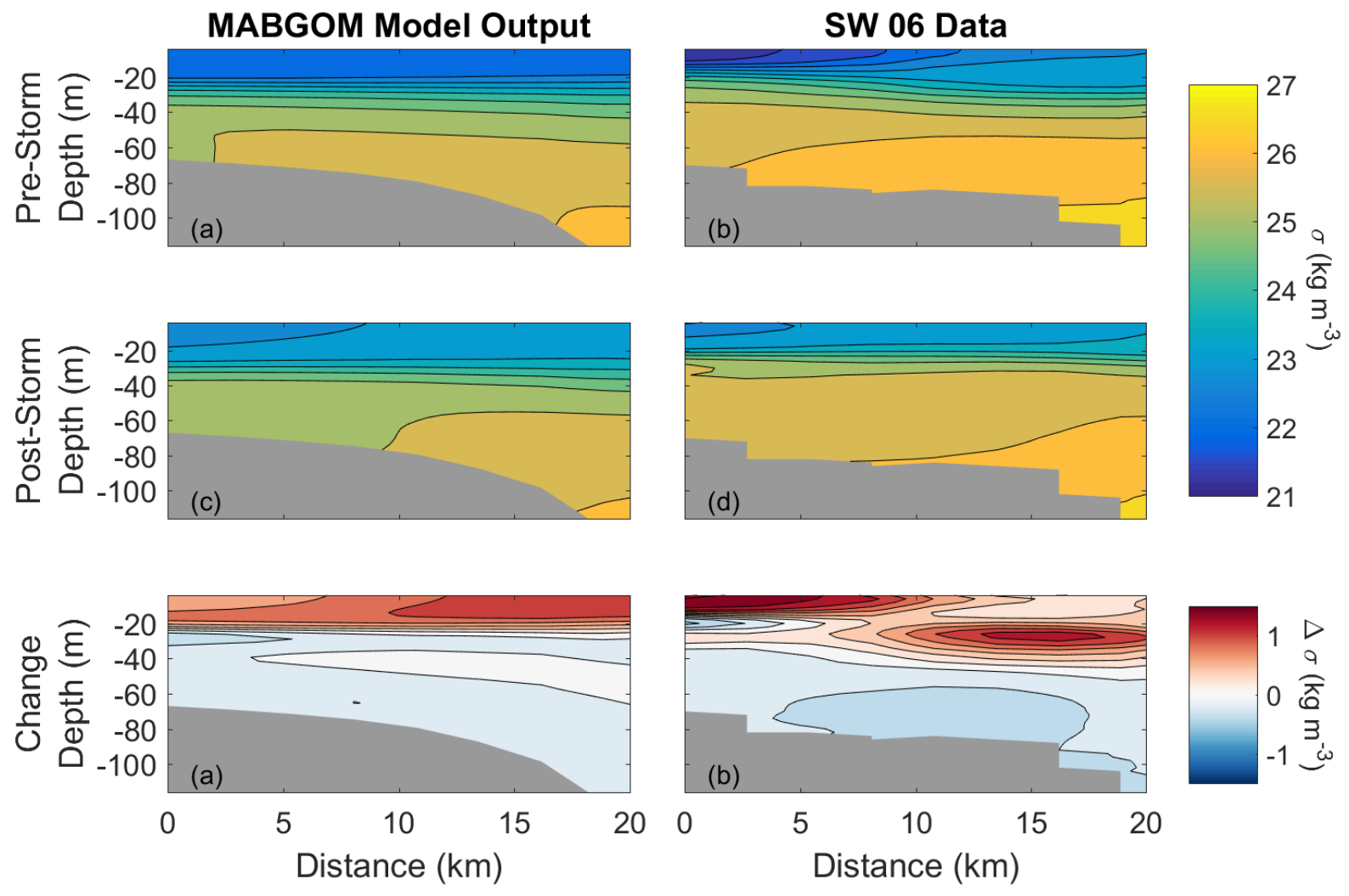

Figure 2-17: As in Figure 2-15 but with potential density $(\sigma)$.

shelf. Near the bottom on the shelf, there was a decrease in salinity and a decrease in potential temperature. The changes to the potential density show that both the model and observations have a decrease in potential density at depth, indicating that the decrease in salinity had a larger impact on potential density than the decrease in potential temperature. This further emphasizes that changes to salinity are important in understanding how stratification changes on the shelf off of New Jersey, where the cross-shelf salinity gradients are large due to the presence of the Hudson River discharge.

\subsection{Conclusions}

Analysis of ten years of the modeled seasonal evolution of stratification over the New Jersey shelf demonstrates large interannual variability in the initial fall stratification and the date at which stratification is broken down. The initial fall stratification in each year is not correlated to the end date of stratification, making predictability for the breakdown of stratification in a given year 
extremely difficult without knowledge of the wind and buoyancy forcing. Comparing results from both a one-dimensional mixing model and a three-dimensional regional circulation model shows that surface heat fluxes alone are often not as important as wind forcing in reducing stratification.

Storms are often one of the most important factors in reducing stratification in the fall. Downwellingfavorable winds are more effective at reducing stratification than upwelling-favorable winds through both an Ekman buoyancy flux and an enhanced velocity shear. The difference in the effectiveness between downwelling-favorable and upwelling-favorable winds in reducing stratification is largely due to the cross-shelf transport of salinity. Understanding the magnitude of the cross-shelf salinity gradients is important in informing how the stratification over the New Jersey shelf will break down during high wind events.

Model-data comparisons during Tropical Storm Ernesto show evidence that the model physics are qualitatively consistent with the observations. Changes in the salinity and temperature structures suggest that cross-shelf buoyancy fluxes are indeed important to the change in stratification on the shelf for a downwelling-favorable storm. Further analysis with upwelling-favorable winds are needed to confirm the differential effects between storms in each along-shelf direction.

Knowing how stratification breaks down throughout the fall can aid in informing fisheries science and regulation, and storm forecasting. Cold pool temperatures in fall are directly impacted by changes to stratification and these cold pool temperatures have been tied to the recruitment of species like yellowtail flounder (Sullivan et al., 2005). Tropical storm intensities have recently been found to be dependent on the cooling ahead of the eye of the storm, which is dependent on how much thermal stratification is broken down (Glenn et al., 2016). Maintaining measurements of not only the temperature structure, but salinity structure is important to better understand and protect coastal communities. 


\title{
Chapter 3
}

\section{Shelfbreak Jet structure and variability}

\section{off New Jersey using ship of opportunity data from the $C M V$ Oleander}

This chapter was originally published as Forsyth, J., Andres, M., \& Gawarkiewicz, G. (2020). Shelfbreak Jet structure and variability off New Jersey using ship of opportunity data from the $C M V$ Oleander. Journal of Geophysical Research: Oceans, 125, e2020JC016455. https://doi.org/10.1029/2020JC016455

\begin{abstract}
Repeat measurements of velocity and temperature profiles from the $C M V$ Oleander provide an unprecedented look into the variability on the New Jersey Shelf and upper continental slope. Here 1362 ADCP velocity sections collected between 1994-2018 are analyzed in both Eulerian and streamcoordinate reference frames to characterize the mean structure of the Shelfbreak Jet, as well as its seasonal to decadal variability. The Eulerian mean Shelfbreak Jet has a maximum jet velocity of $0.12 \mathrm{~m} \mathrm{~s}^{-1}$. The maximum jet velocity peaks in April and May and reaches its minimum in July and August. In a stream coordinate framework, the jet is only identified in $61 \%$ of transects, and the mean stream coordinate Shelfbreak Jet has a maximum jet velocity of $0.32 \mathrm{~m} \mathrm{~s}^{-1}$. Evidence is found that Warm Core Rings, originating from the Gulf Stream arriving in the Slope Sea adjacent to the New Jersey Shelf, shift the Shelfbreak Jet onshore of its mean position or entirely shutdown the Shelfbreak Jet's flow. At interannual timescales, variability in the Shelfbreak Jet velocity is correlated with the temperature on the New Jersey Shelf 2 months later. When considered in a stream-coordinate framework, Shelfbreak Jet have decreased over the time period considered in the study.
\end{abstract}




\subsection{Introduction}

The Middle Atlantic Bight (MAB) Shelfbreak Jet is an equatorward flowing jet, concentrated over the shelf break. This Shelfbreak Jet is part of a coastal current system, flowing from the Labrador Sea, along the east coast of North America at the edge of the shelf, until it reaches the Gulf Stream at Cape Hatteras. From north to south, the Shelfbreak Jet transport declines from a few Sverdrups in the Labrador Sea, to a fraction of a Sverdrup on the MAB (Loder et al., 1998; Fratantoni \& Pickart, 2007). The mean circulation of this coastal current has been studied as both a continuous feature, and at specific regional sites. Most commonly, hydrographic studies have documented the mean geostrophic transport using the thermal-wind equations (e.g Linder \& Gawarkiewicz, 1998; Fratantoni \& Pickart, 2007)).

In the MAB, the Shelfbreak Jet is typically associated with the Shelfbreak Front. This front separates the cool fresh shelf waters from the warm saltier slope water, leading to a large gradient in density. Calculations of the Shelfbreak Jet's barotropic and baroclinic components have found that roughly half of the total transport is baroclinic (Fratantoni \& Pickart, 2007). The identity of the Shelfbreak Jet is not dependent on being found in the Shelfbreak Front, however, the density gradients greatly enhance the transport of the Jet.

The Shelfbreak Jet in the MAB has been regularly sampled since 1992 using shipboard acoustic Doppler current profilers (ADCPs) from the ship of opportunity program Container Motor Vessel $(C M V)$ Oleander (Figure 3-1). Flagg et al. (2006) used the Oleander observations from 1992-2002 to detail the Shelfbreak Jet during time periods without Warm Core Rings present on the Oleander's route. Using these observations, they were able to study the mean structure of the Shelfbreak Jet. With over 200 transects, Flagg et al. (2006) also quantified the seasonal to interannual variability.

The impact of Warm Core Rings on the Shelfbreak Jet is contested and may depend on the region and time period considered. Fratantoni and Pickart (2003) found that rings were not a significant driver of variability on the New England Shelf, however, other studies have shown that Warm Core Rings are able to shift the position of the Shelfbreak Jet, or even reverse the direction of the jet on the New England Shelf and MAB (Beardsley et al., 1985; Zhang \& Gawarkiewicz, 2015). Not including rings to study the variability of the jet may miss a key mechanism which influences the Shelfbreak Jet, especially as more Warm Core Rings have been observed per year since 2000 in the 


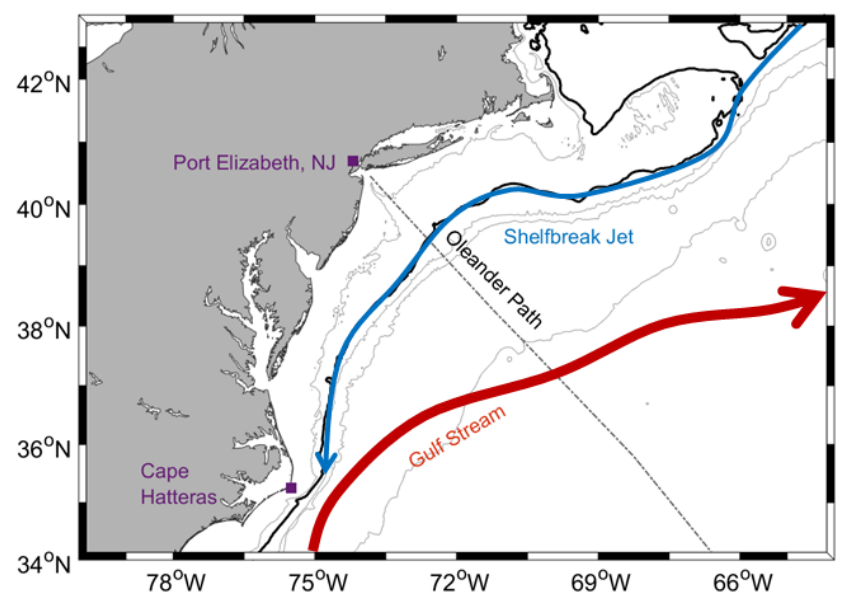

Figure 3-1: Map of the MAB including the locations of the Shelfbreak Jet (blue) and Gulf Stream (red). The Oleander path (grey dashed line) goes from Port Elizabeth, New Jersey, to Bermuda. Grey contours of bathymetry are shown indicating the 40, 1000, 2000, and 4000-m isobath, with the 100-m isobath shown in black.

Northwest Atlantic (Gangopadhyay et al., 2019). Since the increase in rings per year, Warm Core Rings have been a driver in some marine heatwaves on the shelf (Gawarkiewicz et al., 2019).

Here we present observations from the $C M V$ Oleander from 1994-2018, building on the Flagg et al. (2006) study of the Shelfbreak Jet with an additional 14 years of velocity sections, and considering sections where Warm Core Rings are present. By including all sections, we are able to establish the mean velocity structure at the shelf break and the velocity variability. Using this ADCP data also allows for a greater understanding of the spatial scales of the Shelfbreak Jet and its variability relative to the hydrographic and mooring based studies. The 25 years of data is unprecedented in this region, and allows for the study of variability on time scales previously not considered.

In the following, we describe the relevant data sets from the $C M V$ Oleander and from satellites in section 3.2. We discuss our methodologies to create gridded and quality controlled temperature and velocity products. Within section 3.2, we also outline our methodology for identifying the Shelfbreak Jet. The Eulerian mean Shelfbreak Jet structure and the seasonal variability of this jet are described in section 3.3. We then further analyze the Shelfbreak Jet structure by creating means using a stream coordinate framework. The Shelfbreak Jet's variability is investigated by employing 
several conditional averaging techniques. Lastly, we relate the interannual Shelfbreak Jet variability to the temperature variability on the shelf. We present our conclusions in section 3.5.

\subsection{Data and Methods}

\subsubsection{Oleander measurements}

Since 1977, the CMV Oleander has taken measurements of upper-ocean properties on its weekly trips between Port Elizabeth, New Jersey, and Bermuda. Temperature profiles measured with expendable bathythermographs (XBTs), and surface temperature and salinity observations using bucket measurements, have been collected since 1977, while ocean velocity profiles from ADCPs began in late 1992. Beginning in 2000, a thermosalinograph (TSG) was used to measure the surface temperature and salinity, replacing the bucket measurements. Here we describe two gridded products that we generated from the XBT and ADCP data.

\section{XBT temperature sections}

The XBT data set was previously used in Forsyth et al. (2015). Here we report updates to the methodology from the previous work, and describe the details of the final gridded product. To reduce errors from slight variations in the $C M V$ Oleander track from one transit to the next, we only use data taken within $15 \mathrm{~km}$ of the Oleander's median path between New Jersey and Bermuda (Flagg et al., 2006). The data are then projected onto the median path. Each individual transect is gridded with $10 \mathrm{~km}$ horizontal resolution and $5 \mathrm{~m}$ vertical resolution due to the spacing of sampling, and the recording of the earlier data.

We create a monthly product from the individual XBT temperature transects which are taken approximately 14 times a year. In months with multiple transects, we average the gridded transects within the month. If no data exist in a particular month, we use the following mapping technique to fill the gaps. First, we remove the seasonal cycle from all available gridded transects by subtracting the climatological monthly signal from each. Then we calculate the decorrelation time scale at each grid point, and use these to map the temperature anomalies where we did not previously have data. Lastly, the monthly climatological signal is added back in. The final product comprises monthly gridded temperature sections spanning the New Jersey Shelf, to the northern edge of the Gulf 
Stream from 1977-2018. We only grid data to the north wall of the Gulf Stream as XBT data south of this are not consistently available in the earlier parts of the record.

\section{ADCP velocity sections}

Two different ADCPs have been used on the Oleander since 1992, a $150 \mathrm{kHz}$ unit was used from 1992-2004, and in 2005 a $75 \mathrm{kHz}$ ADCP replaced the higher frequency model. Here we examine data from 1994-2018, which comprises 808 crossings from the $150 \mathrm{kHz}$ ADCP and 977 crossings from the $75 \mathrm{kHz}$ unit. Data were binned at varying vertical resolutions, and at 5 minute intervals, which gives a typical horizontal resolution of $2.4 \mathrm{~km}$ (Flagg et al., 2006). As with the XBT measurements, we only consider data that fall within $15 \mathrm{~km}$ of the Oleander's median path. We then apply a previously developed quality control mask (Flagg et al., 1998). While this removes most of the bad data, we apply additional quality control measures described below to further reduce errors. Using all of the ADCP data, we establish the mean bathymetry along the Oleander line (from the bottom reflections), and then remove all data that fall beneath this depth.

The $150 \mathrm{kHz}$ ADCP recorded data in 4-m depth bins on the shelf, defined as shallower than the $100-\mathrm{m}$ isobath, with the surface bin centered at $10 \mathrm{~m}$. Offshore of the $100-\mathrm{m}$ isobath, the bin resolution was $8 \mathrm{~m}$ with the shallowest bin centered at $20 \mathrm{~m}$ depth. In contrast, the $75 \mathrm{kHz}$ ADCP most often recorded data onshore of the 1000- $\mathrm{m}$ isobath with $8 \mathrm{~m}$ bins, with the surface bin centered between $20-22 \mathrm{~m}$. Offshore of the 1000-m isobath, the $75 \mathrm{kHz}$ ADCP recorded at a $16 \mathrm{~m}$ bin resolution with the top bin centered at $30 \mathrm{~m}$. While both ADCPs typically gathered data at the aforementioned bin sizes, the bin size, and the depth of the surface bin varies between transects. Due to differences in the data acquisition settings for the two different ADCPs, and the differences in data acquisition settings within an individual transect, we divide the data based on ADCP and depth region to further quality control the data.

For each ADCP and depth region, we calculate the mean velocity and standard deviations at each depth level for horizontal and vertical velocities. Binned data with vertical velocities outside two standard deviations from the mean are removed. This primarily removes data in the surface layer where the measurements are noisy and plagued by bubble sweep down. Individual bins with horizontal velocities over two standard deviations from the mean are flagged and examined further. Flagged data are removed unless they are part of a feature, like a Warm Core Ring impinging on the 
shelf or a large meander of the Shelfbreak Jet, which could indeed have velocities over two standard deviations away from the time mean shelf and slope velocities. Additionally, entire transects are removed if data return is poor and inconsistent throughout the transect.

After this quality control, we have $693150 \mathrm{kHz}$ transects and $66975 \mathrm{kHz}$ transects. We then remove the barotropic tides (Egbert \& Erofeeva, 2002). The $150 \mathrm{kHz}$ data are gridded with $4 \mathrm{~km}$ horizontal and $8 \mathrm{~m}$ vertical resolution. For the $75 \mathrm{kHz}$ data, we grid the data on a $4 \mathrm{~km}$ horizontal resolution, with the shallow data with $8 \mathrm{~m}$ vertical resolution and the deeper data on a $16 \mathrm{~m}$ vertical resolution. For ease of comparison, we linearly interpolate the deeper $75 \mathrm{kHz}$ data onto an $8 \mathrm{~m}$ vertical grid. These data sets are then combined for a total of 1362 transects of ADCPmeasured horizontal velocity on a $4 \mathrm{~km}$ by $8 \mathrm{~m}$ grid from 1994-2018. The distance grid is set based on Ambrose Light, which is in New York Harbor, at the north western end of the Oleander transect (Figure 3-1).

In this study, we define our velocities based on the orientation of the shelf break along the median path of the Oleander line on the New Jersey Shelf. The shelf break runs in the northeast-southwest direction with the mean Shelfbreak Jet flowing to the southwest. Thus, we rotate our velocities to be in the along-shelf, or southwest direction $\left(225^{\circ} \mathrm{T}\right)$, and cross-shelf, or southeast $\left(135^{\circ} \mathrm{T}\right)$ direction.

\section{Shelfbreak Jet Identification}

In order to study the Shelfbreak Jet, we develop a method to identify the jet in a given transect. First, we identify features which could be the Shelfbreak Jet by finding all the local depth-averaged alongshelf velocity maxima within a segment of the Oleander track spanning $120 \mathrm{~km}$ centered at the 100-m isobath. Next, we calculate the depth averaged velocity, the direction of the mean velocity, and the relative vorticity bracketing each velocity maximum. Here we define relative vorticity, $\zeta=\frac{\partial u}{\partial y}$, as the change in along-shelf flow in the cross-shelf direction which is in the direction of the Oleander transect. Along-shelf gradients in the cross-shelf flow tend to be much weaker in this region and thus we use this simplified form of relative vorticity. If TSG data exist during the ADCP transect (during 473 of the ADCP transects), we additionally consider the salinity, and the cross-shelf salinity gradient.

Our method identifies a Shelfbreak Jet and finds its position only when the following four criteria are met: (1) maximum velocity is above $0.15 \mathrm{~m} \mathrm{~s}^{-1},(2)$ the direction of the flow is predominantly 
along-shelf, (3) the relative vorticity on both sides of the jet is larger than the background values, and (4) the jet's along-shelf velocity decreases below $100 \mathrm{~m}$. The velocity used for criterion (1) is chosen because it is about half as strong as the core of the time-averaged Shelfbreak Jet calculated using a stream coordinate frame (Flagg et al., 2006). Requiring the identified jets to decrease in along-shelf velocity with depth prevents our method from mistaking onshore meanders of the more barotropic Slope Jet as the Shelfbreak Jet (Flagg et al., 2006). If we do not have data below $100 \mathrm{~m}$, either because the water depth is shallower than $100 \mathrm{~m}$ or because the data deeper than $100 \mathrm{~m}$ were removed in the quality control, we assume criterion (4) is satisfied.

If multiple velocity cores are identified in one transect using the above criteria, we compare the velocity cores' properties and rank them to be consistent with the observed Shelfbreak Jet identified in past research (Linder \& Gawarkiewicz, 1998; Fratantoni et al., 2001; Flagg et al., 2006). The properties and highest rank of each property are, the velocity core with the highest velocity, velocity cores where the magnitude of the relative vorticity on the cyclonic side is greater than the magnitude of relative vorticity on the anticyclonic side, the velocity core that is closest in distance to the mean climatological position of the Shelfbreak Jet, and if TSG data exist for the section, the velocity core that is closest to the 34.5 isohaline which is taken to define the Shelfbreak Front (Linder \& Gawarkiewicz, 1998). The velocity core that is the most consistent with past observations of the Shelfbreak Jet is then selected as the jet.

\subsubsection{Satellite}

We use satellite data to study spatial variability along the MAB and Slope Sea from 1994-2018 and to provide spatial context for the variability observed at the Oleander Line. For sea surface temperature (SST) we use National Oceanographic and Atmospheric Administration (NOAA) Optimum Interpolation (OI) $\frac{1}{4}^{\circ}$ daily SST (AVHRR-only; Reynolds et al. (2007)). Additionally, we use daily mapped absolute dynamic topography at $\frac{1}{4}^{\circ}$ resolution, available through E.U. Copernicus Marine Environmental Monitoring Service to provide sea surface height (SSH) data, and SSH-derived geostrophic velocities.

To verify that satellite altimetry can be used to study the Shelfbreak Jet, we interpolate the mean SSH-derived geostrophic velocities calculated from SSH gradients onto the Oleander path. The maximum along-shelf velocity from satellite altimetry is $0.11 \mathrm{~m} \mathrm{~s}^{-1}$, and is found at the $91-\mathrm{m}$ 
isobath. These values are similar to what we will report later as the position and maximum jet velocity of the Eulerian mean Shelfbreak Jet from the in-situ ADCP measurements. The position of the jet is accurate within the satellite spatial feature resolution, which is approximately $40 \mathrm{~km}$ (Chelton et al., 2011). We find that the satellite data are able to reproduce the features we are studying, though at a much coarser scale that is still useful in providing broader spatial context.

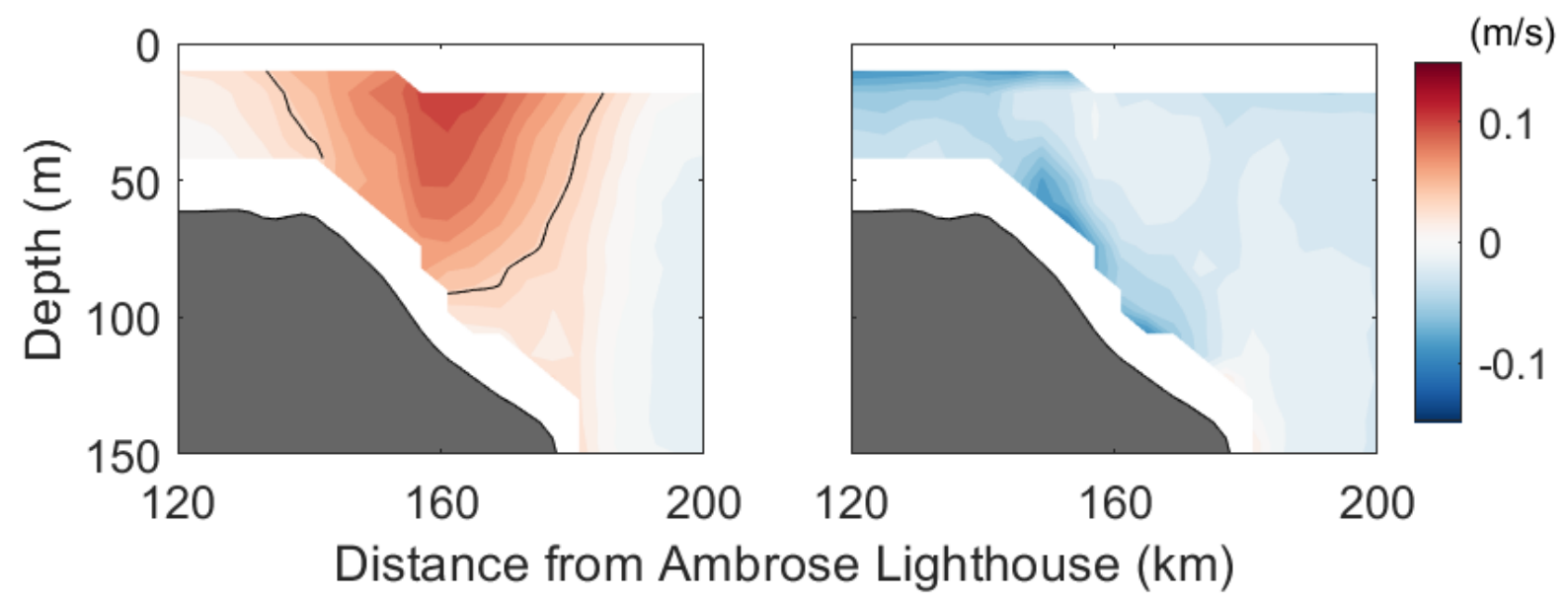

Figure 3-2: Eulerian mean along-shelf velocity (left column) and cross-shelf velocity (right column) from 1362 sections. The e-folding isotach (black line) is plotted for mean along-shelf velocity.

\subsection{Mean and Climatological Structure}

\subsubsection{Eulerian Mean Shelfbreak Jet Velocity Structure and Transport}

Using all 1362 gridded velocity sections, we calculate Eulerian mean transect across the shelf break (Figure 3-2) in the along-shelf direction (southwest) and the cross-shelf direction (southeast). The Eulerian mean Shelfbreak Jet is centered over the 115-m isobath (161 km from Ambrose Light), has a maximum along-shelf velocity of $0.11 \mathrm{~m} \mathrm{~s}^{-1}$, an e-folding width of $50 \mathrm{~km}$, and an e-folding depth of $90 \mathrm{~m}$. The maximum velocity occurs in the surface bin, which is centered at $18 \mathrm{~m}$ depth, and velocities decrease with depth. These time-averaged jet properties are similar with previous work based on ADCPs, hydrographic data, and moorings, though our maximum jet velocity is on the lower bound of velocities previously reported (e.g. Linder \& Gawarkiewicz, 1998; Flagg et al., 2006; Fratantoni \& Pickart, 2007)). The transport calculated by integrating the along-shelf velocity within 
the e-folding isotach $\left(0.04 \mathrm{~m} \mathrm{~s}^{-1}\right)$ is $0.16 \mathrm{~Sv}$, where the transport includes only the directly-measured velocity.

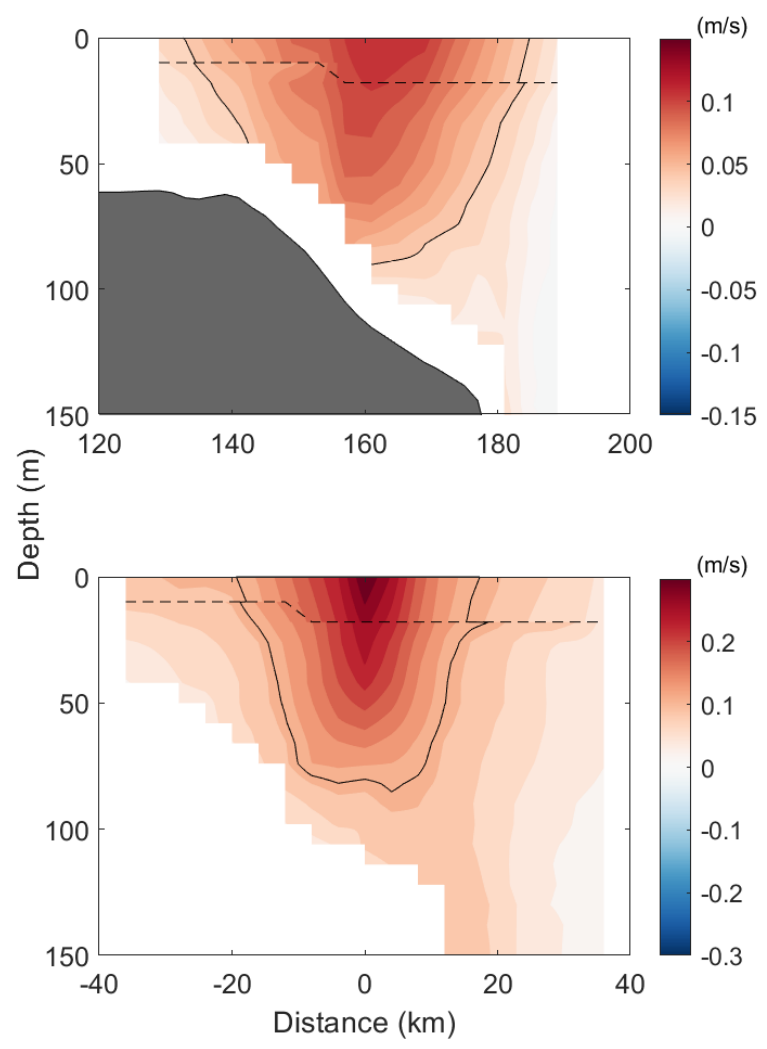

Figure 3-3: Eulerian mean along-shelf velocity (top) and stream coordinates mean along-shelf velocity (bottom) with extrapolated data above the dashed line. The e-folding isotach (black line) is plotted for each case.

This mean transport is smaller than most previous work (Table 3.1), however, this is largely because shipboard ADCPs are not able to measure the surface layers where the strongest Shelfbreak Jet velocities are typically found. In order to obtain a better estimate of the mean Shelfbreak Jet transport, we extrapolate data to the surface. At each horizontal bin within the Shelfbreak Jet, we choose either a linear or exponential fit depending on the vertical structure of the existing data in the deeper bins. Each fit is then used to calculate estimates for the along-shelf velocities at the surface (shaded contours above the dashed line in Figure 3-3). The estimated mean maximum jet velocity is $0.12 \mathrm{~m} \mathrm{~s}^{-1}$, with the same e-folding length and depth scales of $50 \mathrm{~km}$ and $90 \mathrm{~m}$ respectively. Using these estimates of velocities in the shallowest layers gives transport within the mean Shelfbreak 
Jet of $0.21 \pm .02 \mathrm{~Sv}$, which is similar to previously reported values (Table 3.1). Our error estimate is calculated from resampling the 1362 transects with replacement and calculating a new mean Shelfbreak Jet using the randomly selected resampled transects. We iterate this resampling 1000 times, calculating the Eulerian mean transport of the Shelfbreak Jet in each iteration, and 95\% of the resampled Eulerian mean transports fall within the aforementioned error range. These estimates suggest that about $24 \%$ of the mean Shelfbreak Jet transport is carried in the upper $14 \mathrm{~m}$ of the water column.

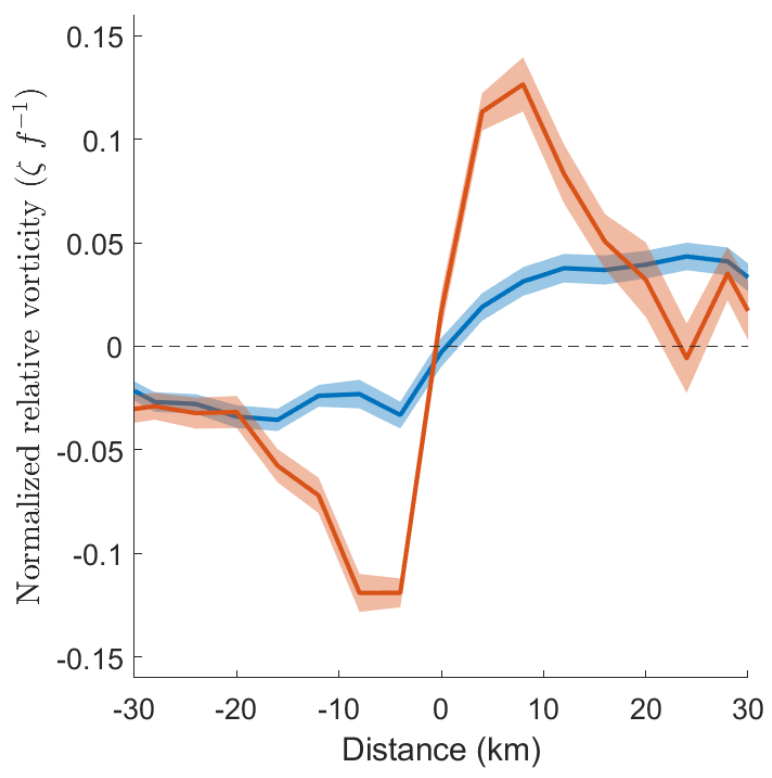

Figure 3-4: Eulerian mean (blue) and stream coordinates mean (red) normalized relative vorticity from the shallowest bin of velocity data. Mean standard errors of the normalized relative vorticity are shown in the shaded colors.

We calculate the absolute value of the normalized relative vorticity, or Rossby number, here defined as $\left|\frac{\partial u}{\partial y} \cdot f^{-1}\right|$, for the Eulerian mean Shelfbreak Jet in the shallowest layer of data (bin centered at $18 \mathrm{~m}$, Figure 3-4). We do not calculate the normalized relative vorticity for the surface layer since we do not have direct observations of the surface velocities. The relative vorticity on either side of the Shelfbreak Jet is not strongly peaked. The ratio of cyclonic to anticyclonic relative vorticity within the e-folding width scale of $50 \mathrm{~km}$, is 1.17 . The normalized relative vorticity reaches a maximum value of 0.05 , reinforcing that geostrophy is a good approximation in this region.

Capitalizing on the large number of transects measured by the Oleander over the years, we are able to create a monthly climatology over the shelf break in contrast to past climatologies that 


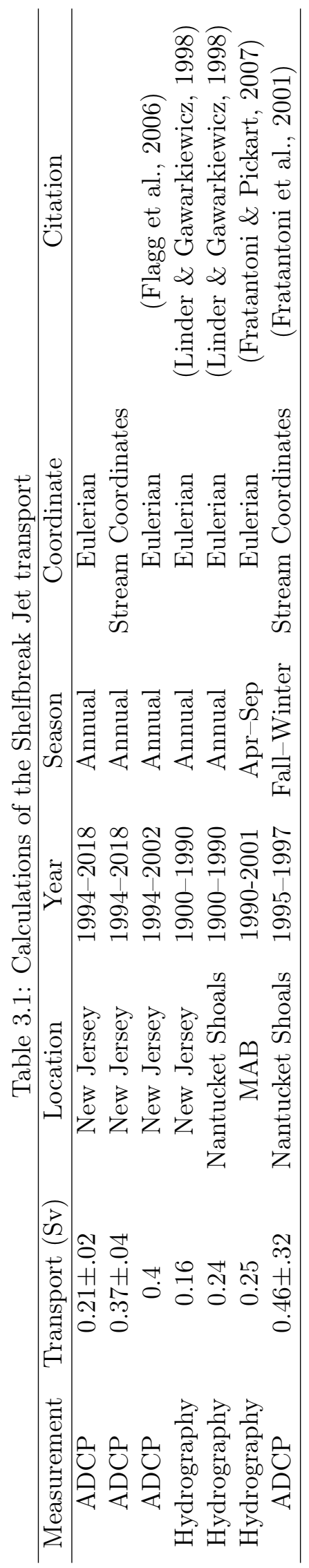


have been limited to bi-monthly or seasonally-averaged analyses. The along-shelf velocities in this climatology show a strong variability both in the core of the Shelfbreak Jet and over the slope (Figure 3-5). The core of the climatological Shelfbreak Jet reaches a maximum in April-May and a secondary maximum in November. During these peak months, the Shelfbreak Jet has surfaceintensified maximum velocities around $0.16 \mathrm{~m} \mathrm{~s}^{-1}$, and closely resembles the velocity structure of the overall Eulerian mean section. Summer months have the weakest maximum Shelfbreak Jet velocity, with maximum velocities only reaching $0.07 \mathrm{~m} \mathrm{~s}^{-1}$ in July and August. The summer also differs from the rest of the year, in that the Shelfbreak Jet has a subsurface velocity maximum. In July, the maximum velocity occurs in the depth bin centered at $58 \mathrm{~m}$, and in August the maximum velocity is found in the depth bin centered at $42 \mathrm{~m}$.
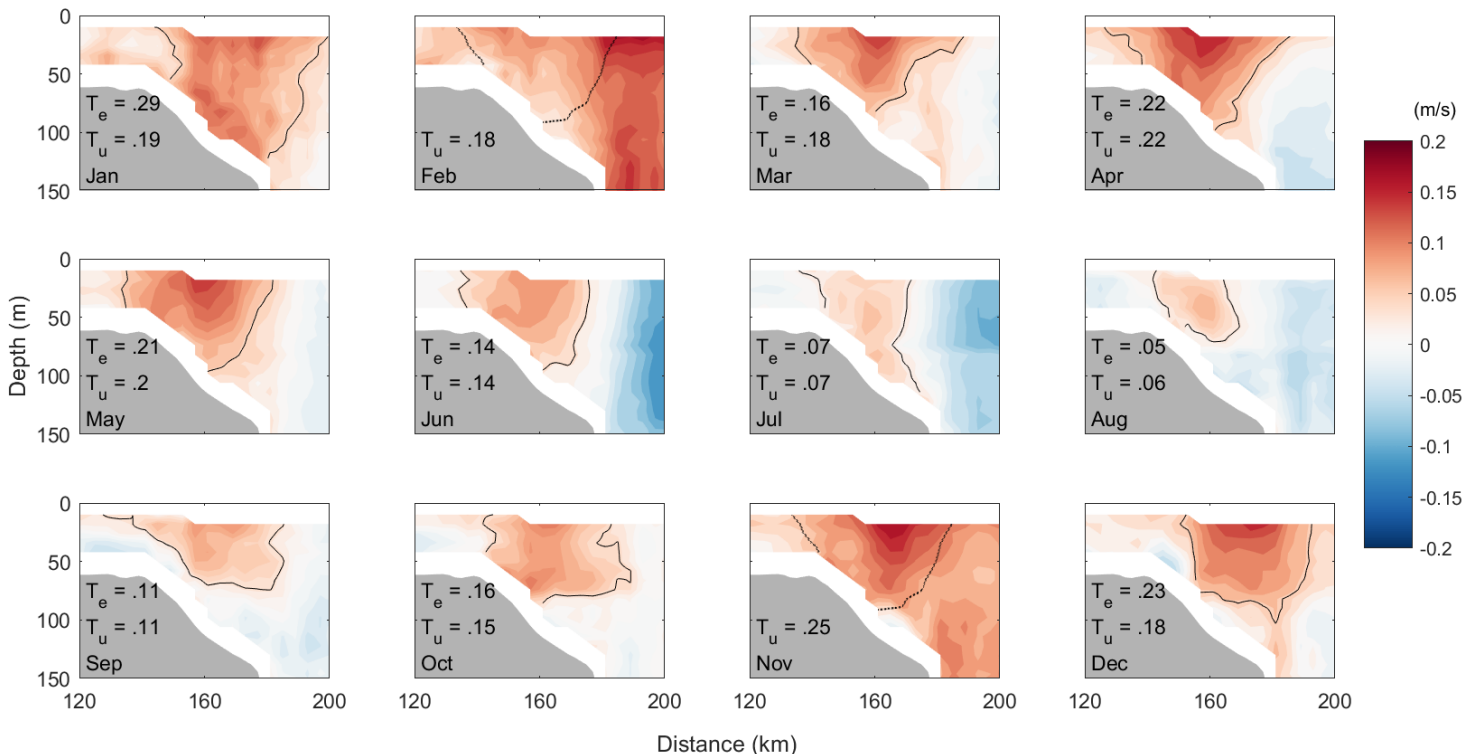

Figure 3-5: Eulerian mean along-shelf velocities in each month. $\mathrm{T}_{e}$ is the transport in Sverdrups within each months e-folding isotach (solid black line) calculated based on the maximum velocity in each month. $\mathrm{T}_{e}$ cannot be calculated during February and November. $\mathrm{T}_{u}$ is the transport in Sverdrups within the climatogical e-folding isotach (dashed black line in February and November) shown in Figure 3-2.

The transport calculations from this monthly climatology show a seasonal cycle similar to that of velocity. Here we calculate transport in two different ways though we note that each methodology likely underestimates the total transport as we do not extrapolate data to the surface here. In the first, $\mathrm{T}_{e}$ is calculated by finding the e-folding isotach in each month and then calculating the 
transport within that cross-sectional area. In the second, $\mathrm{T}_{u}$ relies on the area within the e-folding isotach from the mean Eulerian Shelfbreak Jet to calculate the transport. Both of these methods for calculating the transport are very similar except in January, where the area used to calculate the transport for $\mathrm{T}_{e}$ is $50 \%$ larger than the area for $\mathrm{T}_{u}$. With both methodologies, the highest transport occurs in December and January, with a secondary peak in April and May. In summer, the jet has the smallest maximum jet velocities and also the smallest cross-sectional area, which both contribute to the weakest transport. The transport in summer is approximately $1 / 4$ that of the transport in December/January.

\subsubsection{Stream-coordinate Mean Shelfbreak Jet Velocity Structure and Transport}

The Eulerian framework is useful for studying the overall velocity structure over the shelf break, however, the Shelfbreak Front and Jet are known to have meander amplitudes up to $15 \mathrm{~km}$ in the cross-shelf direction (Gawarkiewicz et al., 2004). In order to study the properties of the meandering Shelfbreak Jet, it is helpful to use a stream coordinates framework (Fratantoni et al., 2001; Flagg et al., 2006). Using our methodology to identify the Shelfbreak Jet (section 3.2.1), we find a jet in $44 \%$ of the ADCP transects. For the remaining $56 \%$ of the sections, a jet cannot be identified because of poor data quality and/or because the jet is absent. When only considering transects that have "good" data over the shelf break, defined here as sections with over $70 \%$ data return, the Shelfbreak Jet is identified in $61 \%$ of the total 669 sections. This shows that the Shelfbreak Jet is intermittent in space and time on the New Jersey Bight. The remaining discussion is based on only sections with over $70 \%$ data return.

Although the Shelfbreak Jet is present in $61 \%$ of the (good) transects, there is large monthly variability in this percentage. The Shelfbreak Jet is most consistently identified during April (74\% of the good sections), and least consistently identified in August (39\% of the good sections). On a seasonal time scale, the jet is more common in spring and fall, and less commonly found in summer and winter. This seasonal cycle is consistent with our Eulerian climatology in which the fastest Shelfbreak Jet core velocities and highest transports were found in spring and fall.

We identify the Shelfbreak Jet most often in the same cross-shelf position as the core of the Eulerian mean Shelfbreak Jet, over the 115-m isobath, $162 \mathrm{~km}$ from Ambrose Light (Figure 36 ). The jet core meanders within $\pm 20 \mathrm{~km}$ of its mean position around $80 \%$ of the time, relatively 

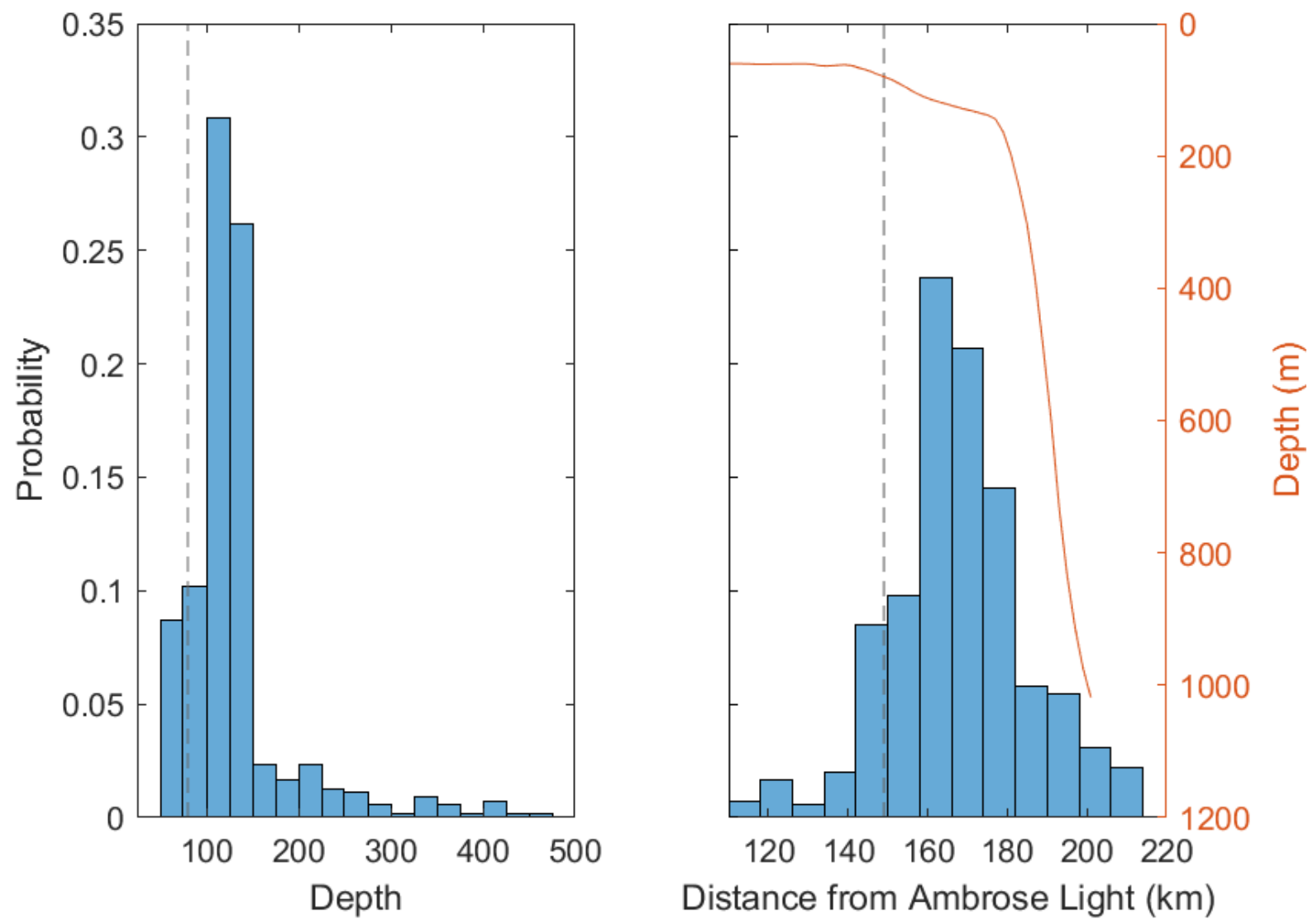

Figure 3-6: Normalized probablities of the location of the Shelfbreak Jet in isobath (left), and distance from Ambrose Lighthouse (right). The mean grounding position of the Shelfbreak Front (80 $\mathrm{m}$ isobath) is found at $149 \mathrm{~km}$ and plotted in the dashed grey line (Linder \& Gawarkiewicz, 1998).

consistent with the $50 \mathrm{~km}$ length scale of the Eulerian mean Shelfbreak Jet. This meander amplitude keeps the Shelfbreak Jet concentrated over the $70-\mathrm{m}$ to the $150-\mathrm{m}$ isobaths. Occasionally, we observe displacements of the core up to $20 \mathrm{~km}$ away from the mean position, similar to previous reports of large amplitude Shelfbreak Jet meanders (Gawarkiewicz et al., 2004). The Shelfbreak Jet is strongly trapped by bathymetry. The jet is found onshore of the $150-\mathrm{m}$ isobath over $75 \%$ of the time, which is the isobath where the slope is the steepest on this transect. Onshore jet displacements reach the 60-m isobath, while rare offshore displacements extend past the shelf break to depths over $1000 \mathrm{~m}$.

Because the Shelfbreak Jet is intermittent and also meanders in the cross-shelf direction, a stream coordinate framework is useful to study the properties of the jet. We create a mean stream coordinate Shelfbreak Jet by taking every good section in which the jet is identified, and rotating the velocity 
in each section into the along-stream direction, which is the direction of the maximum Shelfbreak Jet velocity, and the cross-stream direction. We align and project each transect in horizontal space, accounting for the differences in cross-stream distance due to the projection, where the maximum Shelfbreak Jet velocity is at the origin of the distance axis, and keep the depth coordinates the same.

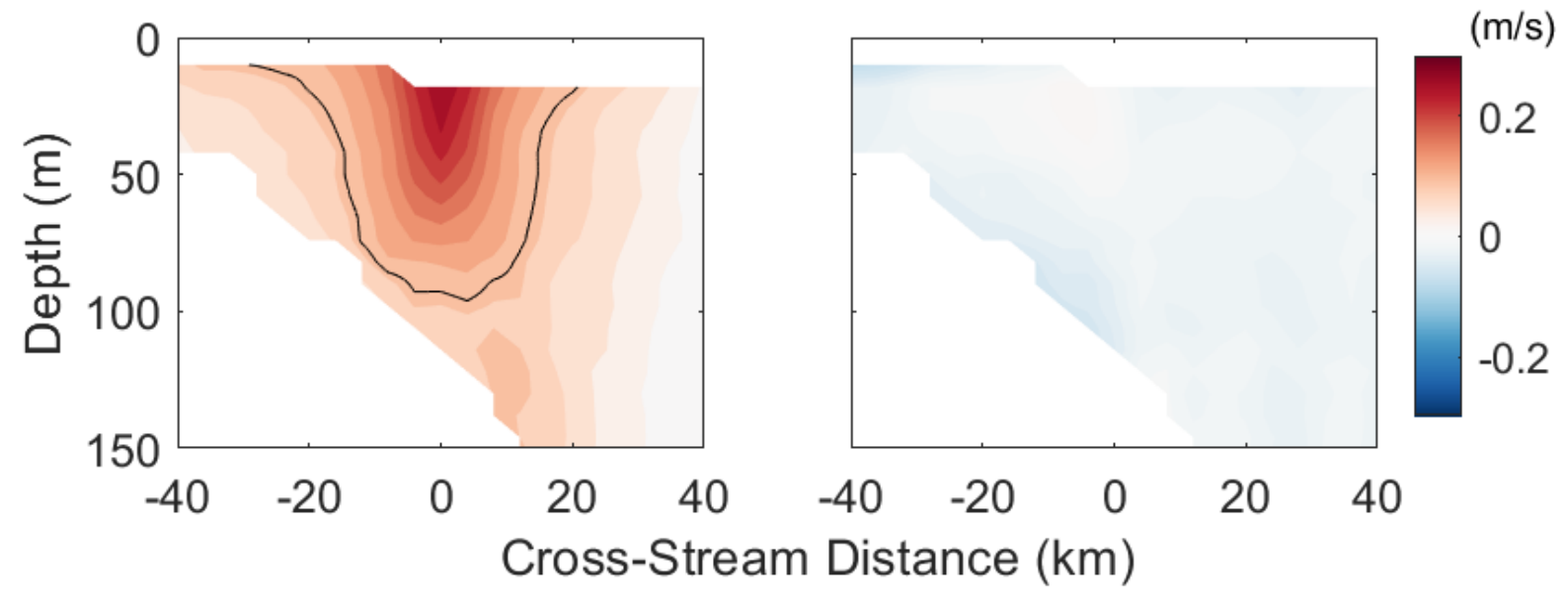

Figure 3-7: Stream coordinates mean along-stream velocity (left column) and cross-stream velocity (right column) of the Shelfbreak Jet. The e-folding isotach (black line) is plotted for the mean along-stream velocity. The Shelfbreak Jet is identified in 546 sections.

The stream-coordinate mean Shelfbreak Jet has a surface intensified velocity maximum of $0.27 \mathrm{~m} \mathrm{~s}^{-1}$, and has an e-folding width scale of $40 \mathrm{~km}$ and depth scale of around $80 \mathrm{~m}$ (Figure 3-7). Transport within the stream-coordinate mean Shelfbreak Jet is $0.34 \mathrm{~Sv}$ without extrapolating data to the surface. Repeating the same fit and extrapolation techniques with the stream coordinates mean as described earlier for the Eulerian mean gives a maximum velocity of $0.32 \mathrm{~m} \mathrm{~s}^{-1}$, a length scale of $35 \mathrm{~km}$ and a depth scale of $85 \mathrm{~m}$ (Figure 3-3). Including extrapolated velocities near the surface increases the transport estimate to $0.37 \pm .04 \mathrm{~Sv}$, which is a similar increase in magnitude to that of the Eulerian mean case, but represents only a $12 \%$ relative increase. The stream coordinates jet has a smaller length scale when including the surface velocities, and thus the transport does not increase as much in a relative sense.

The normalized relative vorticity in the shallowest directly measured layer (bin centered at $18 \mathrm{~m}$ ) of the stream coordinate mean velocity section is distinctly more peaked than that of the Eulerian 
mean section (Figure 3-4). The maximum normalized relative vorticity in the stream-coordinate mean section reaches 0.15 , which is larger than the maximum reached in the Eulerian mean section. In the stream coordinate framework, the ratio of cyclonic to anticyclonic relative vorticity is smaller than the Eulerian ratio at 1.02 . However, if we calculate this ratio for each transect in which the Shelfbreak Jet is identified, the median cyclonic to anticyclonic ratio is 1.12 .

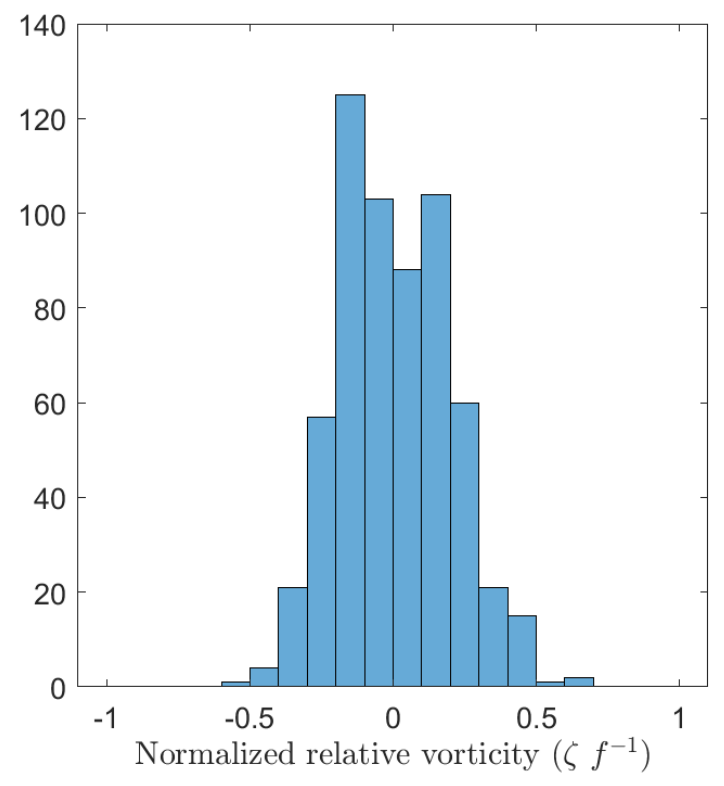

Figure 3-8: Histogram of the maximum and minimum normalized relative vorticity, across the Shelfbreak Jet in every transect when the jet is identified.

For both the stream-coordinate mean and the Eulerian mean, our calculated ratio of cyclonic to anticyclonic relative vorticity differs from the expected 2:1 ratio that was found by Nantucket Shoals (Linder \& Gawarkiewicz, 1998). This could be due to differences in location or methodologies as Linder and Gawarkiewicz (1998) calculated velocities from thermal-wind balance, included velocities up to $5 \mathrm{~m}$ depth whereas our shallowest bin is centered at $18 \mathrm{~m}$ depth, and they looked at bi-monthly averages and not the mean. However, we still see the stronger shear on the slope side of the Shelfbreak Jet, consistent with studies from Nantucket Shoals to just north of Cape Hatteras (Gawarkiewicz et al., 1996; Fratantoni et al., 2001). We create a histogram of the maximum anticyclonic and cyclonic relative vorticity values in the Shelfbreak Jet in every transect where we identify the jet (Figure $3-8)$. We do not take the absolute value of the normalized relative vorticity here to differentiate between the values of anticyclonic and cyclonic. The relative vorticity stays below a magnitude of 
0.5 , on both sides of the jet, $94 \%$ of the time.

The monthly climatology of the velocity sections calculated in stream coordinates is similar to the climatology calculated in an Eulerian framework, with the strongest velocities from November through April and the weakest velocities in June through August. One striking difference between the stream coordinate versus Eulerian mean climatologies, is that the structure of the jet in the stream coordinates case remains consistent throughout the year, resembling the velocity structure of the stream coordinates mean (Figure 3-7). We identify the jet most consistently in Spring and Fall.

\subsection{Conditional Averageing for a Broader View}

\subsubsection{Variability in the Position of the Jet}

In order to study the variability in the position of the Shelfbreak Jet, we create stream coordinate means conditionally averaged when the Shelfbreak Jet is displaced over $10 \mathrm{~km}$ from the mean position, in both the onshore and offshore direction (Figure 3-9). Overall, we find shifts in the position of the Shelfbreak Jet are accompanied by changes in the along-shelf velocity structure. The mean jet when shifted offshore has a maximum velocity of $0.30 \mathrm{~m} \mathrm{~s}^{-1}$, which is larger than the

$0.24 \mathrm{~m} \mathrm{~s}^{-1}$ maximum velocity of the mean jet when shifted onshore. During time periods when the Shelfbreak Jet is shifted onshore, there is a reversal of the stream coordinate velocity over the slope, which is not seen during time periods when the Shelfbreak Jet is offshore of its mean position.

The vertical structure of the Shelfbreak Jet also varies in concert with the onshore/offshore position of the jet. We calculate the velocity shear for the stream coordinate overall mean Shelfbreak Jet (not shown), as well as for both the onshore and offshore shifted Shelfbreak Jet (Figure 3-10). In the (overall) stream coordinate mean Shelfbreak Jet velocity section, the velocity shear decreases in the core of the jet from surface to bottom. The variability and scatter of this velocity shear also decreases with depth. The conditional averages show that when the Shelfbreak Jet is found further offshore, the velocity shear also decreases with depth. However, when the jet is onshore of its mean position, the along-shelf velocity decreases more linearly with depth. The velocity shear is also an order of magnitude larger during time periods when the jet is offshore relative to onshore. Typically, half of the Shelfbreak Jet's transport is baroclinic, however, here the jet is a lot less baroclinic when it 

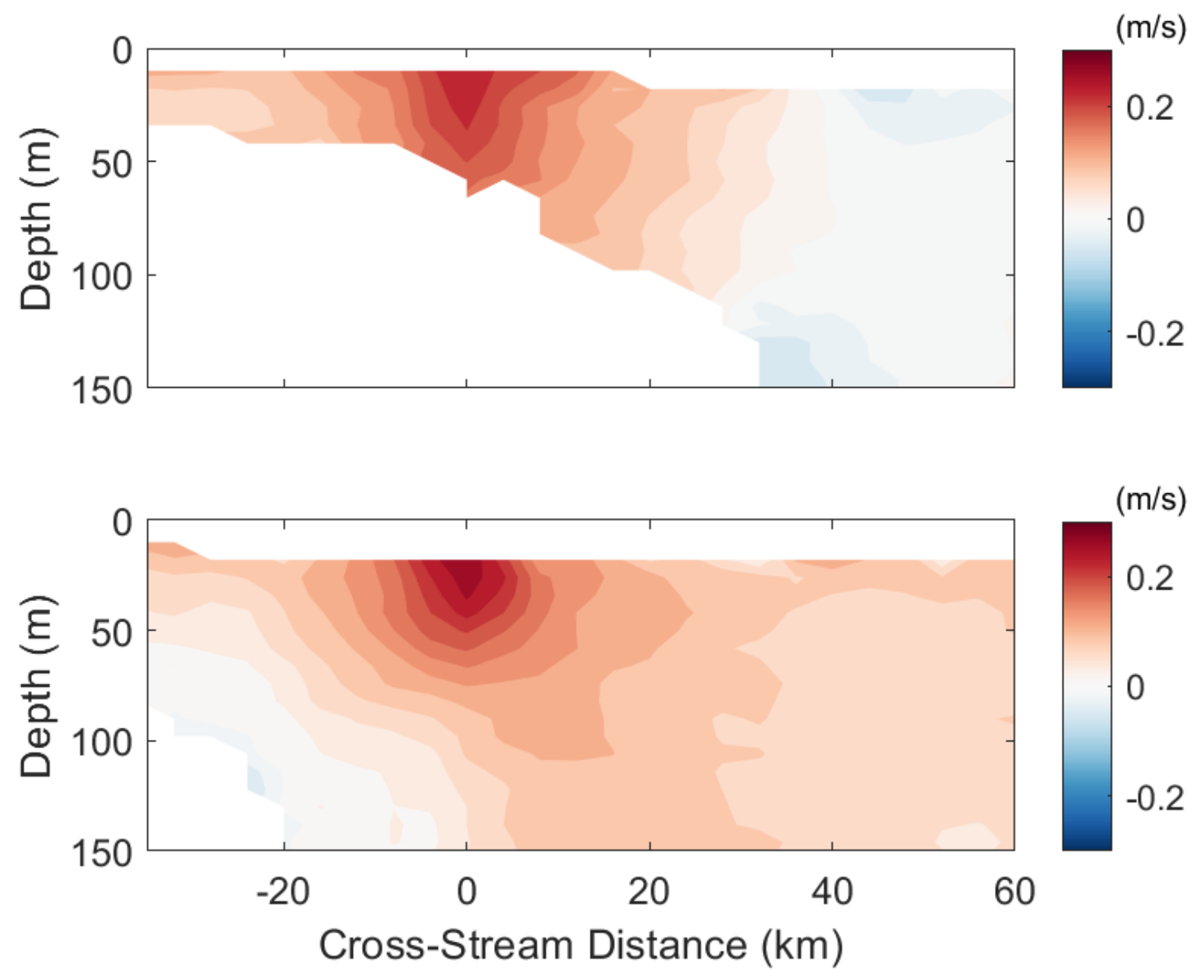

Figure 3-9: Stream coordinate along-stream velocity means (in $\mathrm{m} \mathrm{s}^{-1}$ ) when the Shelfbreak Jet is identified onshore of its mean position (top, calculated from 105 transects) and offshore of its mean position (bottom, calculated from 71 transects).

is shifted onshore (Fratantoni \& Pickart, 2007). This could mean that the onshore shifted Shelfbreak Jet is consistent with a weaker Shelfbreak Front, or that the Jet when found further onshore is not associated with the Shelfbreak Front.

To provide spatial context for the conditionally-averaged mean velocity sections for an onshoreshifted and off-shore shifted Shelfbreak Jet, we create corresponding composite maps from satellite SST and SSH data when the jet is found onshore and offshore of its mean position (Figure 311). When the jet is identified offshore, small negative SSH and SST anomalies are found along the Oleander track. During time periods when the Shelfbreak Jet is shifted onshore, there are large positive SST and SSH anomalies north of the mean position of the Gulf Stream. These SST anomalies extend from the Gulf Stream, through the Slope Sea, and onto the outer shelf, while the 

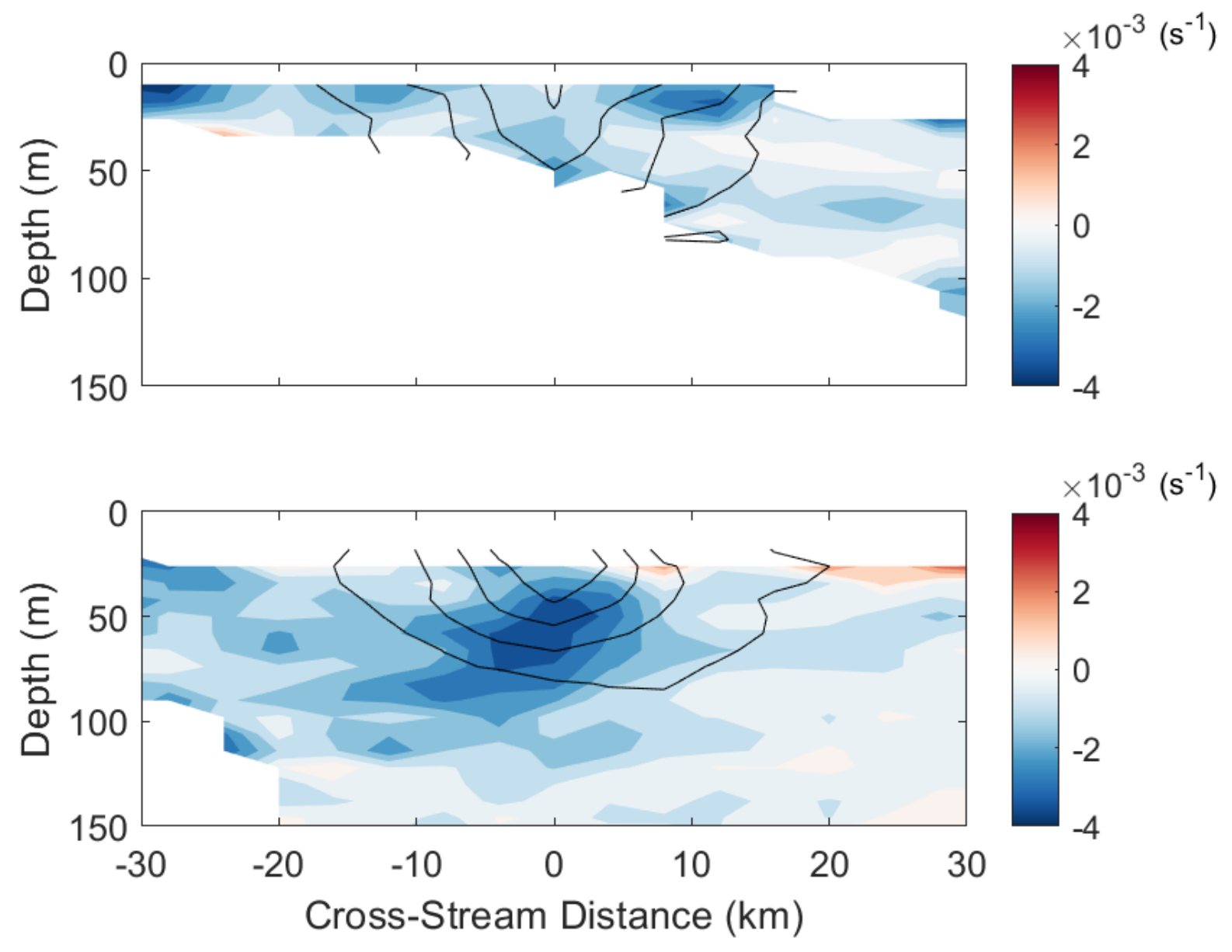

Figure 3-10: Stream coordinate along-stream velocity shear $\left(\partial u / \partial z \mathrm{~s}^{-1}\right)$ in the colored contours when the Shelfbreak Jet is identified onshore of its mean position (top) and offshore of its mean position (bottom). Solid black contours are the stream coordinate along-stream velocity means for the onshore and offshore shifted Shelfbreak Jet from Figure 3-9

SSH anomalies only extend into the Slope Sea. These maps suggest that that the position of the Shelfbreak Jet is related to the SSH and SST of the Gulf Stream just east of Cape Hatteras.

The relationship between variability of the Gulf Stream position and the variability of the Shelfbreak Jet has not been well established. Past research showed that the Gulf Stream was not the main driver of the Shelfbreak Jet variability south of New England, northeast of the Oleander Line (Fratantoni \& Pickart, 2003), while other studies have found significant correlations between the two currents at study sites further downstream of the New England Shelfbreak Jet (Bane et al., 1988; Rossby \& Benway, 2000). Bane et al. (1988) found a positive correlation between the proximity of the Gulf Stream to the shelf and Shelfbreak Jet velocities just north of Cape Hatteras. They hypothesized that when the Gulf Stream was closer to the shelf, it constricts the Slope Sea 

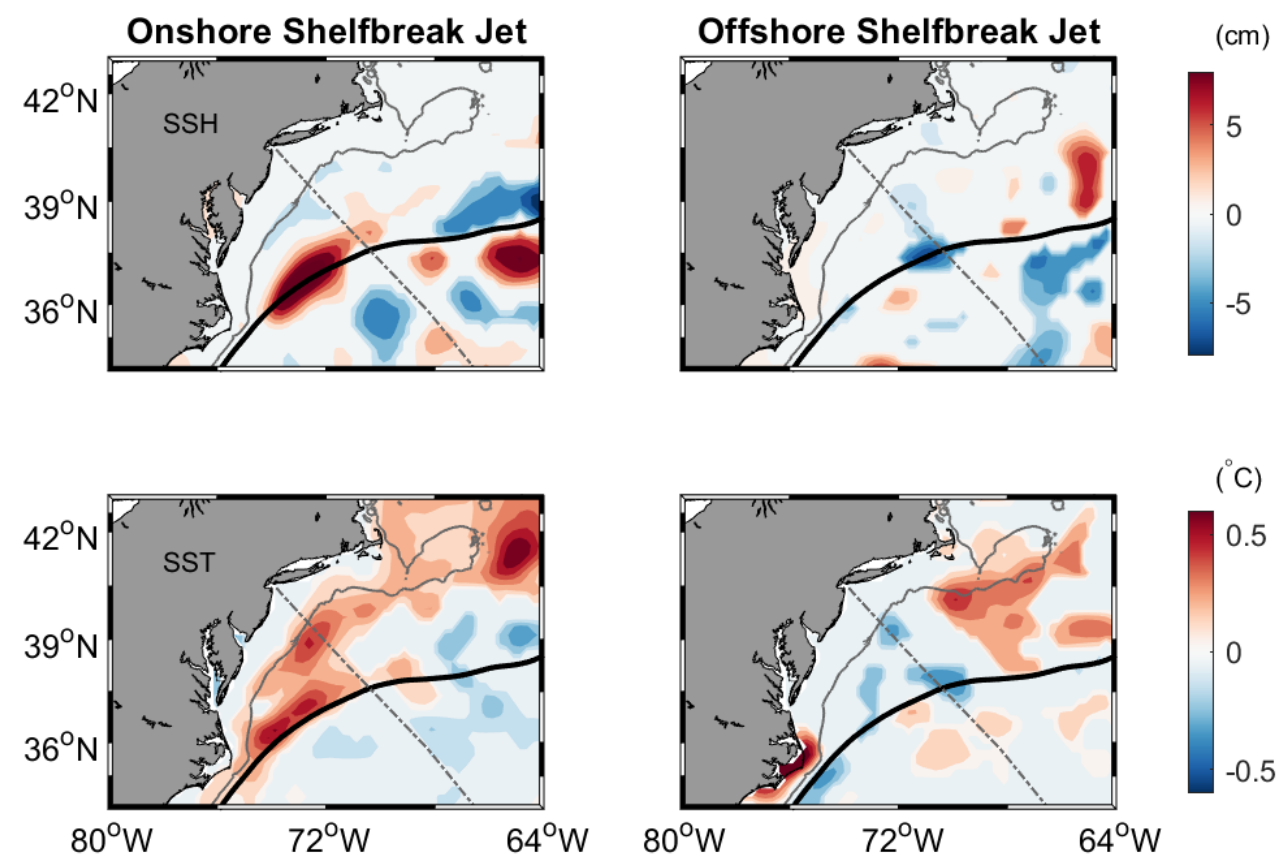

Figure 3-11: Composite maps of SSH anomalies (cm, top row) and SST anomalies $\left({ }^{\circ} \mathrm{C}\right.$, bottom row) when the Shelfbreak Jet is identified onshore of its mean position (left column) and offshore of its mean position (right column). Colored contours are not shown if the mean standard errors overlap with zero. The grey dashed line is the Oleander path, the grey solid line is the $80-\mathrm{m}$ isobath, and the solid black line is the mean position of the $25 \mathrm{~cm}$ SSH contour which is a proxy for position of the Gulf Stream.

gyre, which leads to enhanced Shelfbreak flows towards Cape Hatteras. Rossby and Benway (2000) also found evidence of connections between shelf flows and the position of the Gulf Stream, with the position of the Gulf Stream highly correlated with the Gulf Stream's surface salinity. They suggested that the surface salinity of the Gulf Stream is controlled by the equatorward freshwater transport in the Slope Sea. Reduced transport on the shelf and in the Slope Sea leads to a weaker freshwater anomaly, which is correlated with a more northward position of the Gulf Stream. The correlation between the Slope Sea and Gulf Stream position was further shown by Peña-Molino and Joyce (2008), where they found a correlation between temperatures in the Slope Sea and the Gulf Stream position, also suggesting an advective mechanism for the Slope Water influencing the Gulf Stream position.

Our composite maps are consistent with the correlations found in Rossby and Benway (2000), 
as our onshore-shifted Shelfbreak Jet has reduced along-stream velocities simultaneous with a northward-shifted Gulf Stream as seen by the positive SSH anomaly around the mean position of the Gulf Stream axis (Figure 3-11). This relationship is affirmed by calculating the correlation of the latitude of the $25 \mathrm{~cm}$ SSH contour just east of Cape Hatteras $\left(72-74^{\circ} \mathrm{W}\right)$, a proxy for the Gulf Stream position (Andres, 2016), and the position of the Shelfbreak Jet gives a significant correlation at the $95 \%$ confidence level. In addition, the mean latitude of the $25 \mathrm{~cm} \mathrm{SSH}$ contour just east of Cape Hatteras $\left(72-74^{\circ} \mathrm{W}\right)$ is found on average $\frac{1}{8}^{\circ}$ further north in time periods where the jet is shifted onshore. This suggests a different mechanism than the Slope Sea gyre constriction suggested by Bane et al. (1988) whereby the Gulf Stream was posited to impact the Shelfbreak Jet. Off of New Jersey there is a simultaneous shift of the Gulf Stream and Shelfbreak Jet position. Our results do not contradict the findings of Fratantoni and Pickart (2003), as their dominant mode of Shelfbreak Jet variability was at a 13 day period, a timescale that we cannot consistently resolve with the Oleander ADCP data, which are collected weekly at best. Taken as a whole, the studies suggest that different processes are likely operating at different timescales leading to a complicated relationship between the Shelfbreak Jet and the Gulf Stream.

\subsubsection{Determining the factors causing jet presence or absence}

As previously discussed, the Shelfbreak Jet is only present in $61 \%$ of the ADCP velocity sections. To better establish what is driving the variability of the Shelfbreak Jet, we examine what causes the complete shutdown of the Shelfbreak Jet southeast of New Jersey. We calculate Eulerian mean transects from the sections in which a Shelfbreak Jet is identified, and from the sections in which it is not identified (Figure 3-12). With this conditional averaging, the Eulerian mean from transects with the Shelfbreak Jet identified resembles the velocity structure of the total Eulerian mean (Figure 3-2), but with a stronger velocity core reaching $0.15 \mathrm{~m} \mathrm{~s}^{-1}$. As expected, when the Shelfbreak Jet is not identified, the magnitude of the Eulerian mean along-shelf velocities are weak with velocities around $0.04 \mathrm{~m} \mathrm{~s}^{-1}$. In contrast, cross-shelf velocities on the shelf are stronger when the Shelfbreak Jet is not present, reaching up to $0.1 \mathrm{~m} \mathrm{~s}^{-1}$ in the onshore direction.

Over the continental slope, the differences in the mean along-shelf velocities for the conditional averages with and without a Shelfbreak Jet are even more striking. There are southwest velocities over the slope in both cases, resembling the Slope Jet previously documented from Oleander data 


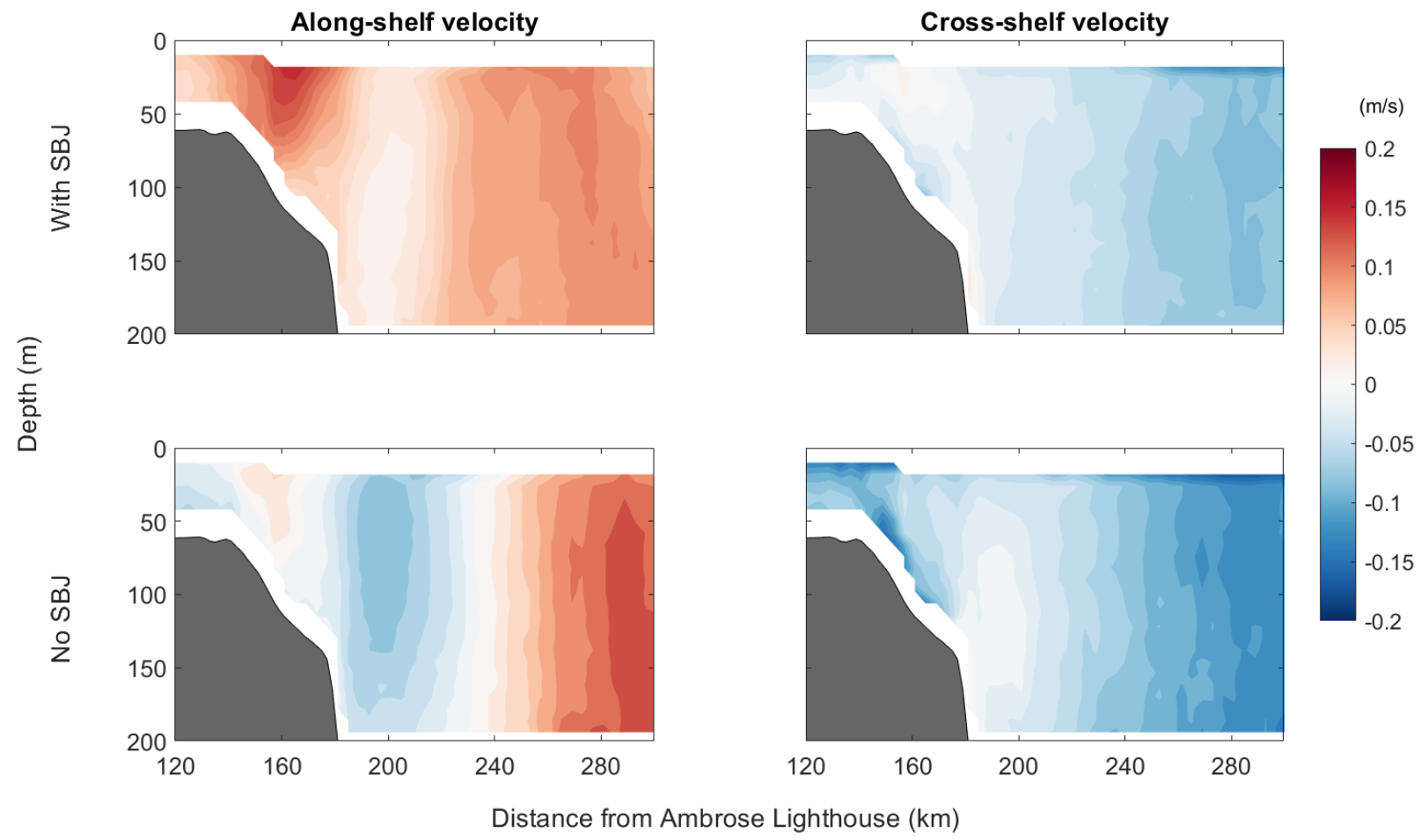

Figure 3-12: Eulerian mean along-shelf velocity (left column) and cross-shelf velocity (right column) during time periods when the Shelfbreak Jet is identified (top row), and time periods when the Shelfbreak Jet is not present (bottom row).

(Flagg et al., 2006), however, only in the mean velocity section generated from the transects with no Shelfbreak Jet do we see northeastward velocities adjacent to the shelf. These northeastward velocities abutting the shelf and adjacent to a Slope Jet, suggest an anti-cyclonic circulation which is the signature of a Warm Core Ring in the Slope Sea. This strongly suggests that Warm Core Rings can serve to disrupt the Shelfbreak Jet.

To examine this further, we construct composite maps showing SSH and SST anomaly fields one month before, during, and one month after we cannot identify the Shelfbreak Jet in an individual ADCP section (Figure 3-13). The composite SSH anomalies show a positive anomaly tracking from northeast of the Oleander line in the Slope Sea, to south of the Oleander line afterwards. This positive SSH anomaly resembles the signature of a Warm Core Ring on the slope, consistent with the along-shelf velocity signals observed in the conditionally-averaged ADCP sections. Using SSH eddy tracking (Chelton et al., 2011), when the Shelfbreak Jet cannot be identified, anti-cyclonic eddies are observed more frequently on the Oleander track in the Slope Sea as compared to time 

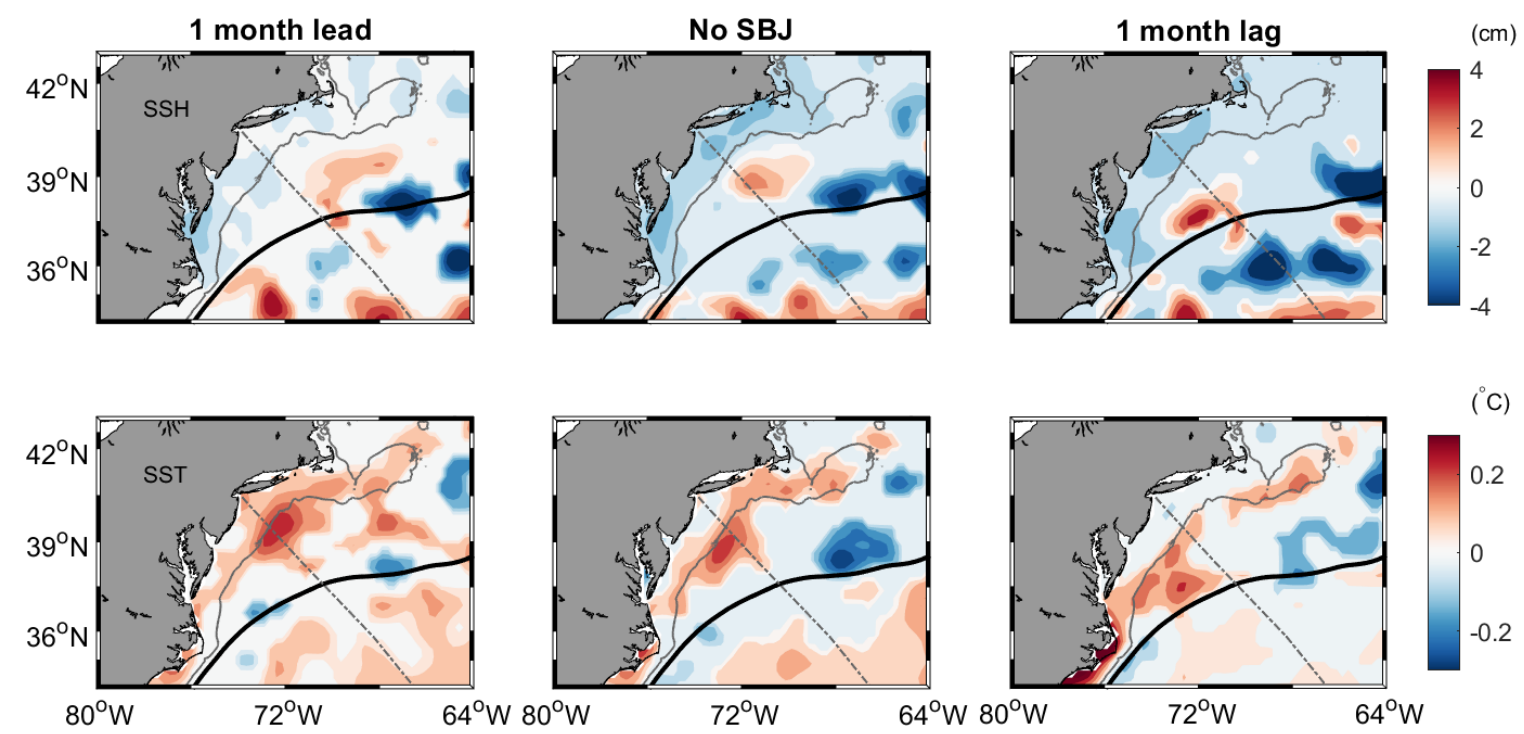

Figure 3-13: Composite maps of SSH anomalies (cm, top row) and SST anomalies $\left({ }^{\circ} \mathrm{C}\right.$, bottom row) around the times that the Shelfbreak Jet cannot be identified in the ADCP data. Composites are shown one month before (left column), concurrently with (middle column), and one month after (right column) the Shelfbreak Jet is not identified in ADCP sections with over $70 \%$ data return. Contours not shown if the mean standard errors overlap with zero. The grey dashed line is the Oleander path, the grey solid line is the $80-\mathrm{m}$ isobath, and the solid black line is the mean position of the $25 \mathrm{~cm} \mathrm{SSH} \mathrm{contour} \mathrm{which} \mathrm{is} \mathrm{a} \mathrm{proxy} \mathrm{for} \mathrm{the} \mathrm{position} \mathrm{of} \mathrm{the} \mathrm{Gulf} \mathrm{Stream.} \mathrm{Note} \mathrm{the} \mathrm{color} \mathrm{bar}$ ranges are both halved from Figure 3-11.

periods when the Shelfbreak Jet is identified. Furthermore, the average azimuthal velocity of those eddies observed when the Shelfbreak Jet is not identified is almost twice that of the average azimuthal velocity of eddies observed during time periods when the Shelfbreak Jet is observed. Research is ongoing to study the impact of these individual tracked rings on the Shelfbreak Jet and shelfbreak region.

During time periods without the Shelfbreak Jet, there is also a broad negative SSH anomaly over the shelf, leading to a reduced SSH gradient across the shelf break. The amplitude of this reduced SSH gradient supports a $0.04 \mathrm{~m} \mathrm{~s}^{-1}$ reduction in SSH-derived geostrophic velocity relative to the total mean SSH-derived geostrophic velocities across the shelf break. The total in-situ velocity difference at the shelf break between time periods without the jet and the total Eulerian mean velocity is $0.09 \mathrm{~m} \mathrm{~s}^{-1}$, suggesting that the change in SSH gradients only account for half of this observed difference. Here we find disruptions in the Shelfbreak Jet may also be in large part due to ageostrophic forces. Ageostrophic velocities have been calculated to make up significant con- 
tributions to Shelfbreak Jet meanders (Gawarkiewicz et al., 2004). We note that a simple linear superposition of an anti-cyclonic ring and a jet may also reverse the flow of the jet depending on the relative strength of both (Gawarkiewicz et al., 2001).

In addition to the positive SSH anomalies associated with times when there is no Shelfbreak Jet at the Oleander Line, we also see strong positive SST anomalies during these same time periods. The composite SST map shows a positive SST anomaly from Nantucket Shoals, through the entirety of the MAB one month before and during time periods without the Shelfbreak Jet. This anomaly signal then advects further south one month later. The warm anomalies over the slope are collocated with the SSH anomalies in the slope, which is consistent for a Warm Core Ring in the Slope Sea. Additionally, these positive SST anomalies are continuous from the Slope Sea into the Shelf, suggesting that there is a cross-shelf exchange process that drives the warmer slope water onto the shelf. This is consistent with the conditionally-averaged ADCP sections discussed above, which show that for times when the Shelfbreak Jet is absent, the (Eulerian) mean cross-shelf (onshore) flow is enhanced. During these same time periods without the Shelfbreak Jet, the ADCP measurements showed enhanced onshelf flow, which would allow for the Warm Core Ring water to advect onto the shelf.

\subsubsection{Interannual variability and connections with temperature}

Considering the warm SST anomalies concurrent with time periods without the Shelfbreak Jet, we would expect the velocities over the shelf break to be related to the shelf temperature. In order to study this relationship we utilize the velocity and temperature profile measurements from the Oleander. We create two velocity time series, one using the Eulerian framework and one using the stream coordinate framework. These time series are created by spatially averaging the top $50 \mathrm{~m}$ in each velocity transect in a $20 \mathrm{~km}$ region with the region differing in the two frameworks. In the Eulerian framework, we spatially average each transect's velocities in a region centered at the Eulerian mean location of the Shelfbreak Jet core (115-m isobath), and then define this time series as the velocity at the shelf break. For the stream coordinates framework, we only use the sections where we have identified the jet and spatially average the velocity data in a $20 \mathrm{~km}$ region centered at the the location of the identified Shelfbreak Jet. This stream coordinate framework we define as the time series of Shelfbreak Jet velocity. Lastly, we use a 12-month moving average for both to 
deseason and temporally grid the sections.

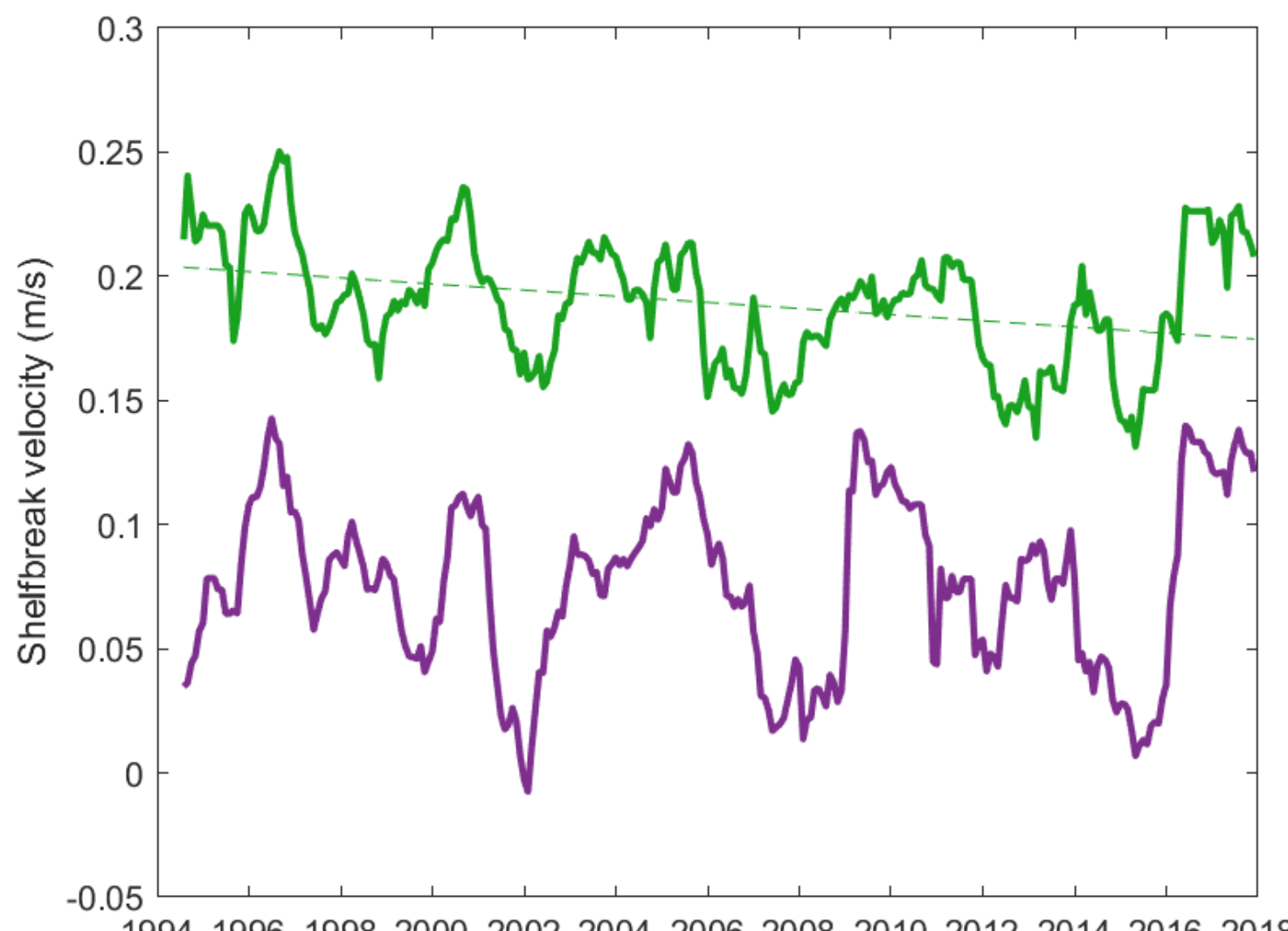

Figure 3-14: Time series of the velocity over the shelf break (purple) and Shelfbreak Jet velocity (green), as defined in section 3.4.33. Both time series are 12-month moving averaged. The dashed lines show the long term trends. Only the linear trend of the Shelfbreak Jet velocity is significantly different from zero.

Both the time series of the velocity over the shelf break and the Shelfbreak Jet velocity demonstrate large interannual variability (Figure $3-14$ ). The mean velocities at the shelf break are $0.07 \mathrm{~m} \mathrm{~s}^{-1}$ with a standard deviation of $0.035 \mathrm{~m} \mathrm{~s}^{-1}$. Minimum values of the velocity over the shelf break time series are below zero indicating poleward flow, while peak velocities reach $0.14 \mathrm{~m} \mathrm{~s}^{-1}$. Large changes due to persistent Warm Core Rings appear in the time series at the end of 2001 and during 2008, exhibited by the near zero velocity. The time series of Shelfbreak Jet velocity exhibits a mean of $0.19 \mathrm{~m} \mathrm{~s}^{-1}$ which is much higher than the mean velocity at the shelf break. However, the standard deviation of the Shelfbreak Jet velocity time series was lower at $0.025 \mathrm{~m} \mathrm{~s}^{-1}$. During the time periods when ring influences can be seen in velocity at the shelfbreak, we do not see anomalous deviations 
of the Shelfbreak Jet velocity time series as they are filtered out in the identification method.

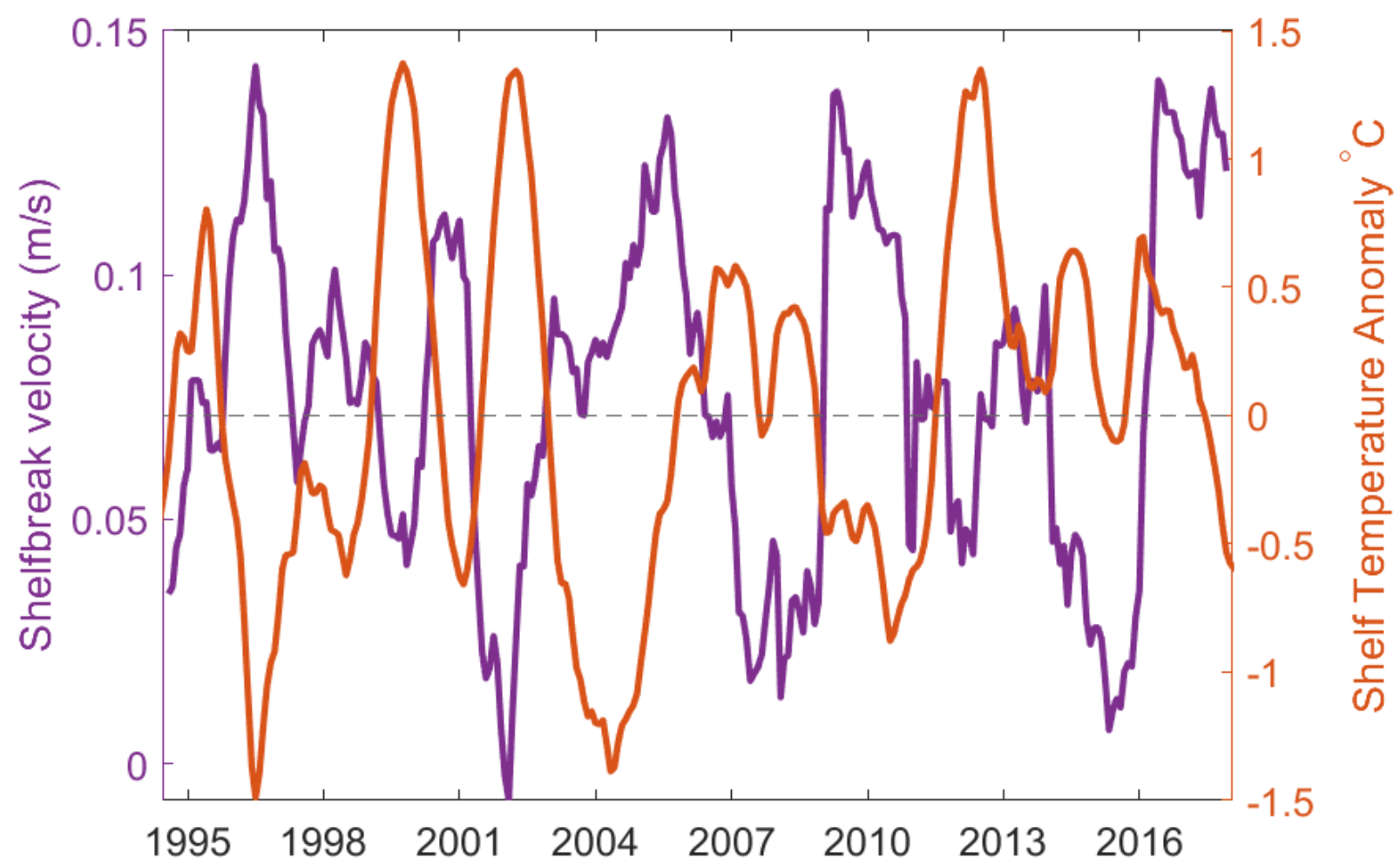

Figure 3-15: Time series of the velocity over the shelfbreak (purple) and temperautre on the shelf (red). Both time series are deseasoned with a 12-month moving average. The two time series are significantly anti-correlated $(\mathrm{p}<0.05)$ with a 1-3 month lag, with velocity leading temperature.

The methodology for defining the time series of shelf temperatures was previously described in Forsyth et al. (2015). This temperature time series only uses observations on the shelf, defined as onshore of the $80-\mathrm{m}$ isobath. In this study, we use a 12-month moving average on the monthly shelf temperatures instead of an annually averaged value. Here we compare the time series of velocity at the shelf break with shelf temperature. These two time series are maximally and significantly correlated at a 2-month lag, with velocity leading temperature $\left(r^{2}=0.29, p<0.05\right.$, Figure 3-15). This correlation is significant at the $95 \%$ confidence level accounting for effective degrees of freedom due to autocorrelation, from a 1-month to a 3 -month lag, and is significant at the $90 \%$ level from a 1-month lead to a 5-month lag.

Enhanced along-shelf velocities lead cold time periods on the shelf, while decreased along-shelf velocities precede warmer time periods on the shelf. The difference in shelfbreak velocities in cold 
and warm periods is on average $0.03 \mathrm{~m} \mathrm{~s}^{-1}$. Stronger along-shelf flows would enhance the transport of cooler waters from upstream. Warm Core Rings are another possible reason for the correlation between Shelfbreak Jet velocities and temperature. A Warm Core Ring impinging on the shelf can both increase the temperature on the shelf and reduce/reverse the Shelfbreak Jet velocities. As discussed previously, when the jet is not identified, there is enhanced onshore flow. A warmer shelf is consistent with enhanced slope water transport onto the shelf, especially if ring water remains in the Slope Sea.

This connection between temperature and velocity is made more clear looking across the entire shelf and slope. Here we show the Eulerian surface (top 50-m) along-shelf velocities and temperatures, using the same methodology as the time series above, with the exception that we do not spatially average these data (Figure 3-16). Cross-shelf velocities are not shown as the variability is small relative to the along-shelf velocity variability. During periods of time with cold anomalies on the shelf, the Shelfbreak Jet is clear, while during warmer time periods the Shelfbreak Jet is not as clearly seen. This is consistent with our Shelfbreak Jet identification, where during cold periods the Shelfbreak Jet is identified $68 \%$ of the time, and only identified $57 \%$ of the time when the shelf is warm. The continuous Shelfbreak Jet in cold time periods is also consistent with an advective mechanism driving along-shelf advection of cooler waters. Stronger and more consistent transport of cooler upstream waters to the MAB shelf could reduce the temperature on the shelf.

Warm time periods are often associated with an anticyclonic velocity signature over the slope, with north-east velocities adjacent to the shelfbreak. When rings are observed in the along-shelf velocity, we can see a concurrent warm anomaly in temperature over the slope and shelf. During 4 of the 6 warm periods identified, (1995, 1999-2000, 2002, and 2008) we can see Warm Core Rings abutting the shelf for at least some portion of time, with 3 of these time periods beginning with Warm Core Rings over the shelf. Of the 2 remaining warm periods identified without Warm Core Rings, the warming beginning in late 2011 has been documented and discussed as primarily being caused by atmospheric forcings (K. Chen, Gawarkiewicz, et al., 2014). While many of the warm time periods can be attributed to oceanic and atmospheric processes, the variability driving cooling time periods has not been the focus of much research, and remains an open question. 

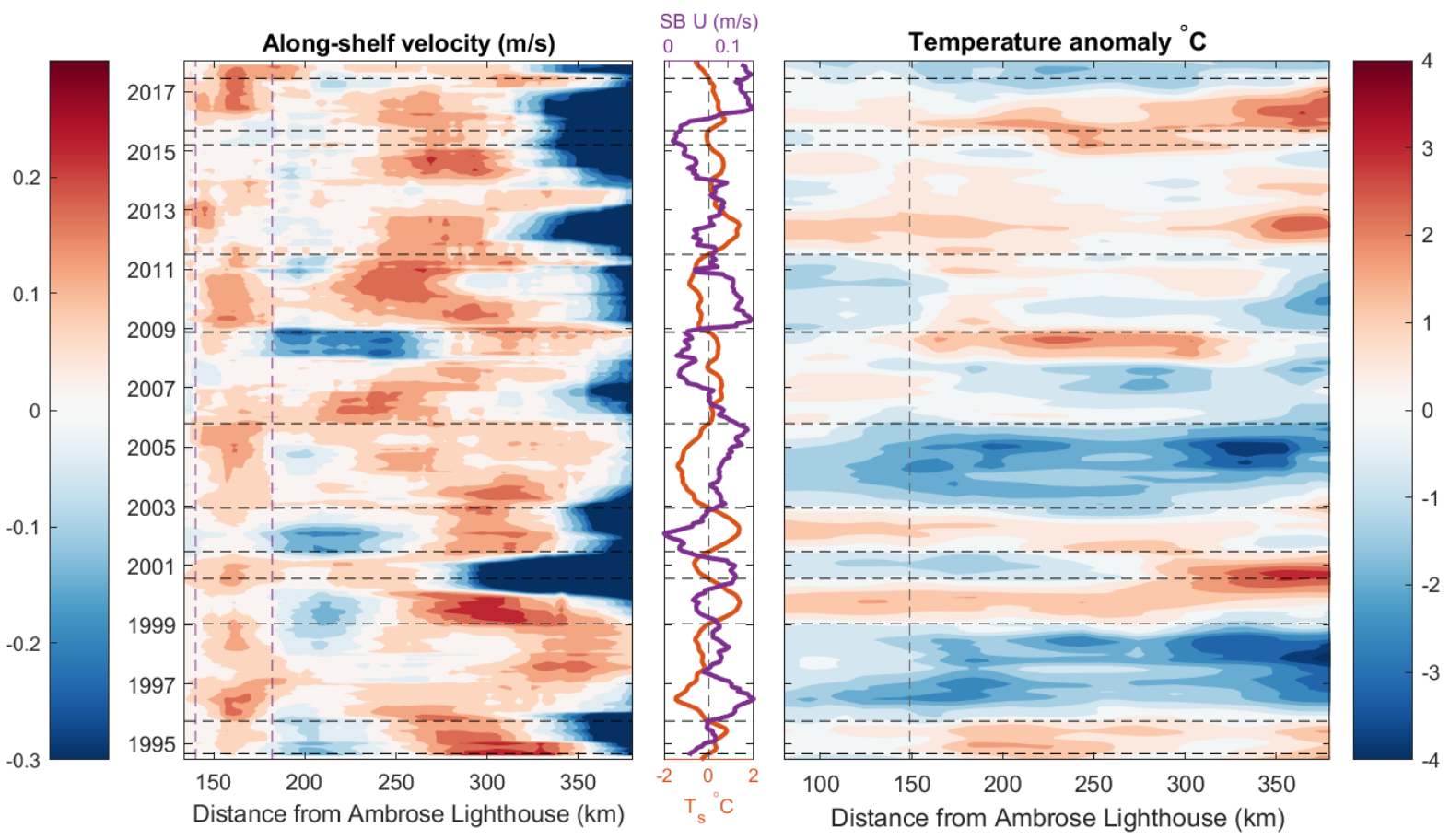

Figure 3-16: Hovmuller diagram of the upper $50 \mathrm{~m}$ along-shelf velocity (left contour plot) and upper $50 \mathrm{~m}$ temperautre (right contour plot). The middle panel shows a time series of the mean shelfbreak velocities from 140-182 m (purple dashed lines in left panel) and upper $50 \mathrm{~m}$ in purple and the mean shelf temperatures onshore of the $80 \mathrm{~m}$ isobath in red (vertical grey dashed line in left and right contour plots). 


\subsubsection{Long term Shelfbreak Jet Variability}

There is no significant long term trend in the time series of the velocity at the shelf break. In contrast, the Shelfbreak Jet velocity time series has decreased in velocity over the 27 years of data (Figure 3-14). We estimate a statistically significant reduction in velocity of $0.03 \mathrm{~m} \mathrm{~s}^{-1}$ over the entirety of the data set. This may be related to a reduction in density gradients across the front. Using the XBT data from the Oleander between 1992-2018, we calculated the average trend in temperature on either side of the mean position of the Shelfbreak Jet. The temperature offshore of the Jet is warming faster than onshore of the Jet, which is consistent with other studies of warming rates on the MAB (Z. Chen et al., 2020). Using the thermal wind equations, assuming that the salinity gradients have not changed and a depth scale of $80 \mathrm{~m}$ for the Shelfbreak Jet, the change in average Shelfbreak Jet velocities due to the changing temperature gradient is a reduction in the Shelfbreak Jet velocity of $0.01 \mathrm{~m} \mathrm{~s}^{-1}$. While this does not account entirely for the decreasing velocity trend over 27 years, it suggests that the warming of the Slope Sea is reducing the velocity of the Shelfbreak Jet.

\subsection{Conclusion}

The data collected by the $C M V$ Oleander have provided a unique opportunity to observe the Shelfbreak Jet over the span of two and half decades. Over the 25 years, we use 1362 velocity transects, allowing us to resolve time scales from individual events, to monthly variability, to long term variability. We focus on analyzing patterns in the velocity data, looking at time periods when the Shelfbreak Jet is shifted in position, or when it does not exist in an ADCP transect. These analyses are able to capture the composite impact of individual events on the Shelfbreak Jet, as well as look at variability that exists within and between years.

Throughout our results, we have demonstrated that the signature of Warm Core Rings are present during many phases of Shelfbreak Jet variability. Both when the Shelfbreak Jet is found onshore of its mean position, as well as during time periods when the Shelfbreak Jet cannot be identified, we see ADCP velocity, and satellite SST and SSH signals that would suggest Warm Core Ring influence. Additionally, the most distinct Warm Core Rings in the velocity data, occur during time periods that are anomalously warm on the shelf, suggesting that Warm Core Rings are 
influencing both the velocity and temperature structure at the shelf break and on the shelf. With increasing numbers of Warm Core Rings since 2000, understanding how these impact the shelf break is growing in importance (Gangopadhyay et al., 2019).

We have found that the Shelfbreak Jet is not a permanent feature, but without simultaneous measurements of temperature and salinity with depth, it is unknown to us how the Shelfbreak Front is impacted during time periods when the Shelfbreak Jet is not identified. If the same processes which shutdown the Shelfbreak Jet also disrupt the Shelfbreak Front, then the non-permanence of these features is crucially important. When these features don't exist, there would be no frontal convergence near the bottom (Houghton \& Visbeck, 1998). Without the convergence, the upwelling of nutrients leading the shelf break to be a productive ecological region would be temporarily reduced. Due to limitations of the shipboard ADCPs in taking measurements near the bottom, we are not able to resolve this convergence, and thus require additional measurements to resolve the relationship between the frontal upwelling and the shutdown of the Shelfbreak Jet.

Average shelf temperatures are also heightened during time periods with a weaker Shelfbreak Jet. Both Warm Core Rings and upstream advective processes are likely influencing the temperature on the shelf. The relative contribution of Warm Core Rings and along-shelf advection on both the shelf temperature and velocity structure remain a question that is of import to study. The shelf break region has economically significant fisheries that are potentially vulnerable to ocean warming and changes in shelf break exchange processes (e.g. Hare et al., 2016; Gawarkiewicz et al., 2018). Recent temperature variability has also influenced the stock distribution of fisheries in the Northeast United States, with certain species recruitment being correlated to temperature (K. Friedland, 2012; Gawarkiewicz et al., 2013; Miller et al., 2016). Understanding the connection between the temperature variability and Shelfbreak Jet system could be important to management of living marine resources in the shelf break region.

We have diagnosed the structure of the mean velocities over the New Jersey shelf break, as well as the mean Shelfbreak Jet velocities. From our climatologies, we have shown that both the structure of the Shelfbreak Jet, and the maximum jet velocity show large seasonal variability. The jet undergoes time periods where it is shifted onshore and offshore, as well as when it can be identified in a velocity transect and not. These variations appear to be forced in part by individual events like Warm Core Rings. Larger scale processes may also be impacting the Shelfbreak Jet such as 
upstream advective flows from the Labrador Sea. The Shelfbreak Jet undergoes variability on time scales of days to decades, and in an ever changing system, it is important to understand the drivers of the variability. 


\section{Chapter 4}

\section{The impact of Warm Core Rings on}

\section{Middle Atlantic Bight shelf temperature}

\section{and Shelfbreak Jet velocity}

\subsection{Abstract}

Warm Core Rings (WCR) are known to disrupt the shelf flow as well as drive strong heat transport onto the Middle Atlantic Bight shelf. We use 16 rings from the $C M V$ Oleander data to study the variability in how different rings impact the shelf break velocities, as well as the temperature on the shelf. WCRs that have higher velocities and are closer to the shelf are found to exert greater influence on the MAB shelf's along-shelf velocities, with the fastest and closest rings reversing the direction of flow at the shelf break. As rings approach the study site, the Shelfbreak Jet is faster than when the rings are about to exit the study site, likely due to steepening then flattening of the isopycnals at the Shelfbreak Front. Rings also have lasting impacts on the shelf temperature, with faster rings cooling the shelf and slower rings warming the shelf. The change in temperature on the shelf as a ring passes is strongly tied to the seasonal cycle. The warmer seasons which have large temperature stratification on the shelf are cooled and time periods when the thermal stratification is weak tend to warm from rings. Rings which cool the shelf additionally have increased upwelling as they pass the study site. 


\subsection{Introduction}

Warm Core Rings (WCR) form from large meanders of the Gulf Stream that get pinched off, leaving an anti-cyclonic eddy of warm salty Gulf Stream water which advects into the Slope Sea and can interact with the shelf. In chapter 3, rings were found to be one of the main drivers for the variability of the Shelfbreak Jet, determining when the Shelfbreak Jet was observable, as well as shifting the Shelfbreak Jet onshore. Since 2000, more rings have been observed to be formed from the Gulf Stream, leading to the possibility that there are greater disruptions to the shelf system (Gangopadhyay et al., 2019). With more rings each year, understanding how rings are able to impact the shelf is increasingly important.

Early studies of WCRs used combinations of limited in-situ observations with satellite thermal imaging to study the properties of the rings and how they interact with the shelf (e.g. Morgan \& Bishop, 1977; Bisagni, 1983; Joyce, 1984; Churchill et al., 1986). These studies focused heavily on quantifying the dynamical properties of the rings, while also estimating cross-shelf fluxes by looking at warm streamers which cross onto the shelf. Estimates of the cross-shelf heat flux during rings suggest that they play a key role in the yearly heat budget for the shelf (Morgan \& Bishop, 1977). Individual shelf streamers were also observed to carry a significant portion of the annual slope water transport to the shelf as estimated from salinity (Churchill et al., 1986). The cross-shelf water mass exchange is modified by both warm streamers moving onto the shelf, and also cold streamers being pulled off of the shelf by WCRs (Joyce et al., 1992; Wei et al., 2008; Cenedese et al., 2013). Cold streamers have been estimated to transport approximately $1 \mathrm{~Sv}$ offshore, depositing the water between the ring and the Gulf Stream.

Observations on the shelf have shown that WCRs impact the shelf circulation and the Shelfbreak Jet (e.g. Beardsley et al., 1985; Pickart et al., 1999; Gawarkiewicz et al., 2001). Pickart et al. (1999) found that a WCR forced a large meander in the Shelfbreak Jet pushing the jet onshore, while Gawarkiewicz et al. (2001) observed that the Shelfbreak Jet was accelerated/slowed on the leading/trailing edge of the ring. Recent modeling studies have also been able to describe individual processes which led to enhanced cross-shelf transport and disruptions of the shelf circulation (K. Chen, He, et al., 2014; Zhang \& Gawarkiewicz, 2015). In particular, Zhang and Gawarkiewicz (2015) described one process by which ring water intrudes directly onto the shelf through a "Pinoc- 
chio's nose" intrusion which resulted from vorticity variation within a warm limb of the ring.

One of the main limitations shared by studies on WCRs to date is that they are typically limited to studying the dynamics of one or two rings. Utilizing data from the Container Motor Vehicle $(C M V)$ Oleander gives repeat weekly transects since 1992, allowing for the study of many rings observed from the same observational platform. Additionally, the $C M V$ Oleander is equipped with instrumentation to measure water velocity and temperature with depth, and surface temperature and salinity, such that both dynamical and hydrographic properties of the ring and shelf system can be quantified. Observing many rings then allows us to describe how rings can differ from each other, and how rings with varying properties are able to impact the shelf and shelf break.

We describe the data from the $C M V$ Oleander and how we use this data to identify ring transects in section 4.3.1. Additionally, section 4.3.2 details data derived from satellites including eddy tracking of the WCRs. The impact WCRs have on shelf circulation and parametric dependencies between different WCRs is discussed in section 4.4.1. We examine the lasting impact of rings on shelf temperature by examining the conditions before and after a ring passes in section 4.4.2. Section 4.5 summarizes our findings.

\subsection{Methodology}

\subsection{1 $C M V$ Oleander}

The $C M V$ Oleander has recorded upper ocean velocity data since 1992 on it's weekly trips between Port Elizabeth, New Jersey and Bermuda, making this dataset uniquely suited to studying multiple rings and the differences between the dynamics of various rings (Figure 4-1. In addition to the ADCP data, there are temperature profiles from expendable bathythermographs (XBTs) approximately once a month since 1977, and in 2000 a thermosalinograph began measuring the surface temperature and salinity. Detailed descriptions of the data acquisition, quality control, and gridding methodology for the ADCP and XBT data are described in Chapter 3. Minor changes to the methodology implemented to better study individual rings are described here.

For the ADCP data, we modify the gridding from Chapter 3 based on individual rings to retain as high a resolution as possible. The horizontal grid scale is increased to $3 \mathrm{~km}$ bins, and the vertical resolution is reduced to $4 \mathrm{~m}$ on the shelf and $8 \mathrm{~m}$ in deeper regions. Data that was acquired with 
coarser vertical resolution are binned at the resolution it was acquired and then linearly interpolated to the vertical resolution above. The data are rotated in the along-shelf (southwest) and cross-shelf (southeast) direction (axis in Figure 4-1).

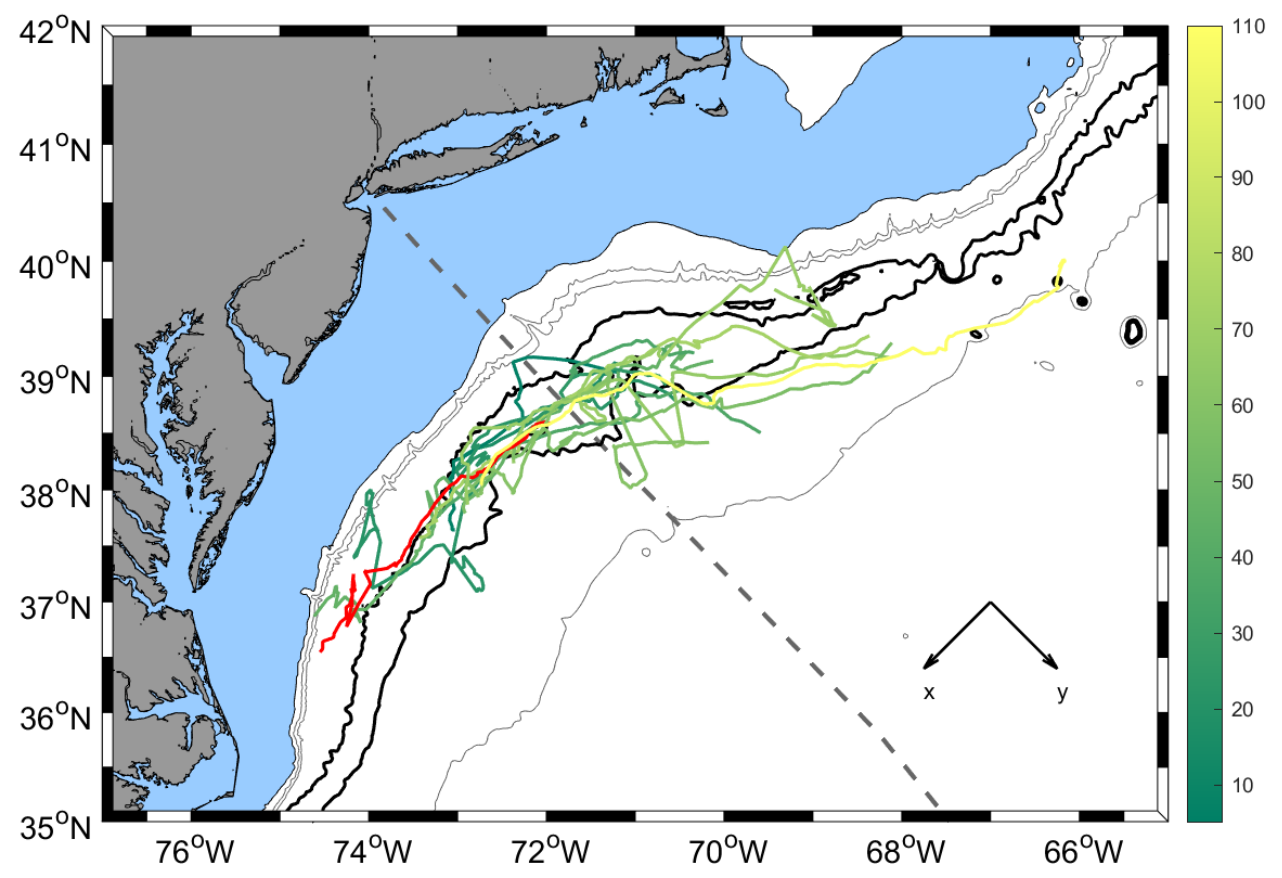

Figure 4-1: Eddy tracks of the 14 WCRs (of our 16 total) that can be identified using the Chelton eddy tracks. Colors indicate the age of the ring when it crosses the $C M V$ Oleander Line (Chelton et al., 2011). One ring track does not cross the Oleander Line in the Chelton Tracks and is plotted in red. The axes are shown in the bottom right. Contours of the 100, 500, and 4000-m isobath are plotted in grey, with the 2400 and 2900-m isobath plotted in black. The shelf region, less than $100 \mathrm{~m}$ depth, is shaded in blue. The grey dashed line shows the Oleander Line.

XBT data are gridded on a $30 \mathrm{~km}$ by $10 \mathrm{~m}$ horizontal and vertical grid. This is coarser than the grid used in our previous analyses with these data, but is more representative of the resolution of the raw data during the time period when most rings were observed in this dataset. We do not use any data filling techniques for the XBT sections in order to preserve the signals from individual events (which would otherwise be smoothed towards a climatology to fill missing temperature profiles). The temperature impact that the rings have on the shelf is quantified using temperature anomalies. To calculate the shelf temperature anomalies, we remove the seasonal signal from the gridded data. This is done by calculating average temperature sections for each month using the entirety of the XBT data, and then subtracting this average monthly temperature section from the gridded data 
in the corresponding month. Finally, we calculate a spatially averaged temperature anomaly for the region onshore of the $100 \mathrm{~m}$ isobath.

In order to study individual Warm Core Rings, we cull the ADCP data to find which rings are sampled by multiple velocity transects. A section with a ring is defined by having two local maximums of depth averaged along-shelf velocity greater than $|0.15| \mathrm{m} \mathrm{s}^{-1}$. The onshore local maximum must have velocity in the northeast direction, with the further offshore velocity maximum in the southwest direction, thus identifying an anti-cyclonic velocity signature. Lastly, we include sections without anti-cyclonic velocity signatures if they are consistent with the velocities anticipated on the leading and trailing edge of the ring, and occur before and after sections with anti-cyclonic velocity respectively. On the leading edge of the ring, the cross-shelf velocities are onshore, and on the trailing edge of the ring the cross-shelf velocities in the ring are offshore (Figure 4-5). We identify 16 rings that are sampled by 5 or more ADCP sections and their properties are summarized in Table B.1. These rings occur between 1997 and 2008. After the ring ADCP sections are selected, we compile all available TSG and XBT data that occur before, during, and after each individual ring. TSG data are only available for 8 rings, while XBT data are partially available for all the rings. 12 rings have XBT data within one month before and also within one month after the ring has passed through the $C M V$ Oleander Line, while 13 rings have XBT data in the ring.

\subsubsection{Satellite Data}

Satellite data have been a tool used by many studies to study rings using both SST and sea surface height (SSH) data. For SST we use National Oceanographic and Atmospheric Administration (NOAA) Optimum Interpolation (OI) $\frac{1}{4}^{\circ}$ daily SST (AVHRR-only; Reynolds et al. (2007)). We use daily mapped absolute dynamic topography at $\frac{1}{4}^{\circ}$ resolution, available through E.U. Copernicus Marine Environmental Monitoring Service to provide sea surface height (SSH) data, and SSH-derived geostrophic velocities.

Additionally, we use eddy tracks from Chelton et al. (2011) to study the path that each ring takes to reach the Oleander Line. 2 of the 16 rings cannot be found in the eddy tracks as they do not last for 28 days as required to be included in the Chelton eddy tracks. For the remaining 14 rings for which we do have the Chelton tracks, we calculate the age of the ring, or how long each ring has existed before it crosses the Oleander Line (colored lines in Figure 4-1). If a ring crosses 
the Oleander Line multiple times, we calculate the age of the ring as the crossing when the ring is closest to the shelf break. The age of the ring ranges from 6 to 109 days, with one ring never crossing the Oleander Line (in the Chelton tracks). The ring which does not cross the Oleander Line was formed just south of the Oleander Line and stayed within the region long enough that there are over 5 sections of ADCP data through the ring despite the center never crossing over the Oleander Line. All but one of the rings intersect with the Oleander Line between the 2400 and the 2900-m isobaths. The rings are tightly bounded by these isobaths, showing how topographically trapped the WCRs are.

To compare the azimuthal velocity derived from the SSH fields in the Chelton tracks, we compute the maximum speed in each ring as a proxy for azimuthal velocity, assuming the predominant motion within the rings is azimuthal and not radial. We find an average difference between the azimuthal velocity derived from SSH and our maximum speed of $0.5 \mathrm{~m} \mathrm{~s}^{-1}$. This shows a limitation of SSH fields to accurately reflect the flows within rings. Comparisons between $C M V$ Oleander ADCP data and SSH fields have shown good agreement in regions of low variance, however, in regions with higher variance, i.e. energetic rings, the consistency between the two measurements are reduced (Worst et al., 2014).

\subsection{Results}

\subsubsection{Warm Core Ring impact on shelf break velocities}

In total, for the $16 \mathrm{WCRs}$, we have 151 velocity sections within the WCRs. From these 151 velocity sections we create an Eulerian mean WCR section (Figure 4-2). Flow is primarily in the along-shelf direction, with weak onshore velocities throughout the slope and shelf. Net onshore flow over the slope is likely a result of having more sections on the leading edge of the ring where flow would be expected to be in the onshore direction (Figure 4-5). The northeastward velocities of the mean Eulerian WCR section show enhanced flow subsurface with maximum velocities at around $80 \mathrm{~m}$. The mean velocity field represented by this Eulerian average is of limited use, as the different rings we study have large variations in velocity structure and our sub-sample of 16 rings (a small fraction of the total rings that cross the Oleander Line, but are not well-sampled by the ADCP) may not accurately represent the distribution of velocities that would be observed from a larger sample of 
rings.

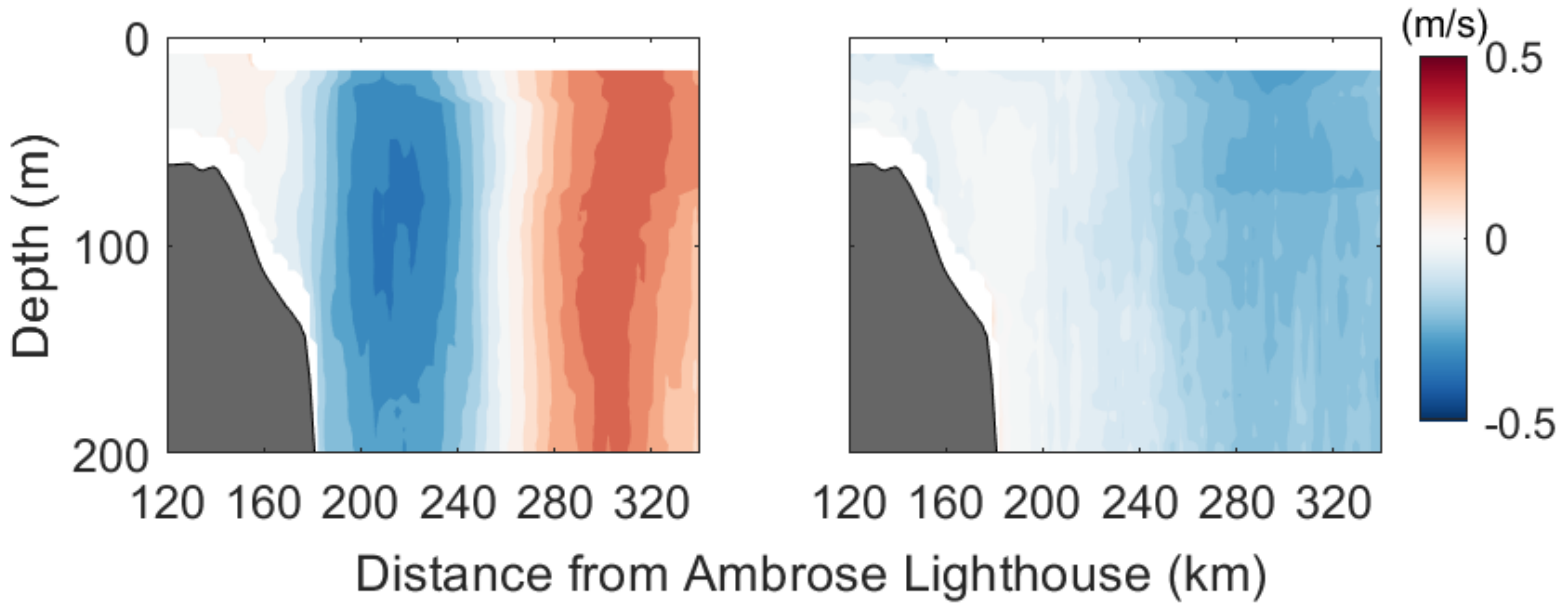

Figure 4-2: Eulerian mean along-shelf velocity (left column) and cross-shelf velocity (right column) from 151 sections during WCRs.

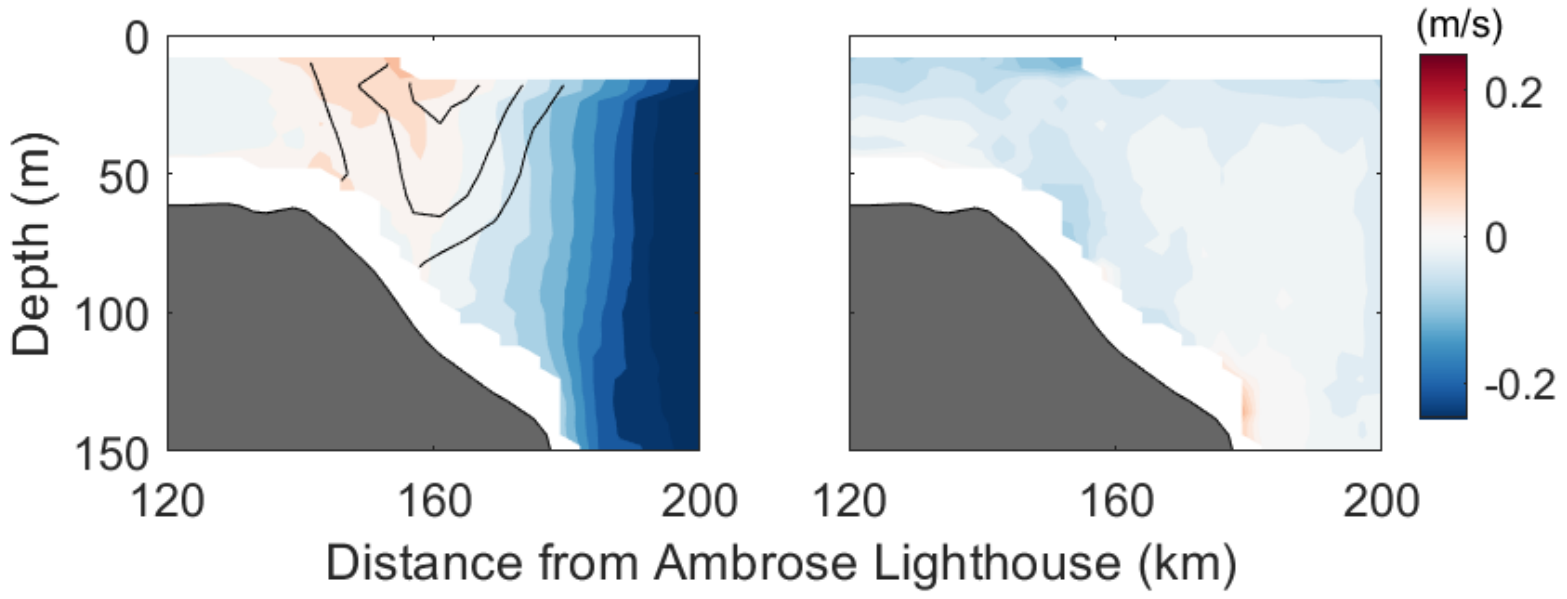

Figure 4-3: Eulerian mean along-shelf velocity (left column) and cross-shelf velocity (right column) from 151 sections during WCRs. The color bar is half the range as Figure 4-2. Black contours are the $0.06,0.08$, and $0.10 \mathrm{~m} \mathrm{~s}^{-1}$ isotachs calculated from the Eulerian mean along-shelf velocity (Figure $3-2)$.

Focusing on the velocity structure over the shelf onshore of the WCR, the 151-section Eulerian mean shows a Shelfbreak Jet during time periods when WCRs are in the Slope Sea (Figure 4-3). In comparison to an Eulerian mean calculated for all 1362 sections (Figure 3-12), the Eulerian mean Shelfbreak Jet during WCRs is shifted onshore, is narrower, and has weaker transport, but a similar 
maximum velocity. This is consistent with the hypothesis in Chapter 3 that WCRs can shift the Shelfbreak Jet onshore and is consistent with past research on rings (Pickart et al., 1999). Overall, we still find an Eulerian mean Shelfbreak Jet during WCR indicating that not all WCRs reverse the flow at the Shelfbreak Jet as found from past studies of individual rings (Beardsley et al., 1985; K. Chen, He, et al., 2014; Zhang \& Gawarkiewicz, 2015). In order to understand how rings impact the shelf flows, we need to look at individual rings instead of the average of all rings, as well as where the ring is in reference to the Oleander Line.

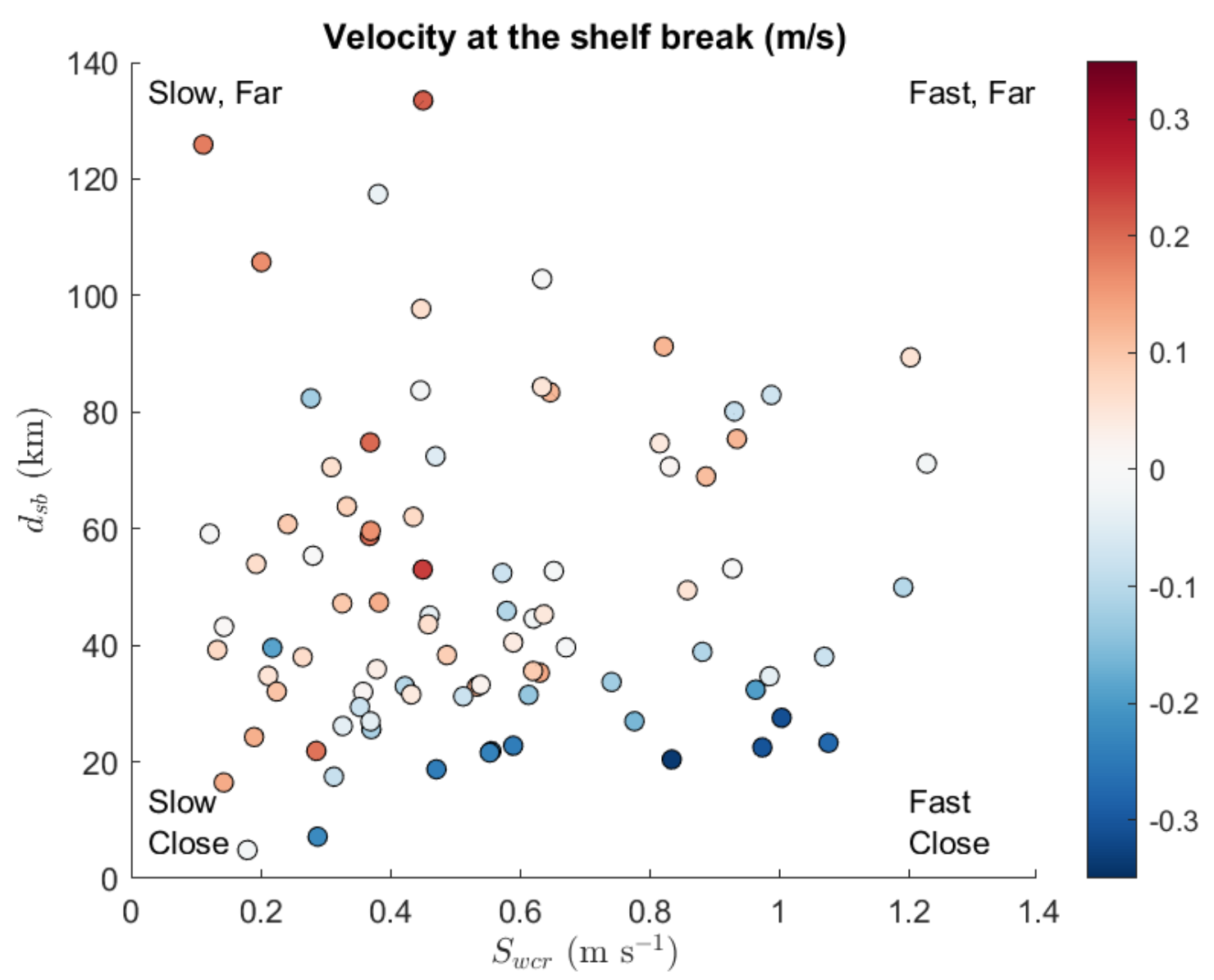

Figure 4-4: The velocity at the shelf break plotted in colors, as a function of the ring speed $\left(S_{w c r}\right.$, $\mathrm{x}$-axis) and distance from the shelf break $\left(d_{s b}, \mathrm{y}\right.$-axis $)$. A linear regression model show both independent variables have significant relationships to the velocity at the shelf break $(\mathrm{p}<0.01)$.

To examine individual rings and their impact on the shelf, rather than focus on a composite average, we calculate several ring and shelf parameters and examine how they co-vary. We calculate the ring speed, $S_{w c r}$, by finding the maximum northeast and southwest depth-averaged velocity 
(top $100 \mathrm{~m}$ ) in each ring section and then average the absolute value of these two depth-averaged velocities. To calculate the ring radius, $r_{w c r}$, we identify the isotach that is half the ring speed and calculate the distance between this isotach on either side of the ring and divide in half. Using this isotach, we also calculate $d_{s b}$, the distance of the onshore edge of the ring to the shelf break. The ring speeds of our 16 rings range from $0.22 \mathrm{~m} \mathrm{~s}^{-1}$ to $0.88 \mathrm{~m} \mathrm{~s}^{-1}$ with the ring radii ranging from $50 \mathrm{~km}$ to $85 \mathrm{~km}$ radius.
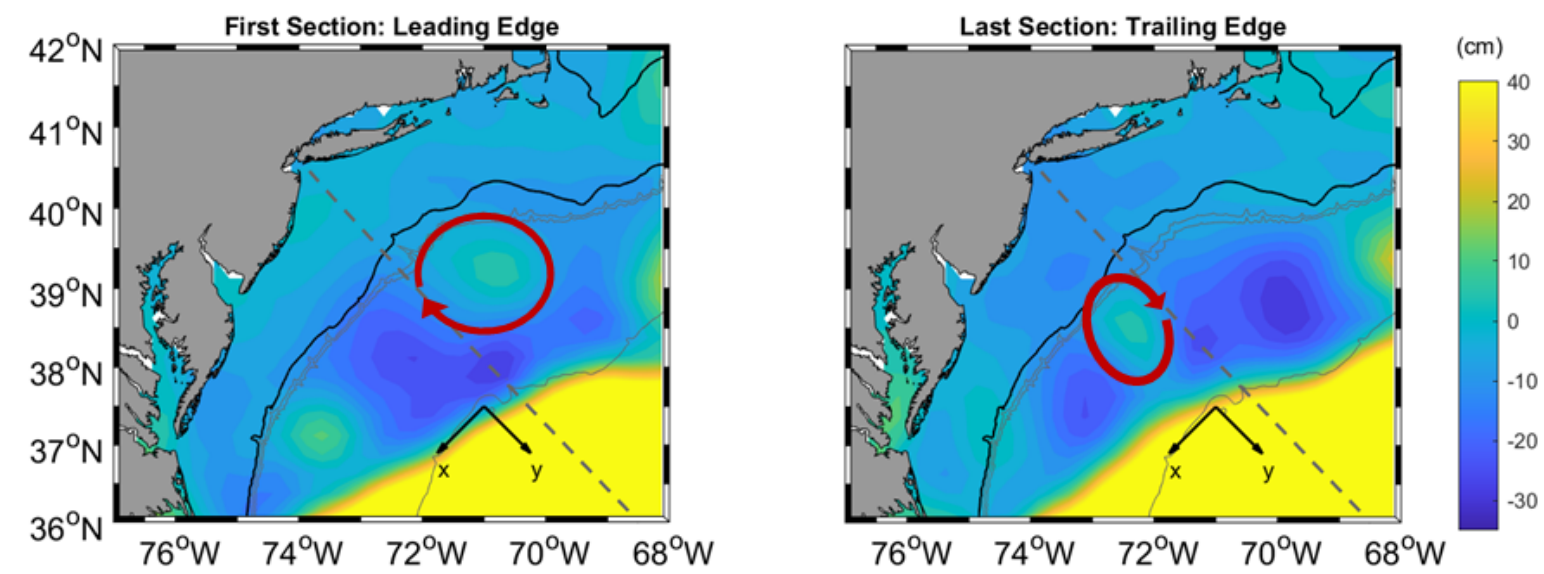

Figure 4-5: Sea surface height colored contours for a ring passing the Oleander Line from August 7th, 1999 to September 15h 1999. The left panel shows the leading edge of the ring, and right panel shows the trailing edge of the ring. Red lines show the circulation of the ring.

In order to quantify the impact of rings on the shelf velocity structure, we calculate the velocity at the mean position of the Shelfbreak Jet by averaging the along-shelf velocities in a box based on the e-folding scale of the Shelfbreak Jet (methodology described in Section 3.4.3). We linearly regress the velocity at the shelf break onto $S_{w c r}$ and $d_{s b}$, finding significant linear relationships with the two variables $(\mathrm{p}<0.01)$. This relationship indicates that the faster and closer a ring is to the shelf break, the more negative (northeast) the along-shelf flow is. Cases when the ring is slow and far from the shelf break tend to have a shelf break velocity that it is more typical of mean shelf break conditions (Forsyth et al., 2020). It is important to note that $S_{w c r}$ and $d_{s b}$ are not correlated with one another (despite each one's correlation with flow at the shelf break). Repeating the regression calculations with the shelf's maximum along-shelf velocity (rather than velocity at the shelf break), results in similar relationships, where faster and closer rings are associated with reduced along-shelf velocities. 
Reversal of the velocities at the shelf break do not necessarily imply that the Shelfbreak Jet does not exist. As discussed in chapter 3, the jet is not always able to be identified, however, that does not mean that the geostrophic dynamics are not present. Assuming a linear interaction between the ring and the jet, the larger ring velocities would overwhelm the jet velocities leading to an observed reversal at the shelf break. Additionally, the weaker velocities on the shelf during rings could be due to a far onshore shift of the Shelfbreak Front, as was observed in a ring in 2017 with the front moving onshore to the 40-m isobath (Gawarkiewicz et al., 2019).

Details of a ring's impact on the velocity field at the Oleander Line likely evolves as the ring crosses the Oleander Line (Figure 4-5). To examine this impact of the timing and evolution of the velocity field, we calculate composite averages of the Eulerian mean velocity fields using the first velocity transect observed from each of the 16 rings, and the last velocity transect observed of each ring (Figure 4-6). The composite averages suggest that at the leading edge of the ring, crossshelf velocities are all onshore within the ring and over the shelf (Figure 4-6 (b)). In the Eulerian means using the final section of each ring, the cross-shelf velocity shows a strong divergence at the location of the equatorward flows in the along-shelf velocity which is the Shelfbreak Jet (Figure 4-6 (c-d), at $175 \mathrm{~km}$ ). This divergence of the cross-shelf velocities can be seen in each individual ring's last transect with onshore velocities at the shelf break, and offshore velocities in the ring over the slope. The reason for this divergence is not fully known. The offshore velocities over the slope are consistent with the ring velocities, and the onshore velocities on the shelf are consistent with the Eulerian mean shelf flows within this region. This divergence is located at the location of the maximum equatorward flows, and is likely associated with the deflection of the Shelfbreak Jet offshore.

We estimate the upwelling at the trailing edge of the ring in this frontal region between shelf and ring water. We assume the divergence at the surface is equivalent to that at our most surface bin $(16 \mathrm{~m})$ and also assume that the vertical velocities are zero at the surface $(\mathrm{z}=0)$. Given those assumptions, we can calculate the upwelling from the rearranged continuity equation

$$
w_{u p}=\left(\frac{\partial u}{\partial x}+\frac{\partial y}{\partial v}\right) \cdot d z
$$




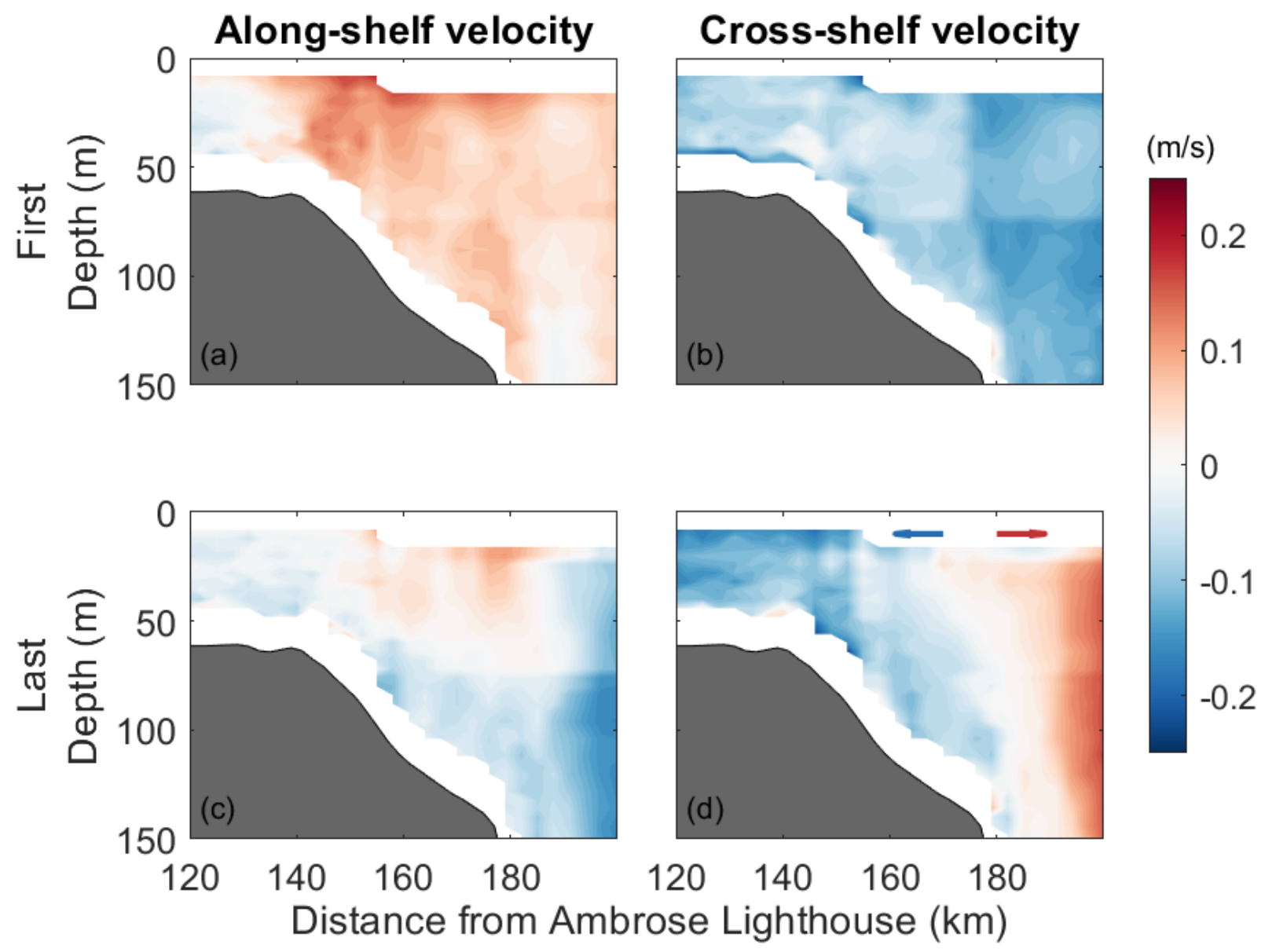

Figure 4-6: Composite averages of along-shelf velocity (left column) and cross-shelf velocity (right column) during the first ring section of each ring (top row), and during the last ring section of each ring (bottom row). In the cross-shelf velocity during the last ring section (d), we label the direction of the flow indicating divergence.

We use $\frac{\partial u}{\partial x}$ from a previous study of WCRs with a value of $-1 \cdot 10^{-5} \mathrm{~s}^{-1}$ (Gawarkiewicz et al., 2001). For rings with sufficient data in the last section of the ring, we calculate $\frac{\partial y}{\partial v}$ at each depth layer above $50 \mathrm{~m}$ and find the location of the maximum divergence. Next we take the depth averaged cross-shelf velocity divergence and use that value in equation 4.1 . The value for $d z$ used is $34 \mathrm{~m}$ which is the difference between the shallowest bin used and the deepest bin used.

This results in a range of $w_{u p}$ values between 9-100 $\mathrm{m} \mathrm{day}^{-1}$, and the average of the 16 rings $w_{u p}$ as $63 \mathrm{~m} \mathrm{day}^{-1}$. Our values are generally larger than a previous calculation on the trailing edge of a Warm Core Ring of approximately $20 \mathrm{~m} \mathrm{day}^{-1}$ (Gawarkiewicz et al., 2001). However, our ring with the weakest $w_{u p}, 9 \mathrm{~m} \mathrm{day}^{-1}$, is consistent with past research of upwelling in the Shelfbreak Front calculated from ADCPs and calculated in a dye release experiment (Barth et al., 1998; Houghton 
\& Visbeck, 1998). This ring has the weakest ring speed, and the Shelfbreak Jet can be observed in every individual transect during the ring. As this ring didn’t impact the Shelfbreak Jet, we believe our estimate of $9 \mathrm{~m} \mathrm{day}^{-1}$ to represent a time period where the shelf is not affected by the ring and thus the consistency with past research verifies that our estimates of upwelling are accurate to first order. Overall, we see a large increase in upwelling as the ring passes. Enhanced upwelling is typically associated with increased nutrients and chlorophyll, and past research has found increased chlorophyll and dense marine mammal sightings at the trailing frontal region of rings (J. P. Ryan et al., 1999; Griffin, 1999). The upwelling on the trailing edge of a ring may have large consequences for the ecology of the shelf.

Along-shelf velocities of the Shelfbreak Jet are strongest on the leading edge of the ring, with the maximum Eulerian mean velocities reaching $0.2 \mathrm{~m} \mathrm{~s}^{-1}$ in the surface layers (Figure 4-6 (a)). The Shelfbreak Jet at the leading edge of the ring is faster than the total Eulerian mean Shelfbreak Jet velocities, though with similar width and depth scales of $50 \mathrm{~km}$ and $80 \mathrm{~m}$ respectively (Figure 3-12). As the ring passes, we see the Eulerian mean Shelfbreak Jet velocities decrease and become narrower. In the Eulerian mean last section of the WCRs, the equatorward Shelfbreak Jet is surface trapped, with weaker velocities (Figure 4-6 (d)). The strengthening and weakening of the Shelbreak Jet as the ring approaches and then moves away is consistent with past research (Pickart et al., 1999; Gawarkiewicz et al., 2001). In Gawarkiewicz et al. (2001), the strengthening of the Shelfbreak Jet on the leading edge of the ring was due to the steepening of the isopycnals in the Shelfbreak Front while the weaker jet on the trailing edge of the ring was attributed to the flattening of the isopycnals in the Shelfbreak Front. This result also holds true without using composite averages. On average, the equatorward shelfbreak velocities are $0.05 \mathrm{~m} \mathrm{~s}^{-1}$ faster on the leading edge compared to the trailing edge.

The composite averages made from sections that sample the leading and trailing edges, respectively, of the rings show a Shelfbreak Jet when a ring approaches and leaves the Oleander Line. Creating a composite average from the sections that sample the middle of the ring, excluding the leading and trailing edges, has maximum equatorward flows at $0.05 \mathrm{~m} \mathrm{~s}^{-1}$ which are typical for mid-shelf flows on the MAB and not the Shelfbreak Jet (Lentz, 2008a). The reversal of the flows at the shelf break (as found in figure 4-4) only occurs when the Oleander Line samples through the center of the ring. A ring takes an average of 30 days to pass over the Oleander Line, leading to 
around $80 \%$ of the transects through rings to be in the middle. The enhancement of the Shelfbreak Jet can only be seen over one or two transects per ring, suggesting this only lasts on the order of a week, while the reversal of flow due to a ring can last on the order of a month.

\subsubsection{Warm Core Rings impact on shelf temperature}

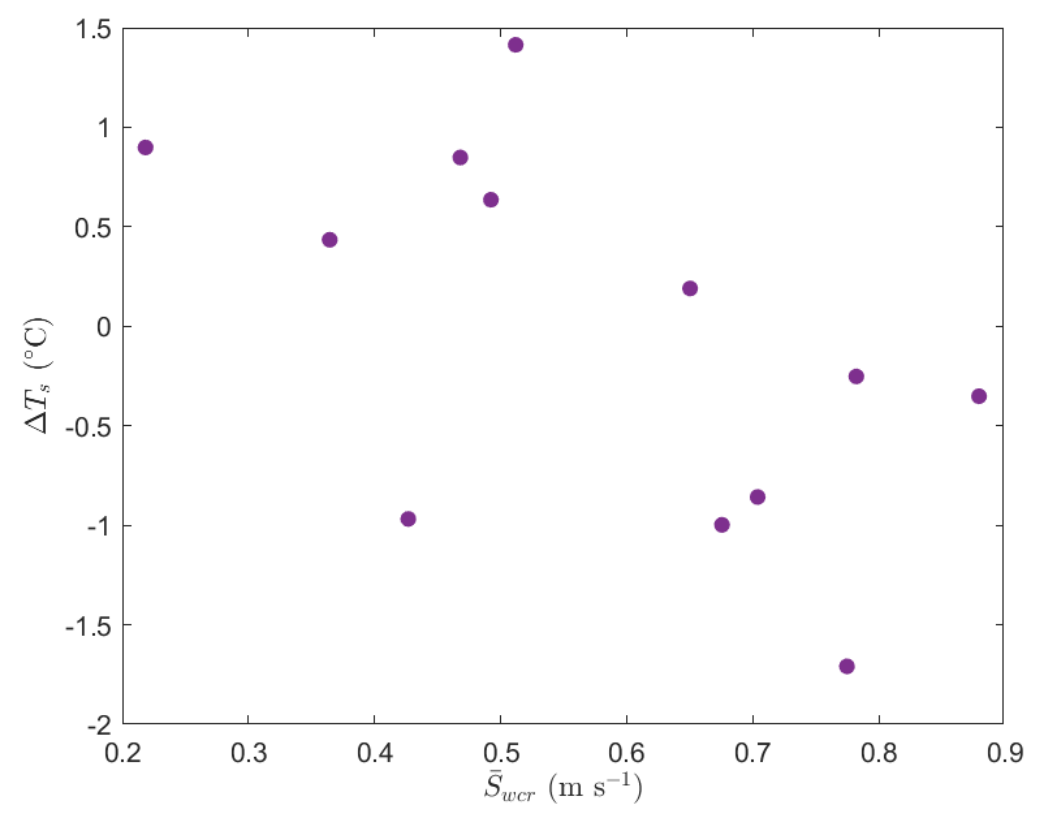

Figure 4-7: Change in spatially averaged shelf temperature anomalies before and after a ring $\left(\Delta T_{s}\right)$ plotted against the average speed of each ring $\left(\bar{S}_{w c r}\right)$. The two variables are significantly correlated at the $95 \%$ confidence interval $(\mathrm{r}=-0.58 \& \mathrm{p}<0.05)$.

In order to understand the lasting impact that rings have on the shelf temperature, we focus on the 12 rings that have XBT data before and after the ring passage. We calculate, $\Delta T_{s}$, which is the difference between the spatially averaged shelf temperature anomaly after and before the ring crosses the Oleander Line. Of the 12 rings with XBT data before and after the ring, 6 of the rings show a cooling of $\Delta T_{s}$ while 6 rings show a warming. The XBT sections are taken at different time intervals after the ring has passed, however, there is no correlation between $\Delta T_{s}$ and the timing of the final XBT sections after the ring has passed. This suggests that other factors are more important in determining the impact on the shelf temperature than time since the ring has passed. We also calculate the change in SST anomaly on the shelf using the same methodology to create $\Delta T_{s}$, where we deseason the data, and then calculate the change in shelf temperature anomaly over the same 
horizontal space that we have for the XBTs, as well as using the same dates as when the XBTs were taken. There is no correlation between $\Delta T_{s}$ and the change in SST anomaly during rings, suggesting that the influence a ring has on the shelf temperature is varied by depth layer.

In order to compare a singular temperature section to properties derived from multiple velocity sections, we average properties found in each section to get the average property for each particular ring. Properties that are averaged over multiple sections will be denoted with a bar, $\bar{S}_{w c r}$ is the average $S_{w c r}$ as calculated in section 4.4.1. A summary of all ring properties can be found in the appendix (Table B.1).

$\bar{S}_{w c r}$ and $\Delta T_{s}$ are significantly anti-correlated at the $95 \%$ confidence interval (Figure 4-7). Faster rings tend to have a cooling relationship with the shelf, while slower rings have a warming relationship. To understand why this is happening, we look at the structure of the velocities within the core of each ring as well as the seasonality of the rings.

As seen in the Eulerian mean velocity section of the rings (Figure 4-2), a subsurface velocity maximum exists in the core of the onshore side of the ring. We further look into the depth at which the velocity maximum occurs in both the northeast and southwest velocity maximums for each section of every ring, and then average the depths found in each section to get, $\bar{z}_{\text {max }}$, the average depth of the velocity maximum for each ring. The difference between the depth of velocity maximums in the the onshore and offshore sides of the ring are highly correlated and not significantly different from each other. We find that only two rings have $\bar{z}_{\text {max }}$ above $50 \mathrm{~m}$, and half of the 16 rings studied have $\bar{z}_{\max }$ below $80 \mathrm{~m}$. Correlating $\bar{z}_{\max }$ to $\Delta T_{s}$, the relationship is not significant, however, it becomes significant if we remove the ring with the smallest $\bar{S}_{w c r}$. As mentioned above, the weakest ring had no impact on the Shelfbreak Jet, and additionally is one of the rings that cannot be tracked through the Chelton analysis. $w_{u p}$ for this ring was also consistent with studies that estimated upwelling when no rings were present. Thus, removing this ring while studying the depth of the maximum velocity seems appropriate.

Rings with deeper $\bar{z}_{\max }$ have $\Delta T_{s}$ that is positive, while shallower $\bar{z}_{m} a x$ rings tend to cool the shelf. Past studies of WCRs have found surface intensified velocity flows. The reasoning for the relationship between the depth of the rings' maximum velocity and the changing shelf temperature is unclear at present. However, the finding that rings have primarily sub-surface intensified velocities is important to report so future modeling focused studies can investigate this. 


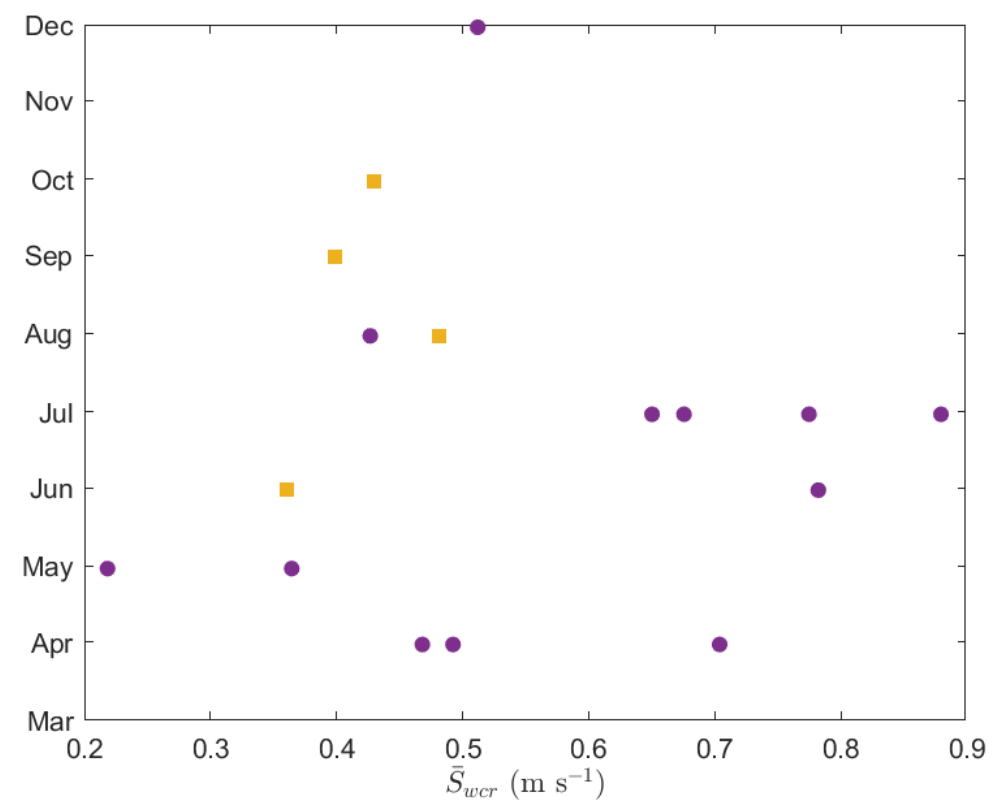

Figure 4-8: The speed of the rings $\left(\bar{S}_{w c r}\right)$ and the month the ring crossed the Oleander Line. Purple dots are when $\Delta T_{s}$ is calculated, yellow squares do not have XBT data before and after the ring passes.

Rings tend to have the largest $\bar{S}_{w c r}$ during the summer months, in June and July (Figure 4-8). This is also the time period when rings are most commonly observed (Gangopadhyay et al., 2020). Unfortunately, we do not observe rings in January-March as data quality in the winter months from the $C M V$ Oleander ADCPs are the least reliable. As such, no WCRs during these months had the prerequisite 5 sections of reliable data through them. The temperature structure of the rings observed has a strong seasonal signal. We look at the temperature difference between the surface and $100 \mathrm{~m}$ depth in each ring, defined as $\delta T_{w c r} . \delta T_{w c r}$ is largest within the Summer Months, reaching up to $14^{\circ} \mathrm{C}$, and weakest during April and May. During April and May, the largest $\delta T_{w c r}$ is only $2^{\circ} \mathrm{C}$, with 3 rings having a $\delta T_{w c r}$ less than $0.5^{\circ} \mathrm{C} . \delta T_{w c r}$ is correlated with $\Delta T_{s}$, however, this likely due to the seasonal differences on the shelf as discussed next.

During the months of June and July, the cold pool is well established. We calculate the surface to bottom temperature differences (within $20 \mathrm{~m}$ of the surface and bottom), or $T_{c p}$, to determine the strength of the stratification. This is done for the XBT section before each ring passes (Figure 4-9, left column), for the XBTs during the ring passage that $\Delta T_{s}$ can be calculated (10 of the 12 , Figure 4-9 right column), and the XBT section after the ring has passed (not shown). $T_{c p}$ before 
a ring passes and $T_{c p}$ during the ring passing are both significantly correlated to $\Delta T_{s}$ at the $95 \%$ confidence interval, while $T_{c p}$ after the ring has passed is not correlated with $\Delta T_{s}$. Additionally, we find that $\delta T_{w c r}$ is significantly correlated to $T_{c p}$ before and during a ring at the $95 \%$ confidence interval. This suggests that stronger stratification limits the ability for a ring to warm the shelf and can act as a barrier for ring water to get on the shelf.
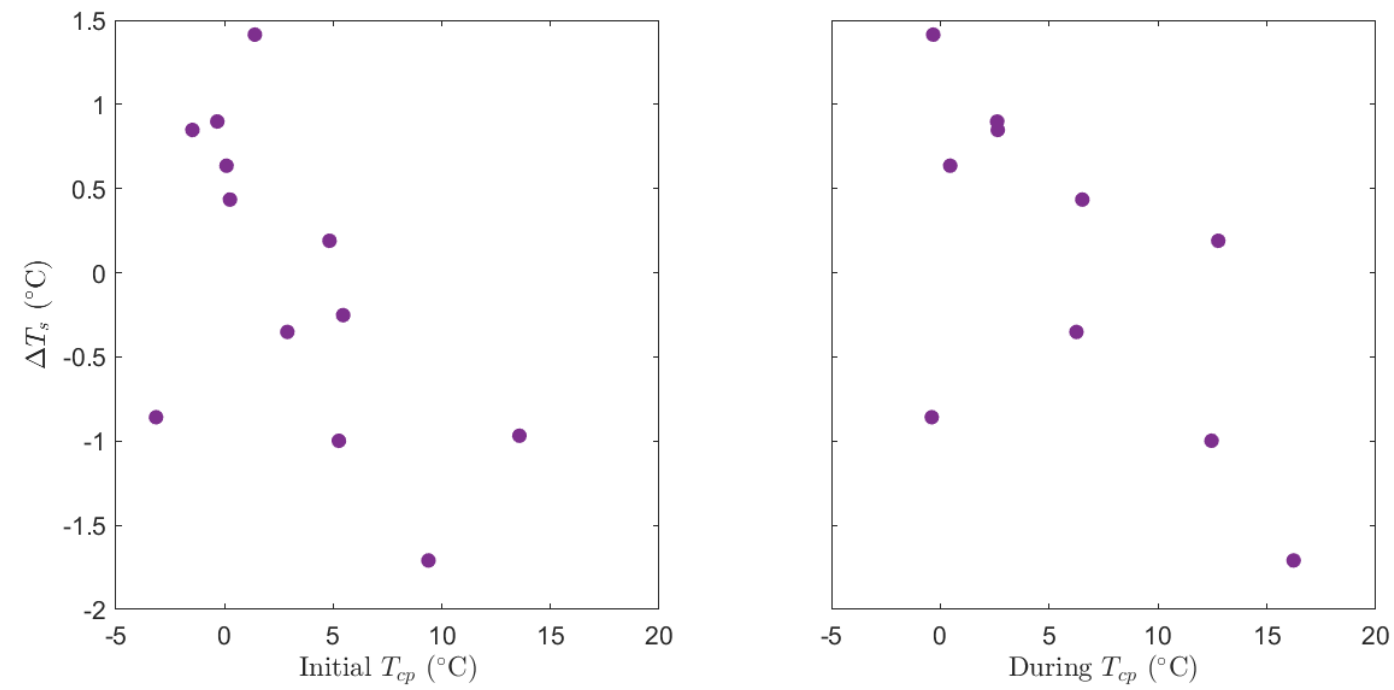

Figure 4-9: $\Delta T_{s}$ plotted against the temperature stratification $\left(T_{c p}\right)$ in the XBT section before the ring passes (left) and the XBT section when the ring is intersecting the Oleander track (right). There are only $10 \mathrm{XBT}$ sections during the ring when $T_{c p}$ can also be calculated. $\Delta T_{s}$ is correlated with both the $T_{c p}$ before the ring passes $(\mathrm{r}=-0.6 \& \mathrm{p}<0.05)$ and $T_{c p}$ when the ring is on the Oleander Line $(\mathrm{r}=-0.66 \& \mathrm{p}<0.05)$.

To understand how stratification limits the ability for ring water to warm the shelf, we estimate the density of the ring water. Using data from the TSG, we find that the salinity of WCRs range from $35-36$, while temperatures range from $20-28^{\circ} \mathrm{C}$, mostly varying with season. Taking the average of these values, we can estimate that the density of the ring water near the surface as $\rho=1024 \mathrm{~kg} \mathrm{~m}^{-3}$. Shelf water has salinity values from 32-34. Given a salinity of 33, the ring water has equal density to the shelf water when the shelf is at a temperature of $17^{\circ} \mathrm{C}$. Using climatological temperature sections from the Oleander XBTs, during June-September, the ring water would be more dense than the shelf surface water and less dense than the cold pool water. For this density structure, ring water would have to intrude onto the shelf as a mid-depth salinity maximum intrusion. Our estimates here are consistent with past studies which found no high salinity intrusions in the months of November- 
April (Churchill et al., 1986). Linear models have also shown that enhanced stratification limits the ability for cross-shelf motions across the slope, potentially limiting the warming impact of rings (Chapman \& Brink, 1987). This aids in explaining why shelf temperatures do not warm when the cold pool is present, but does not explain why there is cooling after the ring has passed.

One possible mechanism for cooling could be upwelling of colder waters due to the divergence driven by the trailing edge of the ring. The divergence of the rings was calculated in section 4.4.1 based on the last available velocity section during each WCR. We plot $w_{u p}$ versus $\Delta T_{s}$ (Figure 4-10). There is no correlation between $w_{u p}$ as a ring passes and $\Delta T_{s}$. However, if we remove the most positive $\Delta T_{s}$, there is a strong linear relationship between $w_{u p}$ and $\Delta T_{s}$. This relationship suggests that larger values of $w_{u p}$ are associated with rings that cool the shelf while reduced values of $w_{u p}$ are found in rings that tend to warm the shelf. For some rings, upwelling is an important mechanism to explain the changes to shelf temperatures from a ring.

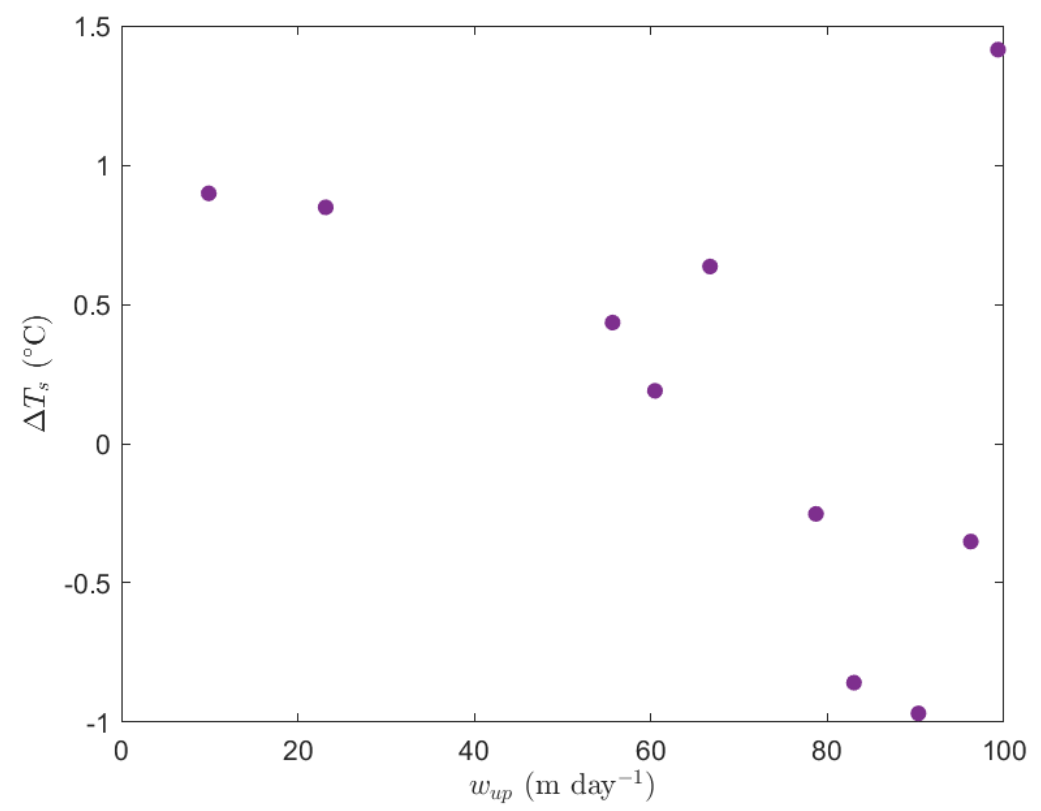

Figure 4-10: $\Delta T_{s}$ plotted against the upwelling velocities $\left(w_{u p}\right)$ estimated from equation 4.1.

The age of the ring calculated in section 4.3 is also found to be significantly correlated at the $95 \%$ confidence interval with $\Delta T_{s}$. Rings that are older when they cross the Oleander Line tend to have a cooling impact on the shelf, whereas younger rings have a warming impact on shelf temperatures. The older a ring is when it crosses the Oleander Line, the more eastward it was formed. This 
correlation still holds true if we replace the age of the ring with the longitude that the ring was formed. Understanding why rings formed further east tend to cool the shelf would be important in predicting shelf temperatures to aid in fisheries management decisions.

\subsection{Conclusion}

Warm Core Rings impact the shelf system by both modifying the velocity fields when the ring is abutting the shelf, and creating lasting temperature changes. The velocity on the shelf is most affected by rings that have high velocities and are closer to the shelf. We affirm past findings from studies south of Martha's Vineyard that the Shelfbreak Jet is accelerated as a ring approaches, likely due to the steepening of the Shelfbreak Front, while at the trailing edge of the ring the Shelfbreak Jet tends to be slower (Pickart et al., 1999; Gawarkiewicz et al., 2001). There is also a divergence in the cross-shelf velocities at the trailing edge of the rings, leading to the possibility of enhanced upwelling.

The shelf temperature's relationship with rings is more complicated, with multiple factors likely influencing how the temperatures change on the shelf due to a ring. There is a strong seasonality to how rings are able to impact the shelf temperature. Larger values of stratification on the shelf are connected to rings that had a net cooling impact on the shelf temperature. The stratification likely limits the ability for ring water to intrude onto the shelf as the density of ring water requires it to intrude sub-surface. Sub-surface intrusions of ring/slope water have only been found during the summer months due to the density structure on the shelf (Aikman III, 1984; Churchill et al., 1986). We note that past observations of rings that had large intrusions which warmed the shelf took place before the seasonal summer stratification was set up, consistent with our observations (Gawarkiewicz et al., 2019; Zhang \& Gawarkiewicz, 2015).

In addition, rings that have more upwelling due to the divergence in cross-shelf velocities as the ring passes are correlated with cooling the shelf, while weak values of upwelling are correlated with a warming on the shelf. Enhanced upwelling has large consequences for the impact that the ring has not just on temperature, but on the productivity of the shelf. Satellite measurements of chlorophyll show enhanced chlorophyll at the shelf break after the passing of a WCR (J. Ryan et al., 2001). This was attributed to upwelling on the trailing edge of the ring as divergent cross-shelf 
velocities were observed. Thus, rings could be a powerful mechanism for modifying productivity on the shelf, as we estimate rings can increase the upwelling by an order of magnitude for a limited time. However, not all rings had as large of divergence in the cross-shelf velocities, suggesting that not all rings increase the productivity at the shelf break.

We have established that rings have large variability between each other, and thus to understand the impact that rings have on the shelf, it is necessary to study multiple rings. Because the $C M V$ Oleander is consistently monitoring the same line, the data are incredibly valuable for studying many individual events of rings impinging on the shelf. However, these data are limited to a two dimensional framework, and thus developing a dynamical understanding for the differences between rings is limited. We have noted key properties of rings that deserve greater study through modeling or long-term monitoring data sets with observations in three dimensions. 


\section{Chapter 5}

\section{Conclusions and Future Work}

\subsection{Conclusions}

This thesis has addressed the variability in temperature and velocity at the Oleander Line by studying processes which change these shelf properties on timescales ranging from days, to decades. I have highlighted the importance of researching variability on a wide range of timescales in order to fully understand the shelf. Thus, this also shows the need to collect data which allows for the study of the timescales at which the ocean varies.

Throughout this thesis I have described how the velocities at the shelf break, as well as the Shelfbreak Jet velocities, undergo variability connected with many processes. At the shortest time scales studied here, strong wind events modify the cross-shelf velocities on the shelf which leads to changes in the thermal structure on the shelf. Other events like Warm Core Rings have short term impacts on the velocities. This impact of Warm Core Rings was examined in both Chapters 3 and 4, with conclusions that seem contradictory at first, but which are in fact consistent when considering the effect of averaging cross sections. In chapter 3, the presence of a ring near the Oleander line was hypothesized to be a large reason for why the Shelfbreak Jet was not able to be identified in some velocity sections. However, in chapter 4, where I examined individual sections rather than composite averages of sections, the impact rings have on Shelfbreak Jet velocities was found to vary in time. As a ring approached the Oleander Line, Shelfbreak Jet velocities were enhanced, while as a ring moved away, the Shelfbreak Jet velocities were weak but still detectable in the velocity sections. The consistency between chapters 3 and 4 occurs in those velocity sections when the Oleander sampled 
the center of the ring, rather than the leading or trailing edge. During these time periods, rings which are close to the shelf break and have fast azimuthal velocities reverse the velocities at the shelf break, which would lead the the Shelfbreak Jet not being identified.

On seasonal timescales, the Shelfbreak Jet reaches its highest velocities in late spring and late fall, and is slowest in summer. These seasonal differences in velocity are likely driven by the variability in the density gradients across the Shelfbreak Front, where the density gradients are weakest in summer. Conditional averaging showed that the variability of the Shelfbreak Jet at the Oleander Line is connected to Gulf Stream variability. Northward shifts of the Gulf Stream occur simultaneously as onshore shifts of the Shelfbreak Jet. Over the total 25 years of study, the average velocities of the Shelfbreak Jet have declined.

Temperature variability is considered throughout all three science chapters in this thesis. Chapters 2 and 4 discuss the variability of temperature due to individual events. Temperature stratification can be greatly reduced by high wind events, particularly if the wind is in the downwellingfavorable direction. Warm Core Rings have the ability to both warm and cool the shelf, changing the average shelf temperature by over $1.5^{\circ} \mathrm{C}$. These individual events are responsible for variability on longer time scales, as high wind events drive the seasonal change in temperature during fall, and the impact that Warm Core Rings have on the shelf is seasonally dependent. Hence understanding how often these events occur is important for studying the shelf conditions in any given year and between years. More wind events lead to an earlier destratification of the shelf. Interannual variability of temperature is discussed in reference to the velocities at the shelf break, where increasing equatorward velocities lead colder time periods on the shelf.

\subsection{Middle Atlantic Bight}

This thesis focused on analyzing temporal variability, with data taken across the shelf at a consistent location. However, there is also along-shelf variability in properties which may lead to some differing results if this work were done further north or south of the Oleander Line.

The destratification of the shelf in Fall is dependent on the frequency and intensity of downwellingfavorable winds and the cross-shelf density gradients. The processes discussed in chapter 2 are likely

important throughout the MAB. However, inherent in the name Middle Atlantic Bight (MAB), the 
$\mathrm{MAB}$ has a rotating orientation, where the northern $\mathrm{MAB}$ is rotated $90^{\circ}$ from the southern $\mathrm{MAB}$. A storm which is downwelling-favorable in the southern MAB may not be downwelling-favorable in the northern $\mathrm{MAB}$, and thus the same storm events may not lead to destratification uniformly along the shelf. Cross-shelf salinity gradients are also larger in the southern MAB as compared to the northern MAB due to river inflow continually freshening the shelfwaters as they flow towards Cape Hatteras. Larger cross-shelf density gradients were associated with more destratification due to winds, and thus wind may be more important to the southern MAB. However, the extent and strength of the cold pool is not consistent throughout, and the Oleander Line is at the center of the cold pool (Z. Chen et al., 2018). The timing of when the cold pool disappears in fall varies by position in the MAB and thus the timing of destratification across the MAB is likely highly varied.

As shown in table 3.1, as well as in studies of the Shelfbreak Jet (Loder et al., 1998; Fratantoni \& Pickart, 2007), the transport of the jet decreases from north to south. The seasonal variability of the Shelfbreak Jet may not be consistent throughout the MAB due to the varied nature of the cold pool, as well as seasonal variability in fresh water outflow leading to stronger and weaker frontal density gradients. Velocity leading temperature as an advective signal is likely a relationship that would be persistent throughout the MAB, as increased transport of cold water leads to a cooling shelf.

Previous studies have found that Warm Core Rings have similar influences on the velocities upstream of the Oleander Line on the leading and trailing edge (Pickart et al., 1999; Gawarkiewicz et al., 2001), as well as through the center of the rings (Beardsley et al., 1985; Zhang \& Gawarkiewicz, 2015). How rings influence the shelf temperatures upstream and downstream of the Oleander Line is less well known. Enhanced stratification in summer is likely still a barrier to ring water penetrating the shelf throughout the MAB. However, the summer rings studied here were found to be formed further east, meaning they were likely younger and warmer when they were offshore of the northern MAB than rings formed in other seasons. This could lead to rings not having a cooling impact further north. 


\subsection{Future $C M V$ Oleander Work}

This thesis has taken advantage of an amazing data set from the Oleander Line. The consistency of data return over many decades is apt for studying question of variability over a range of time periods. However, certain constraints on the data gathered have limited the questions that could be answered. For example, the deployment of expendable conductivity temperature depth (XCTDs) across the Shelfbreak Front would help analysis of the baroclinicity of the Shelfbreak Jet, and how that varies over the processes studied here. As XCTDs are more expensive, limited deployment at opportune times would be needed. For example, choosing to deploy XCTDs on the leading and trailing edge of Warm Core Rings could confirm if the steepening and flattening of the isopycnals drives the changes to the Shelfbreak Jet during Warm Core Rings in this region. These XCTDs could also be used to determine what happens to the Shelfbreak Front when the Shelfbreak Jet cannot be identified in velocity sections. XCTDs during offshore and onshore meanders of the Shelfbreak Jet without rings would also better answer if the meanders of the jet are always consistent with those of the front and allow for further consideration of ageostrophic effects on the jet velocity.

Overall, there are still many more questions that the Oleander data could resolve. In preliminary analysis, I found the presence of a Slope Jet between the Shelfbreak Jet and the Gulf Stream, consistent with the work Flagg et al. (2006). The question of what the Slope Jet is has often been asked and debated at presentations I have given. A deeper investigation into the structure and variability of this feature merits further study. With additional long term observational data being gathered (i.e. Ocean Observatories Initiative Pioneer ) questions about the along-shelf variability can be answered over many time scales. Further uses of the Oleander data are certainly there for future research, as there are few data sets that cover the temporal scales of the $C M V$ Oleander. 


\section{Appendix A}

\section{Figures}
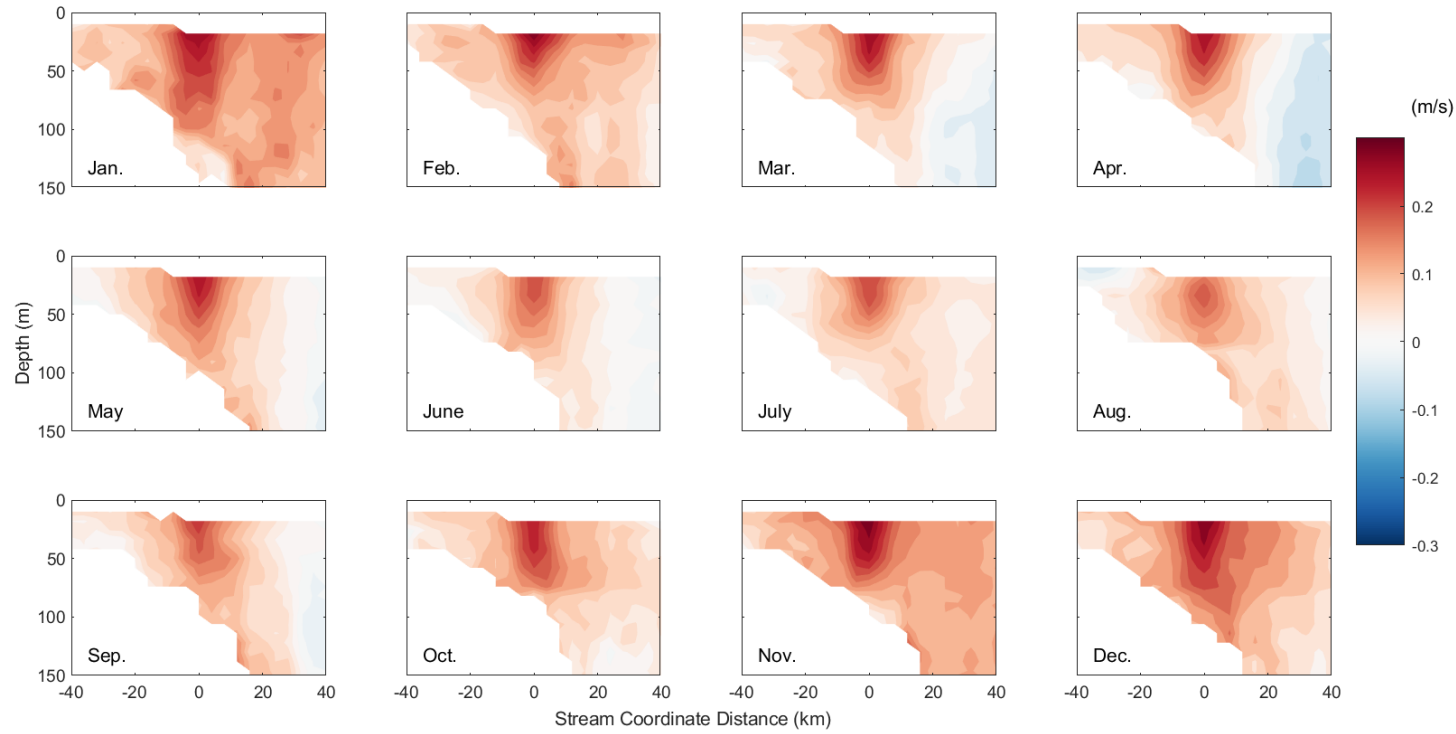

Figure A-1: Stream coordinate mean streamwise velocities in each month. 


\section{Appendix B}

\section{Tables}

Table B.1: The properties of the individual Warm Core Rings (WCRs) studied in Chapter 4. Date start and date end are the dates of the first and last transect that the signature of a WCR can be found in the Acoustic Doppler Current Profiler (ADCP) data as defined in section 4.3. Transects is the number of ADCP transects within the ring. The following 4 variables are defined in section

4.4.1. $\bar{S}_{w c r}$ is the ring speed averaged over every section within the ring, $\bar{r}_{w c r}$ is the average radius of the ring, $\bar{z}_{\max }$ is the average depth of the velocity maximum in the ring, and $w_{u p}$ is the estimated upwelling in the last WCR section with data from equation 4.1. Age is defined as the number of days after the ring was formed when it crossed the Oleander transect using the Chelton eddy tracks (Chelton et al. (2011), section 4.3.2). Isobath is the isobath that the ring crosses the Oleander Line at. Temperature variables are defined in section 4.4.2. $\delta T_{w c r}$ is the temperature difference between the surface and $100 \mathrm{~m}$ depth within the ring. $\Delta T_{s}$ is the change in the spatially averaged shelf temperature anomaly from before and after the ring passes. $T_{c p}$ is the surface to bottom temperature difference on the shelf over the mean location of the cold pool. During $T_{c p}$ is when the ring is observed intersecting with the Oleander Line and before $T_{c p}$ uses data from within one month before the ring is observed intersecting with the Oleander Line. 


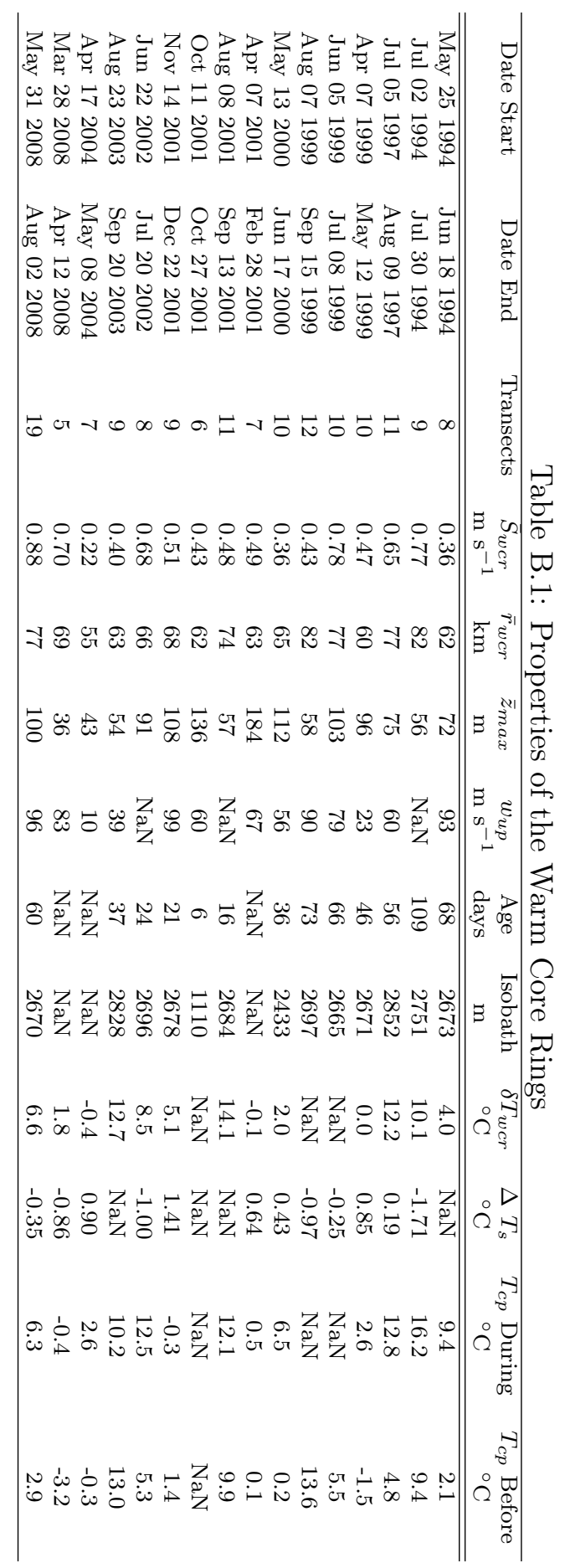




\section{References}

Aikman III, F. (1984). Pycnocline development and its consequences in the middle atlantic bight. Journal of Geophysical Research: Oceans, 89(C1), 685-694. Retrieved from https://agupubs.onlinelibrary.wiley.com/doi/abs/10.1029/JC089iC01p00685 doi: 10.1029/JC089iC01p00685

Andres, M. (2016). On the recent destabilization of the gulf stream path downstream of cape hatteras. Geophysical Research Letters, 43(18), 9836 - 9842. Retrieved from http://dx.doi.org/10.1002/2016GL069966 doi: 10.1002/2016GL069966

Bane, J. M., Brown, O. B., Evans, R. H., \& Hamilton, P. (1988). Gulf stream remote forcing of shelfbreak currents in the mid-atlantic bight. Geophysical research letters, 15(5), 405-407.

Barth, J. A., Bogucki, D., Pierce, S. D., \& Kosro, P. M. (1998). Secondary circulation associated with a shelfbreak front. Geophysical Research Letters, 25(15), 2761-2764. Retrieved from https://agupubs.onlinelibrary.wiley.com/doi/abs/10.1029/98GL02104 doi: 10.1029/98GL02104

Beardsley, R. C., Chapman, D. C., Brink, K. H., Ramp, S. R., \& Schlitz, R. (1985). The Nantucket Shoals Flux Experiment (NSFE79). Part I: A Basic Description of the Current and Temperature Variability. Journal of Physical Oceanography, 15(6), 713 - 748. Retrieved from http://dx.doi.org/10.1175/1520-0485(1985) 015<0713: TNSFEP>2.0.C0;2 doi: $10.1175 / 1520-0485(1985) 015<0713:$ TNSFEP $>2.0 . C O ; 2$

Bisagni, J. J. (1983). Lagrangian Current Measurements within the Eastern Margin of a Warm-Core Gulf Stream Ring. Journal of Physical Oceanography, 13(4), 709-715. Retrieved from https://doi.org/10.1175/1520-0485(1983)013<0709:LCMWTE>2.0.C0; 2 doi: 10.1175/1520-0485(1983)013<0709:LCMWTE $>2.0$.CO;2

Bisagni, J. J. (2016). Salinity variability along the eastern continental shelf of canada and the united states, 1973-2013. Continental Shelf Research, 126 (Supplement C), 89 - 109. Retrieved from http://www.sciencedirect.com/science/article/pii/S0278434316304149 doi: https://doi.org/10.1016/j.csr.2016.08.003

Boicourt, W., \& Hacker, P. (1976). Circulation on the Atlantic continental shelf of the United States, Cape May to Cape Hatteras. Memoires de la Societe Royale des Sciences de Liege, 6, 187-200.

Cenedese, C., Todd, R. E., Gawarkiewicz, G. G., Owens, W. B., \& Shcherbina, A. Y. (2013, 05). Offshore Transport of Shelf Waters through Interaction of Vortices with a Shelfbreak Current. Journal of Physical Oceanography, 43(5), 905-919. Retrieved from https://doi.org/10.1175/JPO-D-12-0150.1 doi: 10.1175/JPO-D-12-0150.1

Chapman, D. C., \& Beardsley, R. C. (1989). On the origin of shelf water in the middle atlantic bight. Journal of Physical Oceanography, 19(3), 384-391. Retrieved from https://doi.org/10.1175/1520-0485(1989) 019<0384:0TOOSW>2.0.C0;2 doi: 10.1175/1520-0485(1989)019<0384:OTOOSW > 2.0.CO;2 
Chapman, D. C., \& Brink, K. H. (1987). Shelf and slope circulation induced by fluctuating offshore forcing. Journal of Geophysical Research: Oceans, 92(C11), 11741-11759. Retrieved from https://agupubs.onlinelibrary.wiley.com/doi/abs/10.1029/JC092iC11p11741 doi: $10.1029 /$ JC092iC11p11741

Chassignet, E. P., Hurlburt, H. E., Smedstad, O. M., Halliwell, G. R., Hogan, P. J., Wallcraft, A. J., ... Bleck, R. (2007). The HYCOM (HYbrid Coordinate Ocean Model) data assimilative system. Journal of Marine Systems, 65(1-4), 60 - $83 . \quad$ Retrieved from http://www.sciencedirect.com/science/article/pii/S0924796306002855 doi: 10.1016/j.jmarsys.2005.09.016

Chelton, D. B., Schlax, M. G., \& Samelson, R. M. (2011). Global observations of nonlinear mesoscale eddies. Progress in Oceanography, 91(2), 167 - 216. Retrieved from http://www.sciencedirect.com/science/article/pii/S0079661111000036 doi: https://doi.org/10.1016/j.pocean.2011.01.002

Chen, K., Gawarkiewicz, G., Lentz, S. J., \& Bane, J. M. (2014). Diagnosing the warming of the Northeastern US Coastal Ocean in 2012: A linkage between the atmospheric jet stream variability and ocean response. Journal of Geophysical Research: Oceans, 119(1), 218 - 227.

Chen, K., \& He, R. (2015). Mean circulation in the coastal ocean off northeastern North America from a regional-scale ocean model. Ocean Science, 11(4), 503 - 517. Retrieved from http://www.ocean-sci.net/11/503/2015/ doi: 10.5194/os-11-503-2015

Chen, K., He, R., Powell, B. S., Gawarkiewicz, G., Moore, A. M., \& Arango, H. G. (2014). Data assimilative modeling investigation of Gulf Stream Warm Core Ring interaction with continental shelf and slope circulation. Journal of Geophysical Research: Oceans, 119(9), 5968 - 5991. Retrieved from http://dx.doi.org/10.1002/2014JC009898 doi: 10.1002/2014JC009898

Chen, K., Kwon, Y.-O., \& Gawarkiewicz, G. (2016). Interannual variability of winterspring temperature in the Middle Atlantic Bight: Relative contributions of atmospheric and oceanic processes. Journal of Geophysical Research: Oceans, 121(6), 4209-4227. Retrieved from http://dx.doi.org/10.1002/2016JC011646 doi: 10.1002/2016JC011646

Chen, Z., Curchitser, E., Chant, R., \& Kang, D. (2018). Seasonal variability of the cold pool over the mid-atlantic bight continental shelf. Journal of Geophysical Research: Oceans, 123(11), 8203-8226. Retrieved from https://agupubs.onlinelibrary.wiley.com/doi/abs/10.1029/2018JC014148 doi: 10.1029/2018JC014148

Chen, Z., Kwon, Y.-O., Chen, K., Fratantoni, P. S., Gawarkiewicz, G., \& Joyce, T. M. (2020). Long-term sst variability on the northwest atlantic continental shelf and slope. Geophysical Research Letters, 47(1), e2019GL085455. Retrieved from https://agupubs.onlinelibrary.wiley.com/doi/abs/10.1029/2019GL085455 (e2019GL085455 2019GL085455) doi: 10.1029/2019GL085455

Churchill, J. H., Cornillon, P. C., \& Milkowski, G. W. (1986). A cyclonic eddy and shelf-slope water exchange associated with a gulf stream warm-core ring. Journal of Geophysical Research: Oceans, 91(C8), 9615-9623. Retrieved from https://agupubs.onlinelibrary.wiley.com/doi/abs/10.1029/JC091iC08p09615 doi: 10.1029/JC091iC08p09615

Csanady, G. T. (1982). Circulation in the coastal ocean. D. Reidel Publishing Company.

Curry, R. (1996). Hydrobase: a database of hydrographic stations and tools for climatological analysis. Woods Hole Oceanographic Institution.

Egbert, G. D., \& Erofeeva, S. Y. (2002). Efficient inverse modeling of barotropic ocean tides. Journal of Atmospheric and Oceanic Technology, 19(2), 183-204. Re- 
trieved from https://doi.org/10.1175/1520-0426(2002)019<0183:EIMOBO>2.0.C0;2 doi: 10.1175/1520-0426(2002)019<0183:EIMOBO > 2.0.CO;2

Fairall, C. W., Bradley, E. F., Hare, J. E., Grachev, A. A., \& Edson, J. B. (2003). Bulk Parameterization of Air-Sea Fluxes: Updates and Verification for the COARE Algorithm. Journal of Climate, 16(4), 571 - 591. Retrieved from http://dx.doi.org/10.1175/1520-0442(2003)016<0571:BPOASF>2.0.C0;2 doi: 10.1175/1520-0442(2003)016<0571:BPOASF $>2.0 . \mathrm{CO} ; 2$

Flagg, C. N., Dunn, M., Wang, D.-P., Rossby, H. T., \& Benway, R. L. (2006). A study of the currents of the outer shelf and upper slope from a decade of shipboard adcp observations in the middle atlantic bight. Journal of Geophysical Research: Oceans, 111 (C6), n/a-n/a. Retrieved from http://dx.doi.org/10.1029/2005JC003116 (C06003) doi: 10.1029/2005JC003116

Flagg, C. N., Schwartze, G., Gottlieb, E., \& Rossby, T. (1998). Operating an acoustic doppler current profiler aboard a container vessel. Journal of Atmospheric and Oceanic Technology, 15(1), 257-271. Retrieved from https://doi.org/10.1175/1520-0426(1998)015<0257:OAADCP>2.0.C0;2 doi: 10.1175/1520-0426(1998)015<0257:OAADCP $>2.0 . \mathrm{CO} ; 2$

Forsyth, J., Andres, M., \& Gawarkiewicz, G. (2015). Recent accelerated warming of the continental shelf off New Jersey: Observations from the CMVOleander expendable bathythermograph line. Journal of Geophysical Research: Oceans, 120(3), 2370 - 2384. Retrieved from http://dx.doi.org/10.1002/2014JC010516 doi: 10.1002/2014JC010516

Forsyth, J., Andres, M., \& Gawarkiewicz, G. (2020). Shelfbreak jet structure and variability off new jersey using ship of opportunity data from the cmv oleander. Journal of Geophysical Research: Oceans, 125(9), e2020JC016455. Retrieved from https://agupubs.onlinelibrary.wiley.com/doi/abs/10.1029/2020JC016455 (e2020JC016455 10.1029/2020JC016455) doi: 10.1029/2020JC016455

Fratantoni, P. S., \& Pickart, R. (2003). Variability of the shelf break jet in the middle atlantic bight: Internally or externally forced? Journal of Geophysical Research: Oceans, $108(\mathrm{C} 5)$.

Fratantoni, P. S., \& Pickart, R. S. (2007). The Western North Atlantic Shelfbreak Current System in Summer. Journal of Physical Oceanography, 37(10), 2509 - 2533. Retrieved from http://dx.doi.org/10.1175/JP03123.1 doi: 10.1175/JPO3123.1

Fratantoni, P. S., Pickart, R. S., Torres, D. J., \& Scotti, A. (2001). Mean structure and dynamics of the shelfbreak jet in the middle atlantic bight during fall and winter. Journal of Physical Oceanography, 31(8), 2135-2156. Retrieved from https://doi.org/10.1175/1520-0485(2001)031<2135:MSADOT>2.0.C0;2 doi: 10.1175/1520-0485(2001)031<2135:MSADOT $>2.0$.CO;2

Friedland, K. (2012). Ecosystem advisory for the northeast shelf large marine ecosystem. Advis. 2012 No, 2.

Friedland, K. D., \& Hare, J. A. (2007). Long-term trends and regime shifts in sea surface temperature on the continental shelf of the northeast united states. Continental Shelf Research, 27(18), 2313 - 2328. Retrieved from http://www.sciencedirect.com/science/article/pii/S0278434307001550 doi: https://doi.org/10.1016/j.csr.2007.06.001

Gangopadhyay, A., Gawarkiewicz, G., Silva, E. N. S., Monim, M., \& Clark, J. (2019). An observed regime shift in the formation of warm core rings from the gulf stream. Scientific Reports, 9(12319). doi: 10.1038/s41598-019-48661-9

Gangopadhyay, A., Gawarkiewicz, G., Silva, E. N. S., Silver, A. M., Monim, M., \& Clark, J. (2020). A census of the warm-core rings of the gulf stream: 
1980-2017. Journal of Geophysical Research: Oceans, 125(8), e2019JC016033. Retrieved from https://agupubs.onlinelibrary.wiley.com/doi/abs/10.1029/2019JC016033 (e2019JC016033 2019JC016033) doi: 10.1029/2019JC016033

Gawarkiewicz, G., Bahr, F., Beardsley, R. C., \& Brink, K. H. (2001). Interaction of a slope eddy with the shelfbreak front in the middle atlantic bight. Journal of Physical Oceanography, 31(9), 2783-2796. Retrieved from https://doi.org/10.1175/1520-0485(2001)031<2783: IOASEW>2.0.C0;2 doi: 10.1175/1520-0485(2001)031<2783:IOASEW > 2.0.CO;2

Gawarkiewicz, G., Brink, K. H., Bahr, F., Beardsley, R. C., Caruso, M., Lynch, J. F., \& Chiu, C.-S. (2004). A large-amplitude meander of the shelfbreak front during summer south of New England: Observations from the Shelfbreak PRIMER experiment. Journal of Geophysical Research: Oceans, 109(C3). Retrieved from http://dx.doi.org/10.1029/2002JC001468 (C03006) doi: 10.1029/2002JC001468

Gawarkiewicz, G., Chen, K., Forsyth, J., Bahr, F., Mercer, A. M., Ellertson, A., ... Han, L. (2019). Characteristics of an advective marine heatwave in the middle atlantic bight in early 2017. Frontiers in Marine Science, 6, 712. Retrieved from https://www.frontiersin.org/article/10.3389/fmars.2019.00712 doi: 10.3389/fmars.2019.00712

Gawarkiewicz, G., Ferdelman, T. G., Church, T. M., \& Luther, G. W. (1996). Shelfbreak frontal structure on the continental shelf north of cape hatteras. Continental Shelf Research, 16(14), 1751 - 1773. Retrieved from http://www. sciencedirect.com/science/article/pii/0278434396000143 doi: https://doi.org/10.1016/0278-4343(96)00014-3

Gawarkiewicz, G., Lawson, G., Petruny-Parker, M., Fratantoni, P. S., \& Hare, J. (2013). The shelf break ecosystem off the northeastern united states: Current issues and recommended research directions. Coop. Inst. for the North Atl. Reg., Woods Hole, Mass./Available at http://cinar. org/fileserver. do, 29.

Gawarkiewicz, G., Todd, R. E., Zhang, W., Partida, J., Gangopadhyay, A., Monim, M.-U.-H., . . Dent, M. (2018). The changing nature of shelf-break exchange revealed by the ooi pioneer array. Oceanography, 31(1), 60-70. Retrieved from http://www.jstor.org/stable/26307788

Glenn, S., Miles, T., Seroka, G., Xu, Y., Forney, R., Yu, F., ... Kohut, J. (2016). Stratified coastal ocean interactions with tropical cyclones. Nature communications, 7.

Griffin, R. B. (1999). Sperm whale distributions and community ecology associated with a warm-core ring off georges bank. Marine Mammal Science, 15(1), 33-51. Retrieved from https://onlinelibrary.wiley.com/doi/abs/10.1111/j.1748-7692.1999.tb00780.x doi: 10.1111/j.1748-7692.1999.tb00780.x

Haidvogel, D., Arango, H., Budgell, W., Cornuelle, B., Curchitser, E., Lorenzo, E. D., .. Wilkin, J. (2008). Ocean forecasting in terrain-following coordinates: Formulation and skill assessment of the Regional Ocean Modeling System. Journal of Computational Physics, 227(7), 3595 - 3624. Retrieved from http://www.sciencedirect.com/science/article/pii/S0021999107002549 doi: $10.1016 /$ j.jcp.2007.06.016

Halliwell, G. R. (2004). Evaluation of vertical coordinate and vertical mixing algorithms in the hybrid-coordinate ocean model (hycom). Ocean Modelling, 7(3-4), 285-322.

Hare, J. A., Morrison, W. E., Nelson, M. W., Stachura, M. M., Teeters, E. J., Griffis, R. B., ... Griswold, C. A. (2016, 02). A vulnerability assessment of fish and invertebrates to climate change on the northeast u.s. continental shelf. PLOS ONE, 11(2), 1-30. Retrieved from 
https://doi.org/10.1371/journal.pone.0146756 doi: 10.1371/journal.pone.0146756

Holliday, N. P., Bersch, M., Berx, B., Chafik, L., Cunningham, S., Florindo-López, C., ... others (2020). Ocean circulation causes the largest freshening event for 120 years in eastern subpolar north atlantic. Nature communications, 11(1), 1-15.

Houghton, R. W., Schlitz, R., Beardsley, R. C., Butman, B., \& Chamberlin, J. L. (1982). The Middle Atlantic Bight Cold Pool: Evolution of the Temperature Structure During Summer 1979. Journal of Physical Oceanography, 12(10), 1019 - 1029. Retrieved from http://dx.doi.org/10.1175/1520-0485(1982)012<1019:TMABCP>2.0.C0;2 doi: 10.1175/1520-0485(1982)012<1019:TMABCP $>2.0$. CO $; 2$

Houghton, R. W., \& Visbeck, M. (1998). Upwelling and convergence in the middle atlantic bight shelfbreak front. Geophysical Research Letters, 25(15), 2765-2768. Retrieved from https://agupubs.onlinelibrary.wiley.com/doi/abs/10.1029/98GL02105 doi: $10.1029 / 98 \mathrm{GL} 02105$

Joyce, T. (1984). Velocity and hydrographic structure of a gulf stream warm-core ring. Journal of Physical Oceanography, 14(5), 936-947. Retrieved from https://doi.org/10.1175/1520-0485(1984)014<0936:VAHSOA>2.0.C0;2 doi: 10.1175/1520-0485(1984)014<0936:VAHSOA $>2.0 . \mathrm{CO} ; 2$

Joyce, T., Bishop, J. K., \& Brown, O. B. (1992). Observations of offshore shelf-water transport induced by a warm-core ring. Deep Sea Research Part A. Oceanographic Research Papers, 39, S97 - S113. Retrieved from http://www.sciencedirect.com/science/article/pii/S0198014911800075 doi: https://doi.org/10.1016/S0198-0149(11)80007-5

Large, W., \& Pond, S. (1981). Open ocean momentum flux measurements in moderate to strong winds. Journal of physical oceanography, 11(3), 324-336.

Lau, W. K. M., Shi, J. J., Tao, W. K., \& Kim, K. M. (2016). What would happen to superstorm sandy under the influence of a substantially warmer atlantic ocean? Geophysical Research Letters, 43(2), 802-811. Retrieved from http://dx.doi.org/10.1002/2015GL067050 (2015GL067050) doi: 10.1002/2015GL067050

Lentz, S. J. (2008a). Observations and a model of the mean circulation over the middle atlantic bight continental shelf. Journal of Physical Oceanography, 38(6), 1203-1221. Retrieved from https://doi.org/10.1175/2007JP03768.1 doi: 10.1175/2007JPO3768.1

Lentz, S. J. (2008b). Seasonal variations in the circulation over the middle atlantic bight continental shelf. Journal of Physical Oceanography, 38(7), 1486-1500. Retrieved from https://doi.org/10.1175/2007JP03767.1 doi: 10.1175/2007JPO3767.1

Lentz, S. J. (2017). Seasonal warming of the middle atlantic bight cold pool. Journal of Geophysical Research: Oceans, 122(2), 941-954. Retrieved from http://dx.doi.org/10.1002/2016JC012201 doi: 10.1002/2016JC012201

Lentz, S. J., Shearman, K., Anderson, S., Plueddemann, A., \& Edson, J. (2003). Evolution of stratification over the New England shelf during the Coastal Mixing and Optics study, August 1996-June 1997. Journal of Geophysical Research: Oceans, 108(C1), 8-1 - 8-14. Retrieved from http://dx.doi.org/10.1029/2001JC001121 doi: 10.1029/2001JC001121

Li, Y., Fratantoni, P. S., Chen, C., Hare, J. A., Sun, Y., Beardsley, R. C., \& Ji, R. (2015). Spatio-temporal patterns of stratification on the northwest atlantic shelf. Progress in Oceanography, 134, 123 - 137. Retrieved from http://www.sciencedirect.com/science/article/pii/S0079661115000051 doi: https://doi.org/10.1016/j.pocean.2015.01.003

Linder, C. A., \& Gawarkiewicz, G. (1998). A climatology of the shelfbreak front in the Middle Atlantic Bight. Journal of Geophysical Research: Oceans, 103(C9), 18405 - 18423. 
Retrieved from http://dx.doi.org/10.1029/98JC01438 doi: 10.1029/98JC01438

Loder, J. W., Petrie, B., \& Gawarkiewicz, G. (1998). The coastal ocean off northeastern north america: A large-scale view. The sea, 11, 105-133.

Lozier, M. S., Reed, M. S. C., \& Gawarkiewicz, G. (2002). Instability of a shelfbreak front. Journal of Physical Oceanography, 32(3), 924-944. Retrieved from https://doi.org/10.1175/1520-0485(2002)032<0924:IOASF>2.0.C0;2 doi: 10.1175/1520-0485(2002)032<0924:IOASF $>2.0 . \mathrm{CO} ; 2$

Manning, J. (1991). Middle Atlantic Bight salinity: interannual variability. Continental Shelf Research, 11(2), 123 - 137. Retrieved from http://www.sciencedirect.com/science/article/pii/027843439190058E doi: http://dx.doi.org/10.1016/0278-4343(91)90058-E

Mellor, G. L., \& Yamada, T. (1982). Development of a turbulence closure model for geophysical fluid problems. Reviews of Geophysics, 20(4), 851 - 875. Retrieved from http://dx.doi.org/10.1029/RG020i004p00851 doi: 10.1029/RG020i004p00851

Miller, T. J., Hare, J. A., \& Alade, L. A. (2016). A state-space approach to incorporating environmental effects on recruitment in an age-structured assessment model with an application to southern New England yellowtail flounder. Canadian Journal of Fisheries and Aquatic Sciences, 73(8), 1261-1270. Retrieved from https://doi.org/10.1139/cjfas-2015-0339 doi: $10.1139 /$ cjfas-2015-0339

Mills, K. E., Pershing, A. J., Brown, C. J., Chen, Y., Chiang, F.-S., Holland, D. S., ... others (2013). Fisheries management in a changing climate: lessons from the 2012 ocean heat wave in the northwest atlantic. Oceanography, 26(2), 191-195.

Mooers, C. N., Fernández-Partagás, J. J., \& Price, J. F. (1976). Meteorological forcing fields of the new york bight: First year's progress report. University of Miami, Rosenstiel School of Marine and Atmospheric Science.

Morgan, C. W., \& Bishop, J. M. (1977, 05). An Example of Gulf Stream Eddy-Induced Water Exchange in the Mid-Atlantic Bight. Journal of Physical Oceanography, 7(3), 472-479. Retrieved from https://doi.org/10.1175/1520-0485(1977)007<0472:AEOGSE>2.0.C0;2 doi: 10.1175/1520-0485(1977)007<0472:AEOGSE $>2.0$. CO;2

Mountain, D. G. (2003). Variability in the properties of Shelf Water in the Middle Atlantic Bight, 1977-1999. Journal of Geophysical Research: Oceans, 108(C1). Retrieved from http://dx.doi.org/10.1029/2001JC001044 (3014) doi: 10.1029/2001JC001044

Paulson, C. A., \& Simpson, J. J. (1977). Irradiance measurements in the upper ocean. Journal of Physical Oceanography, 7(6), 952-956. Retrieved from https://doi.org/10.1175/1520-0485(1977)007<0952:IMITU0>2.0.C0;2 doi: 10.1175/1520-0485(1977)007<0952:IMITUO $>2.0$.CO;2

Pershing, A. J., Alexander, M. A., Hernandez, C. M., Kerr, L. A., Le Bris, A., Mills, K. E., ... Thomas, A. C. (2015). Slow adaptation in the face of rapid warming leads to collapse of the gulf of maine cod fishery. Science, 350(6262), 809-812. Retrieved from http://science.sciencemag.org/content/350/6262/809 doi: 10.1126/science.aac9819

Peña-Molino, B., \& Joyce, T. M. (2008). Variability in the slope water and its relation to the gulf stream path. Geophysical Research Letters, 35(3). Retrieved from https://agupubs.onlinelibrary.wiley.com/doi/abs/10.1029/2007GL032183 doi: 10.1029/2007GL032183

Pickart, R. S., Torres, D. J., McKee, T. K., Caruso, M. J., \& Przystup, J. E. (1999). Diagnosing a meander of the shelf break current in the middle atlantic bight. Journal of Geophysical Research: Oceans, 104(C2), 3121-3132. Retrieved from https://agupubs.onlinelibrary.wiley.com/doi/abs/10.1029/1998JC900066 doi: 
10.1029/1998JC900066

Price, J. F., Weller, R. A., \& Pinkel, R. (1986). Diurnal cycling: Observations and models of the upper ocean response to diurnal heating, cooling, and wind mixing. Journal of Geophysical Research: Oceans, 91(C7), 8411 - 8427. Retrieved from http://dx.doi.org/10.1029/JC091iC07p08411 doi: 10.1029/JC091iC07p08411

Reynolds, R. W., Smith, T. M., Liu, C., Chelton, D. B., Casey, K. S., \& Schlax, M. G. (2007). Daily high-resolution-blended analyses for sea surface temperature. Journal of Climate, 20(22), 5473-5496. Retrieved from https://doi.org/10.1175/2007JCLI1824.1 doi: 10.1175/2007JCLI1824.1

Rheuban, J. E., Kavanaugh, M. T., \& Doney, S. C. (2017). Implications of future northwest atlantic bottom temperatures on the american lobster (homarus americanus) fishery. Journal of Geophysical Research: Oceans, 122(12), 9387-9398. Retrieved from http://dx.doi.org/10.1002/2017JC012949 doi: 10.1002/2017JC012949

Rossby, T., \& Benway, R. L. (2000). Slow variations in mean path of the gulf stream east of cape hatteras. Geophysical Research Letters, 27(1), 117-120. Retrieved from https://agupubs.onlinelibrary.wiley.com/doi/abs/10.1029/1999GL002356 doi: 10.1029/1999GL002356

Rossby, T., Flagg, C., \& Donohue, K. (2005). Interannual variations in upper-ocean transport by the gulf stream and adjacent waters between new jersey and bermuda. Journal of Marine Research, 63(1), 203-226.

Rossby, T., Flagg, C. N., Donohue, K., Fontana, S., Curry, R., Andres, M., \& Forsyth, J. (2019). Oleander is more than a flower. Oceanography, 32(3), 126-137.

Rossby, T., Flagg, C. N., Donohue, K., Sanchez-Franks, A., \& Lillibridge, J. (2014). On the long-term stability of gulf stream transport based on 20 years of direct measurements. Geophysical Research Letters, 41(1), 114-120. Retrieved from http://dx.doi.org/10.1002/2013GL058636 (2013GL058636) doi: 10.1002/2013GL058636

Ryan, J., Yoder, J., \& Townsend, D. (2001). Influence of a gulf stream warm-core ring on water mass and chlorophyll distributions along the southern flank of georges bank. Deep Sea Research Part II: Topical Studies in Oceanography, 48(1), 159 - 178. Retrieved from http://www.sciencedirect.com/science/article/pii/S096706450000117X (Coupled biological and physical studies of plankton populations on Georges Bank and related North Atlantic regions) doi: https://doi.org/10.1016/S0967-0645(00)00117-X

Ryan, J. P., Yoder, J. A., Barth, J. A., \& Cornillon, P. C. (1999). Chlorophyll enhancement and mixing associated with meanders of the shelf break front in the midatlantic bight. Journal of Geophysical Research: Oceans, 104(C10), 23479-23493. Retrieved from https://agupubs.onlinelibrary.wiley.com/doi/abs/10.1029/1999JC900174 doi: 10.1029/1999JC900174

Sallenger, A. H., Doran, K. S., \& Howd, P. A. (2012). Hotspot of accelerated sea-level rise on the atlantic coast of north america. Nature Climate Change, 2(12), 884-888.

Shchepetkin, A. F., \& McWilliams, J. C. (2005). The regional oceanic modeling system (ROMS): a split-explicit, free-surface, topography-followingcoordinate oceanic model. Ocean Modelling, 9(4), 347 - 404. Retrieved from http://www.sciencedirect.com/science/article/pii/S1463500304000484 doi: [http://doi.org/10.1016/j.ocemod.2004.08.002

Shearman, R. K., \& Lentz, S. J. (2003). Dynamics of mean and subtidal flow on the new england shelf. Journal of Geophysical Research: Oceans, 108(C8), n/a-n/a. Retrieved from http://dx.doi.org/10.1029/2002JC001417 (3281) doi: 10.1029/2002JC001417

Shearman, R. K., \& Lentz, S. J. (2010). Long-Term Sea Surface Temperature Variability 
along the U.S. East Coast. Journal of Physical Oceanography, 40(5), 1004 - 1017. Retrieved from http://dx.doi.org/10.1175/2009JP04300.1 doi: 10.1175/2009JPO4300.1

Straneo, F., Kawase, M., \& Pickart, R. S. (2002). Effects of Wind on Convection in Strongly and Weakly Baroclinic Flows with Application to the Labrador Sea. Journal of Physical Oceanography, 32(9), 2603 - 2618. doi: 10.1175/15200485(2002)032<2603:EOWOCI >2.0.CO;2

Sullivan, M. C., Cowen, R. K., \& Steves, B. P. (2005). Evidence for atmosphere-ocean forcing of yellowtail flounder (limanda ferruginea) recruitment in the middle atlantic bight. Fisheries Oceanography, 14(5), 386-399. Retrieved from http://dx.doi.org/10.1111/j.1365-2419.2005.00343.x doi: 10.1111/j.13652419.2005.00343.x

Tang, D., Moum, J. N., Lynch, J. F., Abbot, P., Chapman, R., Dahl, P. H., ... others (2007). Shallow Water'06: A joint acoustic propagation/nonlinear internal wave physics experiment. Oceanography, 20(4).

Wang, Y., \& Wu, C.-C. (2004). Current understanding of tropical cyclone structure and intensity changes-a review. Meteorology and Atmospheric Physics, 87(4), 257-278.

Wei, J., Wang, D.-P., \& Flagg, C. N. (2008). Mapping gulf stream warm core rings from shipboard adcp transects of the oleander project. Journal of Geophysical Research: Oceans, 113(C10), n/a-n/a. Retrieved from http://dx.doi.org/10.1029/2007JC004694 (C10021) doi: $10.1029 / 2007 J C 004694$

Worst, J. S., Donohue, K. A., \& Rossby, T. (2014, 06). A Comparison of VesselMounted Acoustic Doppler Current Profiler and Satellite Altimeter Estimates of Sea Surface Height and Transports between New Jersey and Bermuda along the CMV Oleander Route. Journal of Atmospheric and Oceanic Technology, 31(6), 1422-1433. Retrieved from https://doi.org/10.1175/JTECH-D-13-00122.1 doi: 10.1175/JTECH-D-13-00122.1

Zhang, W. G., \& Gawarkiewicz, G. (2015). Dynamics of the direct intrusion of gulf stream ring water onto the mid-atlantic bight shelf. Geophysical Research Letters, 42(18), 7687-7695. Retrieved from https://agupubs.onlinelibrary.wiley.com/doi/abs/10.1002/2015GL065530 doi: 10.1002/2015GL065530

Zhang, W. G., Gawarkiewicz, G., Jr., D. J. M., \& Wilkin, J. L. (2011). Climatological mean circulation at the new england shelf break. Journal of Physical Oceanography, 41(10), 1874-1893. Retrieved from https://doi.org/10.1175/2011JP04604.1 doi: 10.1175/2011JPO4604.1 